\title{
Peer-driven testing for Chlamydia trachomatis in sexual and social networks
}

Citation for published version (APA):

Theunissen, K. (2016). Peer-driven testing for Chlamydia trachomatis in sexual and social networks: the value for Chlamydia control. [Doctoral Thesis, Maastricht University]. https://doi.org/10.26481/dis.20160707kt

Document status and date:

Published: 01/01/2016

DOI:

$10.26481 /$ dis.20160707kt

Document Version:

Publisher's PDF, also known as Version of record

\section{Please check the document version of this publication:}

- A submitted manuscript is the version of the article upon submission and before peer-review. There can be important differences between the submitted version and the official published version of record.

People interested in the research are advised to contact the author for the final version of the publication, or visit the DOI to the publisher's website.

- The final author version and the galley proof are versions of the publication after peer review.

- The final published version features the final layout of the paper including the volume, issue and page numbers.

Link to publication

\footnotetext{
General rights rights.

- You may freely distribute the URL identifying the publication in the public portal. please follow below link for the End User Agreement:

www.umlib.nl/taverne-license

Take down policy

If you believe that this document breaches copyright please contact us at:

repository@maastrichtuniversity.nl

providing details and we will investigate your claim.
}

Copyright and moral rights for the publications made accessible in the public portal are retained by the authors and/or other copyright owners and it is a condition of accessing publications that users recognise and abide by the legal requirements associated with these

- Users may download and print one copy of any publication from the public portal for the purpose of private study or research.

- You may not further distribute the material or use it for any profit-making activity or commercial gain

If the publication is distributed under the terms of Article $25 \mathrm{fa}$ of the Dutch Copyright Act, indicated by the "Taverne" license above, 


\section{Peer-driven testing for Chlamydia trachomatis in sexual and social networks: the value for chlamydia control}

Kevin Theunissen,

Academische Werkplaats Publieke Gezondheid Limburg 
(C) Copyright: Kevin Theunissen, Maastricht 2016

Design \& Lay-out: Margret Reijnders | Creatieve Communicatie

Photo (cover): Indra Moonen I Contrastique 2016

Printed by: Flyeralarm B.V.

ISBN: 978-90-823808-3-5

No part of this thesis may be reproduced, stored or transmitted in any form or by any means, electronic or mechanical, including photocopy, recording or any information storage or retrieval system, without prior permission of the copyright owner.

This thesis was prepared at the Department of Sexual Health, Infectious Diseases and Environmental Health at the Public Health Service South Limburg, the School of Public Health and Primary Care (CAPHRI) and the Department of Medical Microbiology at the Maastricht University Medical Centre.

The printing of this thesis was financially supported by: GGD Zuid Limburg.
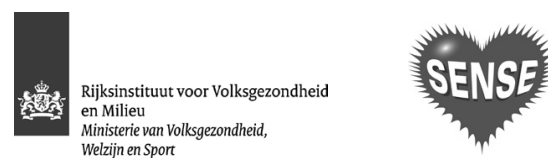

\section{caphri SOAIDS}
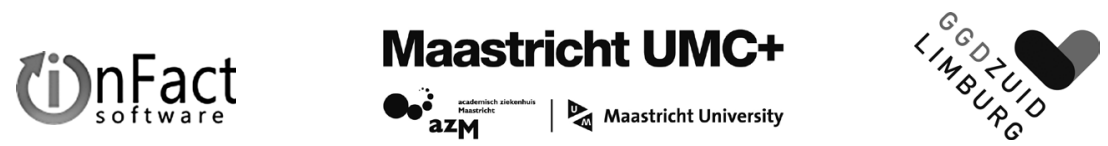


\title{
Peer-driven testing for Chlamydia trachomatis in sexual and social networks: the value for chlamydia control
}

\author{
Proefschrift
}

ter verkrijging van de graad van doctor aan de Universiteit Maastricht op gezag van de Rector Magnificus, Prof. dr. L.L.G. Soete volgens het besluit van het College van Decanen,

in het openbaar te verdedigen

op donderdag 7 juli 2016 om 10.00 uur

door

Kevin Aegidius Theodoor Mathias Theunissen

Geboren op 10 juli 1987 te Heerlen. 


\section{Promotores:}

Prof. dr. C.J.P.A. Hoebe

Prof. dr. G.J. Kok

\section{Copromotor:}

Dr. N.H.T.M. Dukers-Muijrers

\section{Beoordelingscommissie:}

Prof. dr. ir. M.W.J. Jansen (voorzitter)

Prof. dr. M.E.E. Kretzschmar, Universiteit Utrecht

Dr. R. Meertens

Prof. dr. M. Prins, Universiteit van Amsterdam

Prof. dr. R.A.C. Ruiter 
Dit proefschrift is tot stand gekomen vanuit de Academische Werkplaats Publieke Gezondheid Limburg, een samenwerkingsverband tussen de GGD Zuid Limburg, de faculteit Health, Medicine and Life Sciences van de Universiteit Maastricht en de 18 Zuid Limburgse gemeenten. Het gepresenteerde onderzoek is uitgevoerd bij de School for Public Health and Primary Care (CAPHRI). 



\section{Contents}

Chapter $1 \quad$ General introduction

Chapter 2 Using intervention mapping for the development of a targeted secure web-based outreach strategy named SafeFriend, for Chlamydia trachomatis testing in young people at risk.

BMC Public Health 2013; 13:996

Chapter 3 A web-based respondent driven sampling pilot targeting young people at risk for Chlamydia trachomatis in social and sexual networks with testing: a use evaluation.

Int. J. Environ. Res. Public Health 2015; 12: 9889-9906

Chapter $4 \quad$ Chlamydia trachomatis testing among young people:

what is the role of stigma?

BMC Public Health 2015; 15:651

Chapter $5 \quad$ Barriers to and facilitators of partner notification for Chlamydia trachomatis among health care professionals.

BMC Health Services Research 2014; 14:647

88

Chapter 6 Acceptance of home-based chlamydia genital and anorectal testing using short message service (SMS) in previously tested young people and their social and sexual networks.

PLOS ONE 2015;10(7): e0133575

Chapter 7

General discussion

Chapter 8

Summary

Nederlandse samenvatting

Dankwoord

Curriculum Vitae

Publications

Courses and training 162

Valorisation of the thesis 

Aan mijn ouders 


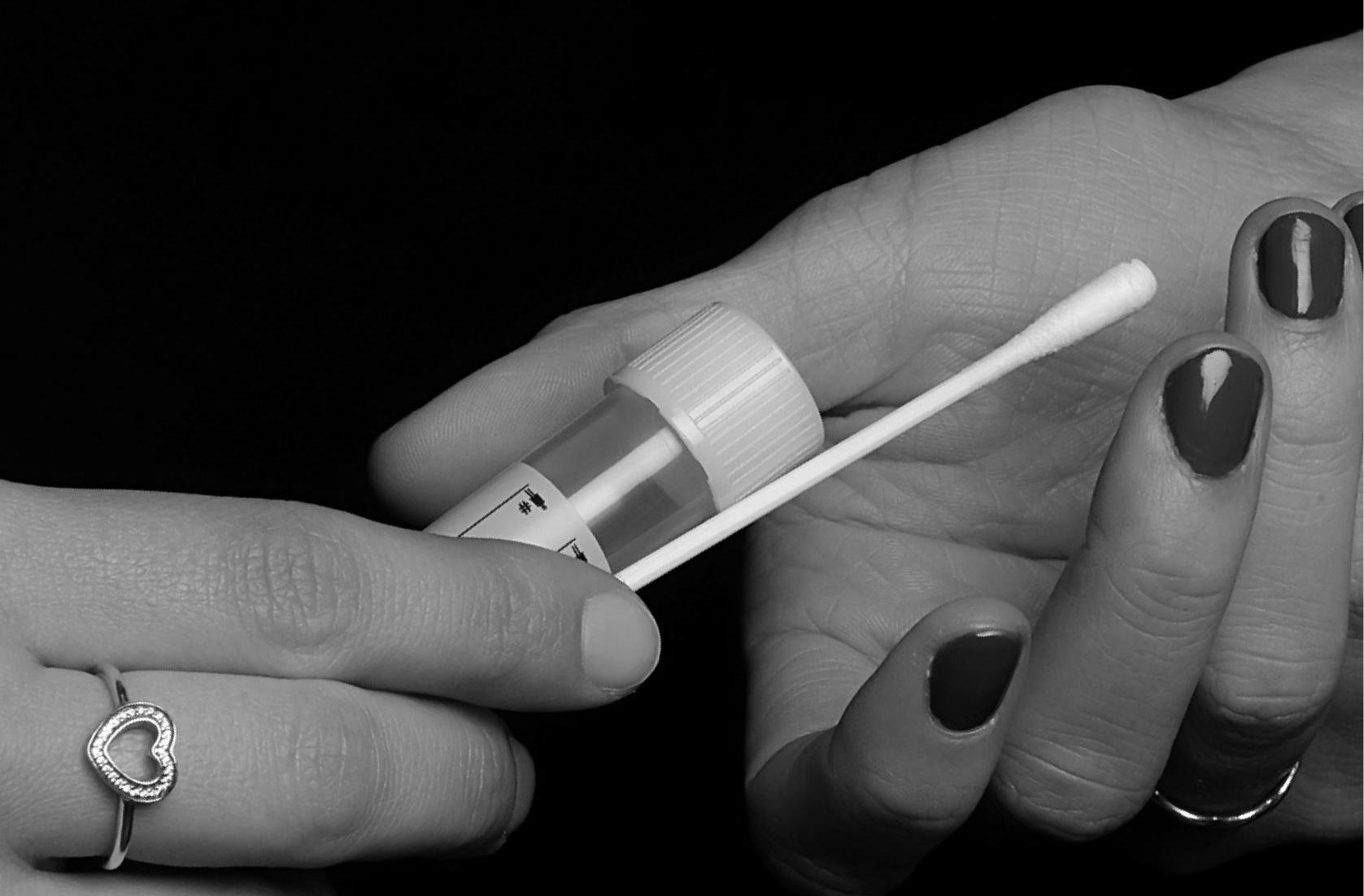




\section{Chapter 1}

General introduction 


\section{Background}

Chlamydia trachomatis (CT) is a common curable bacterial sexual transmitted infection (STI) causing serious sequelae such as pelvic inflammatory disease (PID), ectopic pregnancy and infertility in women, and urethritis and epididymitis in men [1]. Worldwide, it is the most reported bacterial sexual transmitted infection (STI) with at least 100 million new infections every year [2] and numbers are still increasing [3,4]. Next to this, it has been discussed that many infections remain hidden to care and are therefore untreated [2-4]. Young people below 25 years are a major risk group for CT infections, because they show high rates of sexual risk behaviour and are confronted with the greatest burden in terms of sequelae [4]. In the United States prevalence in this age group is almost three times higher compared to those who are between 25-39 years of age [3]. Since the majority of people with CT may not experience symptoms [5] and underestimate their own risk [6-8] individuals may have no reason to test for CT, which makes it hard to target and treat the infection in practice [4,9]. Unless someone is notified by a sex partner (i.e., partner notification (PN)) or is screened actively or routinely, most of the asymptomatic individuals will not present to clinical services to test for $\mathrm{CT}$ and therefore remain hidden to standard sexual health care [4]. However, PN and testing are hampered by several barriers such as stigma and confidentially issues [10,11]. To improve access beyond standard care, a population-based testing strategy (e.g., Chlamydia Screening Implementation program "CSI") was set up to target young people between 16 and 29 years of age in the Netherlands in 2008 [12]. In two cities, (i.e. Amsterdam and Rotterdam) and one region (i.e. South Limburg) all young people were invited via a letter to request a home sampling test kit on the Internet if they were sexual active. Unfortunately, the success of this early initiative was limited, with low participation and low positivity rates [12]. New methods need to be developed to improve access beyond standard care and increase testing among hidden young people; those sexual active who never tested before. Internationally, several strategies exist for the prevention and control of STIs [4,13]. In table 1 an overview is given of five strategies defined by the Centre of Disease Control (CDC) in the USA, which can be divided into primary prevention strategies (i.e., education) and secondary prevention strategies (i.e., testing and treatment) [13].

In this thesis we focus on the secondary prevention and control of CT by developing, implementing and evaluating innovative testing strategies that target CT infected young people via sexual and social networks using CT home sampling test kits. 
Table 1: Prevention and control strategies for STIs

\begin{tabular}{|c|c|}
\hline Primary prevention strategies & Secondary prevention strategies \\
\hline $\begin{array}{l}\text { Education and counseling of individuals at risk to avoid } \\
\text { STIs through sexual behaviors changes. }\end{array}$ & $\begin{array}{l}\text { Identification of asymptomatically infected individuals } \\
\text { and symptomatically infected individuals associated } \\
\text { with STIs. }\end{array}$ \\
\hline \multirow[t]{2}{*}{$\begin{array}{l}\text { Pre-exposure vaccination of individuals at risk for } \\
\text { vaccine preventable STls. }\end{array}$} & $\begin{array}{l}\text { Effective diagnosis, treatment, counseling and follow } \\
\text { up of infected individuals. }\end{array}$ \\
\hline & $\begin{array}{l}\text { Evaluation, treatment and counseling of sex partners } \\
\text { of STI infected individuals. }\end{array}$ \\
\hline
\end{tabular}

\section{Chlamydia trachomatis infection}

CT can infect both men and woman genitally, anally and orally [1]. It can be transmitted from mother to child during pregnancy, labour and through unprotected vaginal, oral and anal sex [1]. Although, CT can manifest with symptoms such as abnormal vaginal discharge in woman, anal bleeding and burning sensation when urinating in both woman and men [1], the majority of infections are asymptomatic [9]. When untreated CT may lead to serious sequelae such as pelvic inflammatory disease, infertility, ectopic pregnancy and chronic pelvic pain in woman [14]. In men CT may cause urethritis and epididymitis, but in the long-term men are generally hardly affected by the infection $[3,15]$. However, testing and treating of men is important to prevent the spreading of CT. The golden standard for screening and the diagnosis of CT are nucleic acid amplification tests (NAATs) [15]. These diagnostic tests are preferred because of their high sensitivity $[15,16]$ and specificity [15] and they can be performed on less invasive specimen such as urine samples or vaginal swabs [3]. When a CT infection is diagnosed using NAATs, treatment for genital and oral infections is a single-dose of $1000 \mathrm{mg}$ azithromycin in the US and the Netherlands [17] and for anal infections a 7 day course of doxycycline in the Netherlands [17].

\section{CT epidemiology in the Netherlands}

In the Netherlands, CT care is primarily provided by general practitioners (GPS), STI clinics and gynaecologists [18], and the majority of CT diagnoses are seen by GPs [19]. National surveillance data about CT diagnosis in GP practices is based on a selection of GPs that is representative for all practices and the general population in the Netherlands. CT-related episodes and diagnosis using the International Classification of Primary Care (ICPC-codes) recorded in the GPs electronic medical records (EMRs) were used to calculate an estimate of the episodes and diagnosis in $2013[18,20]$. STI clinics are divided into eight regions that all report their STI 
consultations and test results to the National Institute for Infectious Disease at the National Institute for Public Health and the Environment every year [20].

In STI clinics CT was the most reported infection with 17.753 reported cases and a higher positivity rate in 2014 (12.6\%) compared to 2013 (11.8\%) [20]. The majority of CT infections (59\%) were found among young people below the age of 25 years. Of all tested women and heterosexual men below 25 years of age 17\% were diagnosed with CT (Figure 1). In GP practices an estimated 38.000 CT infections were found in 2013 [20], with the highest percentage among 15-30 years olds [19]. The estimates of GP practices should be interpreted with caution, because data is extrapolated and has not been recorded systematically, i.e., there is unfortunately no ICPD code for CT available [19]. As the number of CT infections has increased in the past years, the coverage of testing seems not enough to decrease or stop the transmission [21]. Estimates based on data published in 2005 revealed 30,000 CT infections diagnosed in STI clinics and General Practitioner (GP) in the Netherlands among young people [22]. However, with an estimate of 60,000 new CT infections in young people every year [17] suggesting that half of the CT infections in the Netherlands remained hidden, i.e. invisible to health care.

Figure 1: Trends in CT positivity rate in women and heterosexual men by age group 2004 -2014

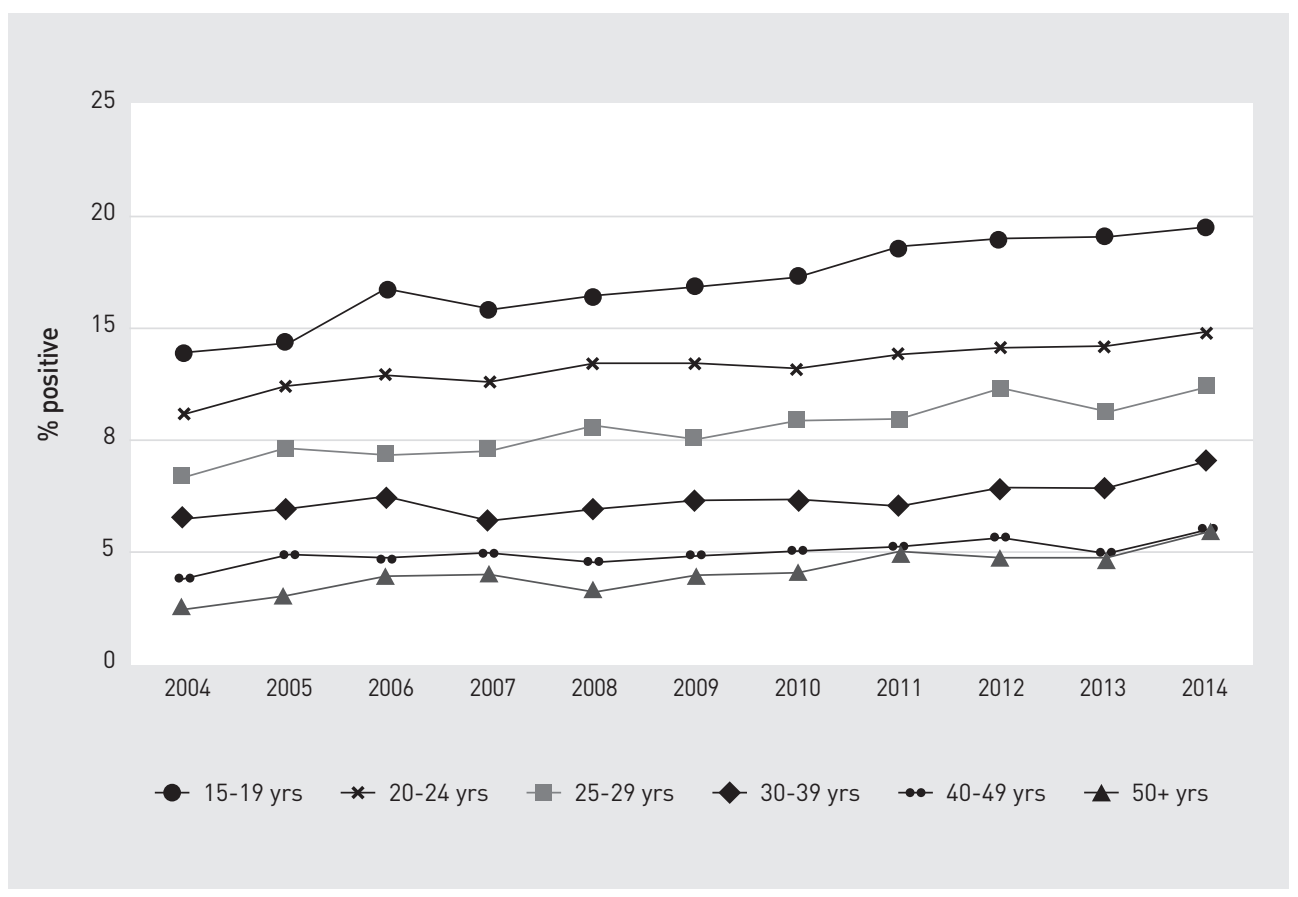




\section{Standard sexual health care in the Netherlands}

Considering young people below 25 years of age, sexual health care in the Netherlands relies on self-presenting to STI clinics and GP practices to test for CT. Testing in STI clinics is free of charge for this high-risk group, but not in GP practices and hospitals. Once a person is CT positive health care professionals should encourage them to notify their sexual partners of the past six months (i.e., PN) and to be retested annually, as recommended in the Dutch guidelines for CT control [17]. Yet, many young people at risk for CT may not seek standard sexual health care by themselves to re(test) due to several factors such as the asymptomatic nature of the bacterial infection [9], underestimation of own risk [6,7] fear for the testing method used [23], a positive test result and associated stigmatization and privacy concerns [24]. Next to this PN can be hampered due to embarrassment, blaming the sexual partner for acquiring an infection, low emotional commitment towards a partner, fear of reaction and perceived stigmatization [25, 26]. To overcome above barriers and increase timely testing new innovative testing strategies have been developed to improve access beyond standard care and increase testing among hidden high-risk young people; those who have never tested before and CT positive.

\section{The levels of CT testing strategies}

CT infections can affect individuals who are part of sexual relationships, which are part of larger sexual and social networks, which in turn are part of populations [27]. Innovative CT testing strategies try to target individuals with CT (re)testing, their sexual partners through PN and populations with CT testing in combination with evidence-based methods like the Internet, home sampling test kits, and short message service (SMS) [28,29]. However, the targeting of the network level, for example with Respondent Driven Sampling (RDS), is less studied in CT testing, despite its already promising use in finding hidden cases in HIV and Syphilis [30,31]. For an overview of all levels, strategies and methods see table 2 (modification of figure 1 in Low et al. [27]).

Targeting networks is important, because young people can influence each other through their sexual and social relationship. For instance, antibiotics will cure the infection in CT positive individuals, but will not prevent re-infection unless sex partners are notified (PN), tested and treated [27]. To decrease the transmission in a sexual network the notified sex partners of a CT positive individual also need to notify their sex partners and so on [27]. As a result, CT positivity in the population will decrease. Next to this, in social networks attitudes and actions with respect to sexual behaviour and STI testing are constructed [32,33] and information and norms about safe sex are communicated [34]. Consequently, friends (non-sexual partners) of young people who showed sexual risk behaviour could also be at increased risk of getting a CT 
infection, because of similar sexual risk behaviour. In addition, social networks may facilitate venues wherein new sex partners can be met [34]. Therefore, by targeting networks of friends, alongside sexual networks, more CT positive young people could be found than only relying on self-presenting of individuals to standard sexual health care and PN [31,33].

Table 2: Overview of levels, strategies and methods of additional innovative CT testing strategies

\begin{tabular}{lllll} 
Level & Individual & Sexual partner & Network & Population \\
Strategies & (Re)testing & PN & $\begin{array}{l}\text { Respondent Driven } \\
\text { Sampling (RDS) }\end{array}$ & $\begin{array}{l}\text { Population testing } \\
\text { lopportunistic or } \\
\text { systematic) }\end{array}$ \\
\hline Methods & Internet & Internet & Internet & Internet \\
& $\begin{array}{l}\text { Home sampling } \\
\text { test kits }\end{array}$ & $\begin{array}{l}\text { Home sampling } \\
\text { test kits }\end{array}$ & $\begin{array}{l}\text { Home sampling } \\
\text { test kits }\end{array}$ & $\begin{array}{l}\text { Home sampling } \\
\text { test kits }\end{array}$ \\
& & & \\
& & & \\
& EPT^ & & \\
\hline
\end{tabular}

^ Expedited Partner Therapy

\section{Innovative CT testing strategies and methods}

Worldwide several innovative strategies focus on opportunistic or active systematic populationbased testing using the Internet and/or home sampling testing to engage young people in CT testing [12,35-37]. Although, the Internet and home sampling test kits are highly accepted among participants $[35,36,38]$, both participation and CT positivity rates in population-based testing strategies are generally low $[12,35,37]$.

Other testing strategies specially target sexual partners of young CT positive individuals, because timely notification, testing and treatment of partners decreases the duration of the infectiousness, interrupts the transmission and prevents re-infections in individuals [39]. On the level of sexual partners, evidence-based methods like the Internet, home sampling testing and expedited partner therapy (EPT) have been introduced in the past years [39-42]. Internet partner notification (IPN) is complementary to standard provider- and patient-referral PN. Providerreferral concerns the notification of sexual partners of CT positives by trained health care professionals. Whereas in patient-referral, individuals notify their sexual partners themselves [43]. In an Australian survey study about IPN among 202 CT positive men and woman the Internet was valued useful for the notification of partners when also providing the option for anonymous notification [44]. Anonymous notification increases the ability to notify partner who would otherwise not been reached due to confidentially reasons, stigma and lack of contact 
details other than email $[40,44]$. Internationally, two websites exist that facilitate IPN for heterosexual individuals, Let Them Know in Australia and INSPOT in the United States. These websites provide the option to send personal or anonymous emails, e-cards and or mobile text messages (SMS) to encourage partners to test for CT [41]. So far, the effectiveness of these IPN strategies is unclear, as no information is available on its outcomes; the proportion of partners actually seeking testing and care $[40,43]$. The value of home sampling test kits for the notification of partners has been demonstrated in a randomized control trail in Denmark [39]. In this study the effectiveness of home sampling test kits has been compared to standard testing by a health care provider. Results showed that more partners were tested and found to be CT positive with home sampling test kits.

Another promising PN method called EPT does not focuses on testing, but on the treatment of sexual partners, which is essential to decrease transmission. There are different variations of EPT such as Patient-Delivered Partner Therapy (PDPT) in which partners are treated without a personal evaluation by a health care professional [45]. Although PDPT has been applied in many countries, the provision of medication to an individual without the clinical evaluation does not comply with current Dutch prescribing guidance. A problem which can be overcome with another form of EPT like Accelerated Partner Therapy (APT), which reduces the time of sex partners getting treated and includes personal evaluation by trained health care professionals using telephone and pharmacies [46]. Further research is needed to study the implementation and acceptability of APT in the Netherlands.

CT testing strategies that target networks of friends and sex partners (hereafter called peers) are scarce. Traditionally in network-based strategies, individuals provide researchers with a list of peers. Researchers use this list to recruit new individuals, who in turn provide the researchers with a list of their peers, and so on [47]. However, in peer-driven strategies individuals recruit their peers themselves. It is assumed that some individuals are only accessible by insiders of social and sexual networks, i.e. their peers [48]. In a study of Rose et al. [49] young people receiving opportunistic CT testing were offered home sampling test kits to provide to their friends. Very few test kits were returned in this study. Additionally, Rose et al. [49] did not explore using high-risk young people like CT positives to distribute home sampling test kits among friends.

An example of a peer-driven strategy that focuses on networks is RDS. In this strategy individuals recruit their peers who in turn recruit their peers and so on (called waves). RDS has not yet been applied to target hidden populations with CT testing, although this strategy has been demonstrated successful in finding new infections using networks in studies with HIV and Syphilis $[30,31]$. 
To decrease staffing, financial resources and time needed to test- the Internet has also been introduced in RDS. However, web-based RDS has only been applied in a high school setting [50].

We hypothesize that peer-driven strategies in combination with home sampling test kits could be an innovative strategy to reach young people at risk for CT who are not accessed by standard care. Social and sexual networks are key in this strategy, because peers influence each other's attitudes and actions with respect to sexual behaviour and STI testing [32]. Consequently, young people who showed risky behaviour and/or were CT positive will have friends and sex partners who are also at risk for CT.

\section{Aim of this thesis}

The aim of this thesis is to assess the value of peer-driven CT testing in social and sexual networks for CT control in terms of number of recruited peers, number of hidden peers (who had never been tested before) and number of CT infections. This thesis therefore describes studies that focus on the development of peer-driven CT testing strategies, the pilot implementation and evaluation in practice of these strategies and its use among young people and sexual health care nurses.

\section{Outline of this thesis}

In chapter $\mathbf{2}$ we describe the development of a peer-driven testing strategy using Intervention Mapping (IM), a systematic approach to develop theory- and evidence-based interventions. This resulted in a web-based Respondent Driven Sampling (web-based RDS) strategy that targeted social and sexual network members surrounding CT positive young people with CT testing. Its aim was to reach young people who had never tested before with home sampling CT test kits. In chapter 3 we pilot implemented this peer-driven strategy at the STI clinic South Limburg and evaluated its uptake and usability among young people and sexual health care nurses. Chapter $\mathbf{4}$ describes semi-structured interviews that focused on the role of stigma in CT and peer-driven testing among young people. The success of peer-driven testing depends on whether individuals disclose their own testing and encourage others to get tested. We assessed whether stigma would hamper disclosure and encouragement, by comparing anticipations and experiences relating to these issues in young men and women who already tested or never tested for CT.

To gain insights in the perceived barriers and facilitators during the PN process /starting point of peer-driven testing at the STI clinic) we also conducted semi-structured interviews among sexual health care nurses as described in chapter 5 . 
Chapter $\mathbf{6}$ describes the development and pilot implementation of a second peer-driven testing strategy. We assessed the acceptance of home sampling test kits offered by short messaging services (SMS) texts among previously tested young people and their sexual and social networks. In chapter $\mathbf{7}$ the main findings are discussed and recommendations are given for sexual health care practice and future research. 


\section{References}

1. Centers for Disease Control and Prevention. Chlamydia - CDC Fact Sheet. http://www.cdc. gov/std/Chlamydia/STDFact-Chlamydia.htm [accessed 26 July 2015].

2. Senior, K. Chlamydia: a much underestimated STI. The Lancet 2012, 12, 517-518.

3. Centers for Disease Control and Prevention. Chlamydia Prevention: Challenges and Strategies for Reducing Disease Burden and Sequelae. http://www.cdc.gov/mmwr/ preview/mmwrhtml/mm6012a2.htm [accessed 5 August 2015].

4. European Centre for Disease Prevention and Control. Chlamydia control in Europe. http://ecdc.europa.eu/en/publications/ Publications/0906_GUI_Chlamydia_Control in_Europe.pdf [accessed 10 August 2015].

5. Geisler WM. Duration of Untreated, Uncomplicated Chlamydia trachomatis Genital Infection and Factors Associated with Chlamydia Resolution: a Review of Human Studies. JID 2010, 201(Suppl 2):s104-s113.

6. Ten Hoor GA, Ruiter RAC, Van Bergen JEAM, Hoebe CJPA, Dukers-Muijrers NHTM, Kok G. Predictors of Chlamydia Trachomatis Testing: Perceived Norms, Susceptibility, Changes in Partner Status, and Underestimation of Own Risk, BMC Public Health 2016.

7. Samkange-Zeeb FN, Spallek L, Zeeb H. school-going adolescents in Europe: a systematic review of published literature. BMC Public Health 2011, 11:727.

8. Duncan B, Hart G, Scoular A, Bigrigg A. Qualitative analysis of psychosocial impact of diagnosis of Chlamydia trachomatis: implications for screening. BMJ 2001;322:195-199.
9. Farley TA, Cohen DA, Elkins W. Asymptomatic sexually transmitted disease: The case for screening. Preventive Med. 2003;36(4):502-9.

10. Balfe M, Brugha R. Disclosure of STI testing activities by young adults: the influence of emotions and social networks. Social Health Illn. 2010;32:1041-58.

11. Pavlin NL, Gunn JM, Parker R, Fairley CK, Hocking J. Implementing chlamydia screening: what do women think? A systematic review of the literature. BMC Public Health. 2006;6:221-31.

12. Van Bergen JEAM, Fennema JSA, van den Broek IVF, Brouwers EHHG, de Feijter EM, Hoebe CJPA, Koekenbier RH, Op de Coul ELM, van Ravesteijn SM, Götz HM. Rationale, design, and results of the first screening round of a comprehensive, register-based, Chlamydia screening implementation programme in the Netherlands. BMC Infectious Diseases 2010, 10:293 doi:10.1186/1471-2334-10-293.

13. Centers for Disease Control and Prevention. Sexually Transmitted Diseases Treatment Guidelines, 2015 http://www.cdc.gov/std/ tg2015/tg-2015-print.pdf [accessed 10 August 2015]

14. Haggerty CL, Gotliebb SL, Taylor BD, Low N, Xu F, Ness RB. Risk of Sequelae after Chlamydia trachomatis Genital Infection in Women. JID 2010, 201(Suppl2):s134-s155.

15. Centers for Disease Control and Prevention. Recommendations for the Laboratory-Based Detection of Chlamydia trachomatis and Neisseria gonorrhoea - 2014 http://www.cdc. gov/mmwr/pdf/rr/rr6302.pdf [accessed 5 August 2015] 
16. Schachter J, Chow JM, Howard H, Bolan G, Moncada J. Detection of Chlamydia trachomatis by nucleic acid amplification testing: our evaluation suggests that CDC-recommended approaches for confirmatory testing are ill-advised. J Clin Microbiol 2006;44:2512-7.

17. National Institute for Public Health and the Environment. Chlamydia trachomatis-infectie (non-LGV) en lymphogranuloma venereum (LGV). http://www.rivm.nl/Documenten_en_ publicaties/Professioneel_Praktisch/ Richtlijnen/Infectieziekten/LCl_richtlijnen/ LCl_richtlijn_Chlamydia_trachomatis_en_ lymfogranuloma_venereum [accessed 12 august 2015].

18. Van den Broek IVF, Verheij RA, van Dijk CE, Koedijk FDH, van der Sande MAB and van Bergen JEAM. Trends in sexually transmitted infections in the Netherlands, combining surveillance data from general practices and sexually transmitted infection centers. BMC Family Practice 2010; May 20:11:39

19. Suijkerbuijk AW, van den Broek IV, Brouwer HJ, Vanrolleghem AM, Joosten JH, Verheij RA, van der Sande MA, Kretzschmar ME. Usefulness of primary care electronic networks to assess the incidence of chlamydia, diagnosed by general practitioners. BMC Fam Pract. 2011 Jul 8;12:72.

20. National Institute for Public Health and the Environment. Sexually Transmitted Infections, Including HIV, in the Netherlands in 2014. Annual Report National Institute for Public Health and the Environment: Bilthoven, The Netherlands, 2015.

21. National Institute for Public Health and the Environment. Chlamydia surveillance en onderzoek 2012 aanknopingspunten voor bestrijding 2012. Report National Institute for Public Health and the Environment: Bilthoven, The Netherlands 2012

22. Van Bergen J, Gotz H.M, Richardus J.H, Hoebe C.J.P.A, Broer J, Coenen A.J.T. Prevalence of urogenital Chlamydia trachomatis increases significantly with level of urbanization and suggests targeted screening approaches: Results from the first national population based study in the Netherlands. Sex. Trans. Infect. 2005, 81, 17-23.

23. Tilson EC, Sanchez V, Ford CL, Smurzynski M, Leone PA, Fox KK, Irwin K, Miller WC.

Barriers to asymptomatic screening and other STD services for adolescents and young adults: focus group discussions. BMC Public Health 2004, 21(4):1-8.

24. Balfe M, Brugha R, O'Donovan D, O'Connell E, Vaughan D. Young women's decision to accept chlamydia screening: influences of stigma and doctor patient interactions. BMC Public Health. 2010;10:425-35.

25. Temple-Smith M, Hopkins C, Fairley C, Tomnay J, Pavlin N, Parker R, Russell D, Bowden F, Hocking J, Pitts M, Chen M: The right thing to do: patients' views and experiences of telling partners about chlamydia. Fam Pract 2010, 27:418-423. doi: 10.1093/fampra/cmq028.

26. Burnet Institute: Partner Notification of Sexually Transmitted Infections in New South Wales: an informed literature review. http://stipu.nsw.gov.au/wp-content/uploads/ NSW_STI_PN_PDF.pdf [accessed 5 August 2015]. 
27. Low N, Broutet N, Adu-Sarkodie Y, Barton P, Hossain M, Hawkes S. Global control of sexually transmitted infections. Lancet. 2006 Dec 2;368(9551):2001-16.

28. Jamil MS, Hocking JS, Bauer HM, Ali H, Wand H, Smith K, et al. Home-based chlamydia and gonorrhoea screening: a systematic review of strategies and outcomes. BMC Public Health. 2013 Mar 4; 13:189. doi: 10.1186/1471-245813-189 PMID: 23496833

29. Desai M, Woodhall SC, Nardone A, Burns F, Mercey D, Gilson R. Active recall to increase HIV and STI testing: a systematic review. Sex Transm Infect. 2015 Mar 10. pii: sextrans2014-051930. doi: 10.1136/ sextrans2014-051930.

30. Choi KH, Ning Z, Gregorisch SE, Pan QP: The Influence of Social and Sexual Networks in the Spread of HIV and Syphilis Among Men Who Have Sex With Men in Shanghai. Epidemiol Soc Sci 2007, 45(1):77-84.

31. Rothenberg R: The tranformation of Partner Notification. CID 2002, 35(2):S138-S145.

32. Youm Y, Laumann EO: Social Network Effects on the Transmission of STI. Sex Trans Dis 2002, 29(11):689-697.

33. Centers for Disease Control and Prevention. Summary of a review of the literature: Programs to Promote Chlamydia Screening. http://www.cdc.gov/std/healthcomm/ chlamydialitreview2008.pdf [accessed 5 August 2015].

34. Drumright LN, Frost SDW: Rapid social network assessment for predicting HIV and STI risk among men attending bars and clubs in San Diego California. Sex Trans Infect 2010, 86(3):iii17-iii23.
35. Novak DP, Karlsson BR: Simplifying chlamydia testing: an innovative Chlamydia trachomatis testing approach using the Internet and a home sampling strategy: population based study. Sex Trans Infect 2006, 82:142-147. doi: 10.1136/ sti.2005.016832.

36. Gaydos CA, Dwyer K, Barnes M, Rizzo-Price PA, Wood BJ, Flemming T, Hogan MT: Internet-Based Screening for Chlamydia trachomatis to Reach Nonclinic Populations With Mailed Self-Administered Vaginal Swabs. Sex Trans Dis 2006, 33(7):451-457. doi: 10.1097/01.olq.0000200497.14326.fb.

37. Kløvstad, H.; Grjibovski, A.; Aavitsland, P. Population based study of genital Chlamydia trachomatis prevalence and associated factors in Norway: A cross sectional study. BMC Infect. Dis. 2012, 12, 150, 1-7.

38. Greenland KE, Op De Coul ELM, Van Bergen JEAM, Brouwers EEHG, Fennema HJSA, Gotz HM, Hoebe CJPA, Koekenbier RH, Pars LL, Van Ravesteijn SM, Van Den Broek IVF. Acceptability of the Internet-Based Chlamydia Screening Implementation in the Netherlands and Insights Into Nonresponse. Sex Trans Dis 2011, 38:6.

39. Østergaard L, Andersen B, Møller J.K, Olesen F. Worm AM. Managing partners of people diagnosed with chlamydia trachomatis: A comparison of two partner testing methods. Sex. Trans. Infect. 2003, 79, 358-362.

40. Levine D, Woodruff A.J, Mocello A.R, Lebrija J, Klausner J.D. inSPOT: The first online std partner notification system using electronic postcards. Plose Med. 2008, 5, e213, 1428-1431. 
41. Bilardi JE, Fairley CK, Hopkins CA, Hocking JS, Sze JK, Chen MY. Let Them Know: evaluation of an online partner notification service for chlamydia that offers E-mail and SMS messaging. Sex Trans Dis.

2010;37(9):563-5. doi:10.1097/

OLQ.0b013e3181d707f1.

42. Stephens SC, Bernstein KT, Katz MH, Philip SS and Klausner JD. The effectiveness of patient-delivered partner therapy and chlamydial and gonococcal reinfection in San Francisco. Sex Transm Dis 2010;37:525-9.

43. Hogben M, Burstein GR, Golden MR. Partner notification in the clinician's office: patient health, public health and interventions. Curr Opin Obstet Gynecol, 2009; 21:365-370.

44. Bilardi JE, Fairley CK, Hopkins CA, Hocking JS, Temple Smith MJ, Bowden FJ, Russell DB, Pitts M, Tomnay JE, Parker RM, Pavlin NL, Chen MY: Experiences and Outcomes of Partner Notification Among Men and Women Recently Diagnosed With Chlamydia and Their Views on Innovative Resources Aimed at Improving Notification Rates. Sex Trans Dis 2010, 37:4.

45. Centers for disease control and prevention: Expedited Partner Therapy in the Management of Sexually Transmitted Diseases: Review and Guidance. Atlanta; 2006 http://www.cdc.gov/ std/treatment/ eptfinalreport2006.pdf

46. Shackleton T, Sutcliffe L, Estcourt C. Is Accelerated Partner Therapy partner notification for sexually transmissible infections acceptable and feasible in general practice? Sex Health. 2011 Mar;8(1):17-22. doi: 10.1071/SH10031.
47. Coleman JS. Relational Analysis: The Study of Social Organizations with Survey Methods. Human Organization. 1958-59;17:28-36.

48. Heckathorn DD. Respondent-driven sampling: A new approach to the study of hidden Populations. Soc. Probl. 1997, 44, 174-199.

49. Rose SB, Lawton BA, Bromhead C, MacDonald EJ, Elley CR. Poor uptake of selfsample collection kits for Chlamydia testing outside primary care. Aust. N. Z. J. Public Health 2010, 34, 517-520.

50. Wejnert C, Heckathorn DD. Web-Based Network Sampling Efficiency and Efficacy of Respondent-Driven Sampling for Online Research. Socio Meth Res 2008;37(1):105-134. 


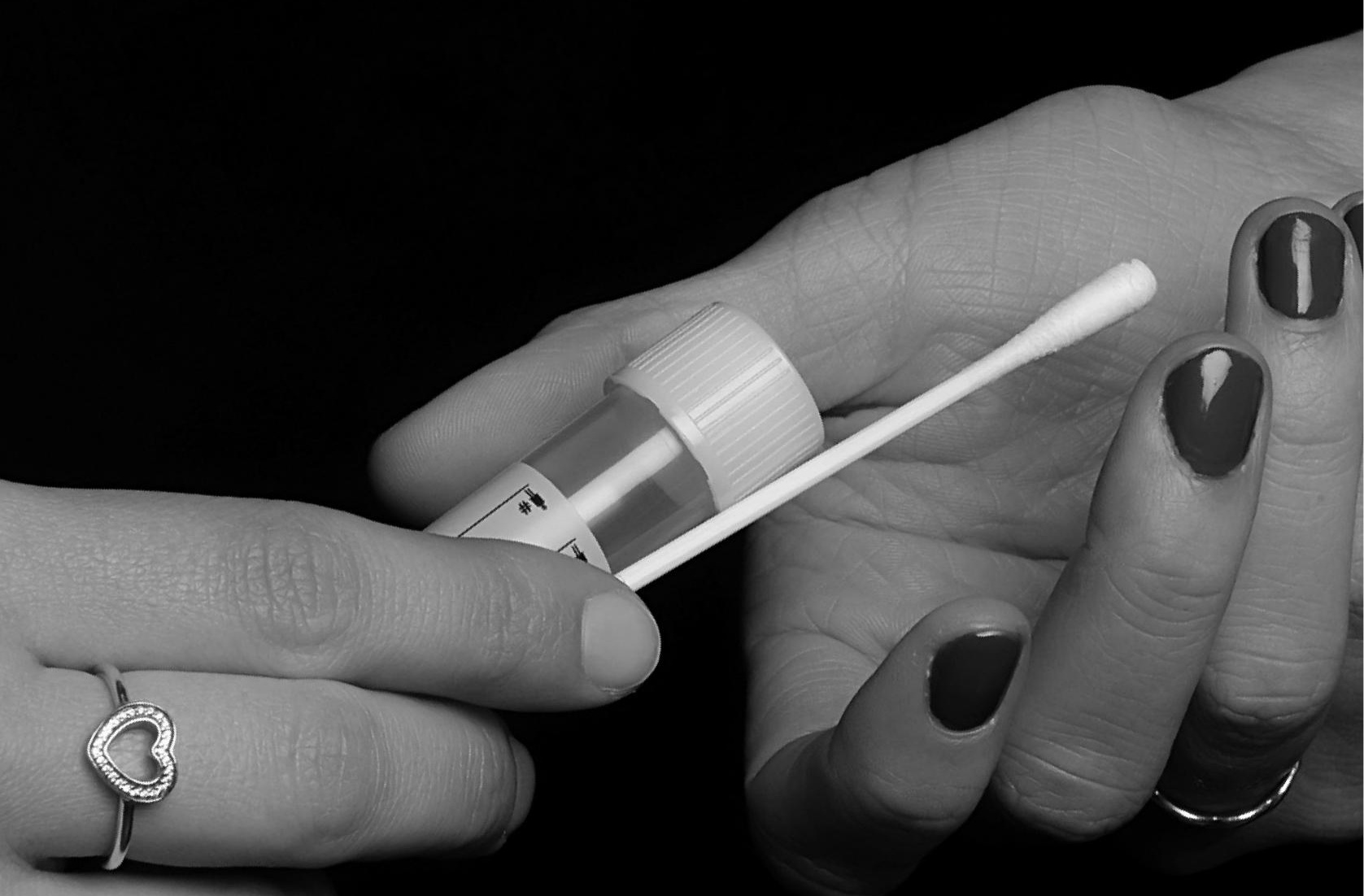




\section{Chapter 2}

\section{Using intervention mapping for the development of a targeted secure web-based outreach strategy named SafeFriend, for Chlamydia trachomatis testing in young people at risk}

Kevin A.T.M. Theunissen, Christian J.P.A. Hoebe, Rik Crutzen, Chakib Kara-Zaïtri, Nanne K. de Vries, Jan E.A.M. van Bergen, Marianne A.B. van der Sande and Nicole H.T.M. Dukers-Muijrers

BMC Public Health 2013, 13:996 


\section{Abstract}

\section{Background}

Many young people at high risk for Chlamydia trachomatis (CT) are not reached by current sexual health care systems, such as general practitioners and public sexual health care centres (sexually transmitted infection clinics). CT is the most frequently diagnosed bacterial sexually transmitted infection (STI) among sexually active people and in particular young heterosexuals. Innovative screening strategies are needed to interrupt the trans-mission of CT among young people and connect the hidden cases to care.

\section{Methods}

Intervention Mapping (IM), a systematic approach to develop theory- and evidence-based interventions, was used to develop a strategy to target CT testing towards young people who are currently hidden to care in The Netherlands. Both clinical users (i.e. sexual health care nurses) and public users (i.e., young people at risk for CT) were closely involved in the IM process. A needs assessment study was carried out using semi-structured interviews among users (n = 21), a literature search and by taking lessons learned from existing screening programmes. Theoretical methods and practical applications to reach high-risk young people and influence testing were selected and translated into specific programme components.

\section{Results}

The IM approach resulted in the development of a secure and web-based outreach CT screening strategy, named SafeFriend. It is developed to target groups of high-risk young people who are currently hidden to care. Key methods include web-based Respondent Driven Sampling, starting from young CT positive sexual health care centre clients, to reach and motivate peers (i.e., sex partners and friends) to get tested for CT. Testing and the motivation of peers were proposed as the desired behavioural out-comes and the Precaution Adoption Process Model was chosen as theoretical framework. End users, i.e., young people and sexual health care nurses were interviewed and included in the development process to increase the success of implementation.

\section{Conclusions}

IM proved useful to develop an intervention for targeted CT testing among young people. We believe this to be the first web-based outreach screening strategy, which combines chainreferral sampling with the delivery of targeted CT testing to high-risk young people within their sexual and social networks.

\section{Keywords}

Intervention mapping, Chlamydia trachomatis, Screening, Partner notification, Web-based respondent driven sampling, Social networks, Sexual networks, Peer influence. 


\section{Introduction}

Testing and treating are essential strategies in Chlamydia trachomatis (CT) control to interrupt the inherent transmission chain [1]. In many countries, including the Netherlands, positivity rates of CT have increased in the past years [2-4]. CT is thereby the most frequently diagnosed bacterial sexually transmitted infection (STI) among sexual active people and in particular young heterosexuals. Young people below 25 years of age comprise a major risk group for CT control, because they show constant high rates of sexual risk behaviour and potentially bear the largest burden of STI sequelae in terms of reproductive morbidity [5].

Web-based CT screening programs have improved the access to sexual health care beyond the sexual health care centre and general practitioners (GPS), by engaging young people in discussions about sexual health, increasing home-based testing, and enhancing the management of CT patients and re-screening positives [6-9]. Unfortunately, the success of such early initiatives was limited in the Netherlands (e.g., Chlamydia Screening Implementation Program "CSI") and in other counties $[8,10,11]$. One of the reasons for this was that such initiatives did not readily reach the targeted high-risk young people $[8,10,11]$, leaving this group largely hidden to health care providers. Therefore there is an urgent need to find new ways to tap into such hidden key populations and find a natural way of motivating them to access sexual health care [12]. To clarify the concept, a key population for a given infection consists of members who are either infected or have a very high-risk of acquiring the infection. Reason for having (high-risk for) infection is the membership to high-risk sexual and social networks. Typically, infections thrive in such networks, which provide the right vehicle for transmission of the infection taking advantage of the inherent risky behaviour and social proximity [13,14]. Currently, a significant number of members of such network remain completely invisible to care (hidden key population).

Members of the social and sexual networks surrounding CT positives typically showed high-risk $[15,16]$; these networks are important targets for interventions [17]. Information about STI can be readily spread within a social network and thereby influence risk behaviour such as unprotected sex practices $[15,17]$. Furthermore, networks can overlap whereby a social network creates a venue to meet new sex partners $[15,17]$. There is now a growing body of evidence on the high success potential of network based interventions, e.g. by using chain-referral sampling methods such as web-based Respondent Driven Sampling (web-based RDS) and peer influence to reach hitherto hidden networks [18]. The basic idea behind RDS is that selected young people are recruited as seeds or ambassadors who themselves motivate others in their own networks to get tested, and so on. The RDS methodology has already proven its worth in other public health areas (e.g., health promotion) and target populations (e.g., injection drug users and HIV patients) [19-21]. 
This paper describes the development of an innovative secure web-based outreach CT screening strategy, whereby young people at high-risk for CT (re)-infection will be targeted and encouraged to go for testing. The project is carried out by one of the eight coordinating public sexual health care centres (STI clinics) in the Netherlands, where the intervention will be developed, tested and implemented. The objective is to develop a cost-effective and sustainable web-based outreach screening strategy for reducing the patient's and population's CT burden, and improving the timing of care. The Intervention Mapping (IM) protocol can be used to guide the systematically development of the intervention based on theory and evidence, which should increase the likelihood of developing an effective intervention [22]. IM has already been applied in different populations and study areas such as drug users, condom use, and stress related mental disorders [23-25], but never in the development of CT screening programs among high-risk young people.

\section{Methods}

\section{Step 1: Needs assessment}

The Intervention Mapping process starts with a need assessment to analyse a specific health problem within a target population and associated important stakeholders. Furthermore, behavioural and environmental risk factors that contribute to the health problem are identified and the underlying determinants are explored. At the end the programme outcomes are stated. To plan and guide the need assessment the PRECEDE-model is used [26].

The Dutch national STI policy targets were explored in order to identify expectations from practical and political stakeholders. A literature search was conducted reporting on CT prevalence in different population groups, including young people, and existing strategies for CT control, why these strategies failed or succeeded, and which methods were cost-effective to reach high-risk young people. Furthermore, semi-structured interviews were held among CT positive young people ( 8 women and 13 men) who were between 17 and 24 years old and visited the sexual health care centre South Limburg for CT treatment. They were from various ages, sexual orientation, educational levels and ethnicity. They were interviewed about partner notification (PN) to find out the determinants to motivate peers to test for CT. Ethical approval of the Regional Medical Ethics committee in the Netherlands was not necessary, because participants in these interviews were not "subjected to procedures or required to follow certain rules of behaviour" [27]. Based on the needs assessment using the PRECEDE-model (Figure 1), the health problem, behavioural and environmental factors, the underlying determinants and the target group were defined, resulting in two desired behavioural outcomes that were selected to be targeted by the intervention. 
Figure 1: Needs assessment using a simplified PRECEDE model (see Methods and Tables).

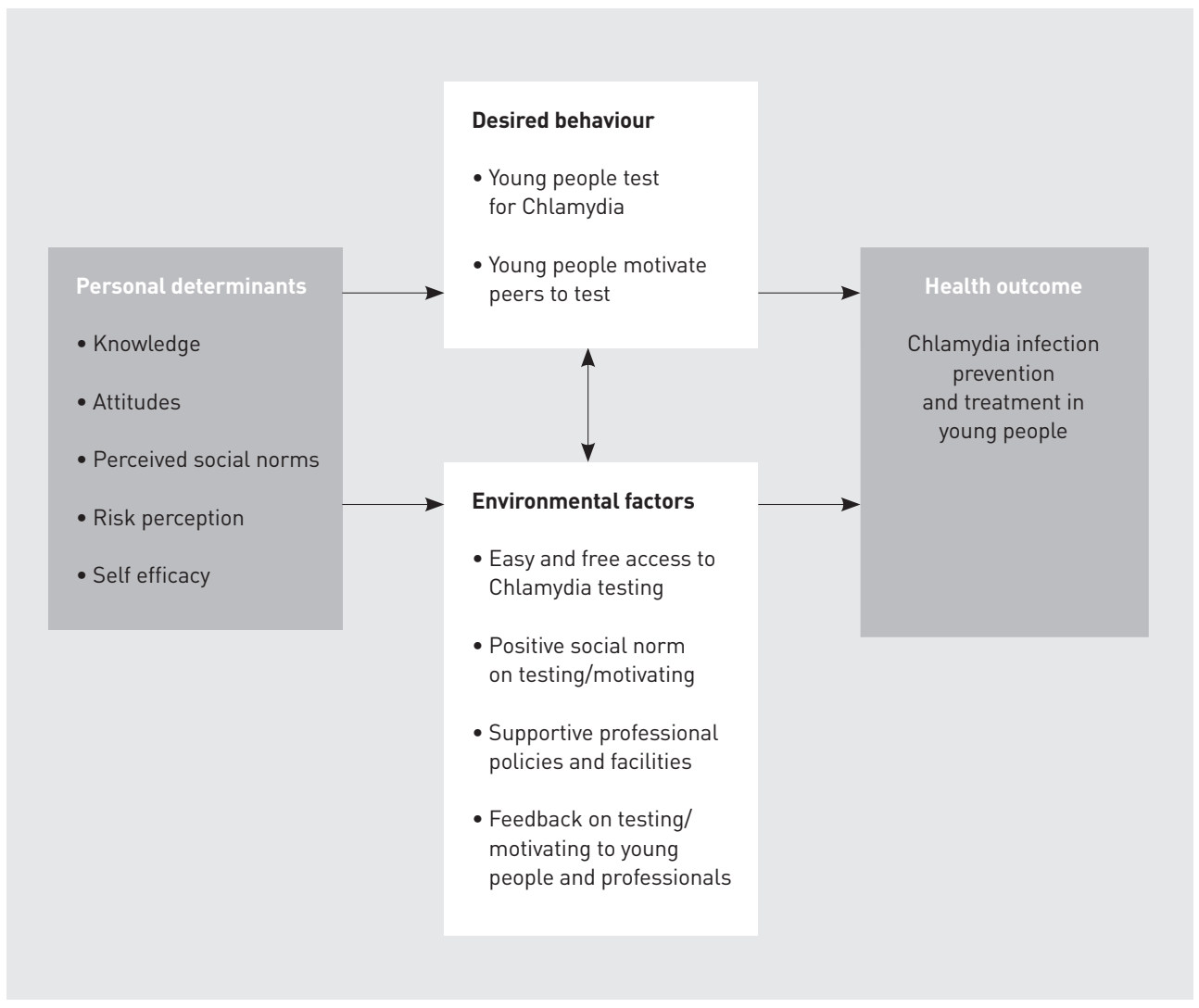

\section{Step 2: Preparing matrices of change objectives}

In step 2, each of the behavioural outcomes is broken down into performance objectives, i.e. the actions that expectedly lead to the desired outcome. For each performance objective, the most important and changeable determinants are stated based on theoretical models for behavioural change. Combining the performance objectives with the determinants identified results in matrices that include the change objectives that guide the intervention development process.

The performance objectives and most important and changeable determinants were selected based on previous studies, the results of the semi-structured interviews and the Precaution Adoption Process Model (PAPM) [28]. The model comprises of a stage theory that ranges from unaware of a problem to action and maintenance of a specific behaviour (e.g., CT testing and motivating network members to test). This model was chosen, because it emphasizes that hazard responses are influenced by behaviours and opinions of peers, which is in line with the 
underlying of social and sexual networks surrounding CT positives. A person's decision concerning the need to test is influenced by the opinion and actions of peers and not just by specific beliefs about the hazard that lead to rational and independent decisions. This social influence may occur at several stages of the model.

\section{Step 3: Selecting theory-informed intervention methods and practical applications}

In step 3, theory-informed intervention methods are selected to create changes in the determinants of the behavioural outcomes. The relevance of methods for a particular project and the changeability that can be realized with a particular method guides this selection process. Practical applications that fit the target population and context are then translated from these theory-informed intervention methods.

Before a final list of methods was determined on the basis of existing evidence and theory, theoretical methods were explored and analysed by a small panel of experts consisting of researchers, prevention experts, informatics-specialists, nurses and medical doctors. The experts then transformed the methods into practical applications taking into account the parameters of use, the literature review and conducted semi-structured interviews.

\section{Step 4: Producing program components and materials}

In this step, the practical applications are combined and translated into programme components and specific materials. During this process several end users are included to select the best program design that fits the user's preferences. The intervention is then pilot-tested among some members of the target population. Eventually, necessary adjustments are made and the definitive intervention developed.

The intervention was constructed, tested and refined with close involvement of CT positive young people and sexual health care nurses. The selected applications were incorporated into two websites: (1) a smart and highly interactive website for young people to communicate and motivate those at high-risk in their social and sexual networks and (2) another website for sexual health care professionals to start recruitment-chains and oversee the process of home-based test kit requests. The final name and look-and-feel of the intervention were set after pre-testing it among young people. The first pre-test of the intervention will be conducted among young people lage $\leq 25$ years) visiting the public sexual health care centre South Limburg for CT treatment. Evaluation will then be done to identify facilitating factors and barriers to use and the application is refined further (specific guidance for graphic designers and programmers).

The last two steps of the IM protocol, step 5 and 6, are outside the scope of this paper and are described briefly here. 


\section{Step 5: Planning program adoption, implementation, and sustainability}

An implementation plan is made to deploy the intervention to a successful outcome. End users and implementers of the intervention are identified and implementation objectives are stated considering dissemination, adoption, implementation and maintenance of the intervention.

Health care professionals (e.g., sexual health care nurses, medical doctors) and policy makers were involved from the start of the project by regular team meetings. They are the key linkage group for the success of the development and implementation and have therefore been involved in the entire research process. The ultimate goal is national implementation in sexual health care centres and the future expansion to GPs will be explored.

\section{Step 6: Planning for evaluation}

In the final step of intervention mapping, an evaluation plan and associated criteria are set up. The level of evaluation is chosen and indicators and measures determine to evaluate the effects and process of the intervention. All program objectives are defined in a measurable form.

To assess whether the intervention leads to changes in determinants and thereby in a change in behaviour of young people (i.e., CT testing and motivate high-risk young people to test for CT) a plan for the quantitative and qualitative evaluation was made. Factors that may hinder or facilitate the use of the intervention will be reviewed in the course of this project and strategies will be explored to positively affect intervention use.

\section{Results}

\section{Step 1: Needs assessment}

\section{Health problem and target group}

The needs assessment started with a literature search and the exploration of national stated aims, which revealed that young people below 25 years of age comprise a major risk group for CT control, because they show constant high rates of sexual risk behaviour and potentially bear the largest burden of STI sequelae in terms of reproductive morbidity [5]. Every year, there is a large new accretion of about 200,000 susceptible sexually active Dutch young people, although not all are at high risk for acquiring CT [1]. Estimates about the total burden of CT in 15-30-year-olds suggest 60.000 new infections yearly [29], with an estimate of only 30.000 infections diagnosed in sexual health care centres and by GPs [Personal communication dr. I van den Broek, based on available data from STI centres and GP-surveillance, $[2,30]]$. Hence, half of the CT infections remain undetected and hidden to care and there is an urgent need to significantly increase CT testing rates among young people at high-risk. Young 
people receive and share information about STI and associated testing through their peers, i.e. a combination of sex partners and friends [17,31]. Their behaviours, attitudes and actions in respect to STIs are strongly influenced by their peers who are therefore key change agents $[17,32]$. There is clear evidence of high STI/CT prevalence in social networks surrounding STI positive people $[15,16,33,34]$. Such networks thrive on high behavioural risk and therefore provide a rich conduit for rapid STI spread and re-infection $[16,17]$. Based on the health problem and selected target group two desired behavioural outcomes were formulated: al High risk young people ( $\leq 25$ years of age) get tested for CT, and b) motivate peers via their social and sexual network to get tested.

Determinants for CT testing and motivating peers to test

Several behavioural barriers for testing among young people have been identified from the literature search (i.e., Table 1). For example the level of knowledge of STI; CT being an asymptomatic disease, the connection between CT and fertility complications and current testing options [35-37]. Another barrier includes misperceived vulnerability; young people do not think they are at risk for $\mathrm{Ct}[35,36,38]$. Embarrassment about the need for testing and fear of a positive test result also plays a role $[36,38,39]$. Shame and fear may be enforced when the provider is a family doctor and young people are charged for testing (note that Dutch sexual health care centres test free of charge) [37-39]. Home-based test kits were found to be acceptable among young people and could be used as a facilitator factor in testing [9,39-41]. Barriers related to motivate peers to get tested for CT include fear of stigmatization among peers, repercussion (e.g. aggression), blaming the other, availability of contact details and the level of emotional commitment [38,42-44].

The analyses of the 21 semi-structured interviews showed several barriers and facilitators related to motivating peers to get tested for CT. CT positive young people can feel embarrassed about their positive CT test result when motivating peers to get tested. Some indicated that in case of a casual sex partner they would like to notify anonymously. Fear of aggression of sex partners can also discourage CT positive young people to motivate peers. Interviewees expressed emotional commitment to their sex partners and felt responsible for informing them about the CT risk. They were aware of the possible health risks for direct and indirect sex partners, whereas others were afraid of re-infection. As stated by one interviewee: "Partner notification is self-evident, when you do not warn your steady partner, you will get reinfected". Social influence plays also an important role. Several interviewees were notified about their CT risk via their sex partners and then visited a sexual health care centre. They also indicated that friends visited a sexual health care centre after talking to them about CT testing and their own positive test result. As noted by one interviewee: "We [friends] talk about everything. We do not have any problems to talk about CT positive test results". 
Table 1: Determinants for Chlamydia (CT) testing and motivating peers for CT testing among young people by systematic literature search (March 2012) and semi-structured interviews ( $=21$ )

\section{Ct Testing Motivating peers \\ Personal determinants \\ Motivating peers
Personal determinants}

Knowledge about:

- STI and in particular asymptomatic disease [35-37]

- CT effects [36,37,39]

- CT testing methods [36,37]

Fear of parental notification [36]
Knowledge about the transmission of CT among sexual and social network members

Attitudes towards motivating:

- Perceived stigmatization/embarrassment [42-44], interviews

- Emotional commitment with peers [42,44], interviews

- Personal health benefit (re-infection) [42], interviews

- Blaming towards sexual partners [42]

- Fear of reaction (e.g. aggression) [42-44], interviews

Attitudes towards testing:

Perceived social norm of motivation among peers

[interviews]

- Shame about CT testing [37-39

.

- Embarrassment about CT testing [36-39]

- Fear of test results [36,38,39]

- Fear of testing procedure [37,39]

Perceived social norms of CT testing among

Availability and accessibility of contact details* [42-44],

peers [38,39], interviews

Interviews

Risk perception towards testing:

- Awareness of vulnerability/risk for CT $[35,36,38]$

- Awareness of severity of CT [36,38]

Self efficacy:

- Afraid to visit public health services [37], interviews

* Will be excluded in this study, because this determinant cannot be changed 


\section{Step 2: Preparing matrices of change objectives}

For each of the two behavioural outcomes four performance objectives were defined (i.e., Tables 2 and 3). Firstly, young people should be able to appraise their own and others CT risk behaviour. Secondly, if necessary, young people should decide to get tested and motivate peers who are at risk for CT to get tested. Thirdly, planning for getting tested or motivating peers is another objective, which will lead to the fourth objective of actually getting tested and motivating other young people at risk for CT. The following determinants were identified as most important and changeable: knowledge, self-efficacy, risk perception, social norms and attitudes. Finally, a matrix of change objectives was developed for each behavioural outcome.

The treatment and follow up for re-testing is already included in the current sexual health care practice and is therefore not described within the matrices.

Table 2: Performance and change objectives for the behavioural outcome: high-risk young people get tested for Chlamydia (CT)

\begin{tabular}{|c|c|c|c|c|c|}
\hline \multirow{2}{*}{$\begin{array}{l}\text { Performance } \\
\text { objectives }\end{array}$} & \multicolumn{5}{|c|}{ Determinants } \\
\hline & Knowledge & Attitude & $\begin{array}{l}\text { Perceived } \\
\text { social norms }\end{array}$ & Risk perception & Self-efficacy \\
\hline $\begin{array}{l}\text { P01.1: Young } \\
\text { people appraise } \\
\text { effects of Ct and } \\
\text { personal risk }\end{array}$ & $\begin{array}{l}\text { K1.1: Describe } \\
\text { different STI and } \\
\text { in particular } \\
\text { asymptomatic } \\
\text { diseases }\end{array}$ & $\begin{array}{l}\text { A1.1: Express } \\
\text { positive attitude } \\
\text { towards self } \\
\text { assessment of } \\
\text { Ct risk }\end{array}$ & & $\begin{array}{l}\text { R1.1: Aware of } \\
\text { the possibility } \\
\text { of getting a Ct } \\
\text { infection }\end{array}$ & \\
\hline & $\begin{array}{l}\text { K1.2: Describe } \\
\text { Ct effects }\end{array}$ & & & & \\
\hline $\begin{array}{l}\text { P01.2: Young } \\
\text { people decide to } \\
\text { get tested for } \mathrm{Ct}\end{array}$ & $\begin{array}{l}\text { K1.3: Describe } \\
\text { test procedure } \\
\text { and test options } \\
\text { for } \mathrm{Ct}\end{array}$ & & & $\begin{array}{l}\text { R1.2: Aware of } \\
\text { the health risk } \\
\text { of not getting } \\
\text { tested }\end{array}$ & \\
\hline $\begin{array}{l}\text { P01.3: Young } \\
\text { people ask for } \\
\text { Ct testing }\end{array}$ & & & & & $\begin{array}{l}\text { SE1.1: Express } \\
\text { confidence in } \\
\text { ability to ask for } \\
\text { testing option } \\
\text { (home based test } \\
\text { kits or appoint- } \\
\text { ment STI centre) }\end{array}$ \\
\hline $\begin{array}{l}\text { P01.4: Young } \\
\text { people get tested } \\
\text { for Ct }\end{array}$ & & $\begin{array}{l}\text { A1.2: Express } \\
\text { positive attitude } \\
\text { towards test } \\
\text { procedure and } \\
\text { results. }\end{array}$ & $\begin{array}{l}\text { SN1.1: } \\
\text { Recognize social } \\
\text { acceptance of Ct } \\
\text { testing among } \\
\text { young people }\end{array}$ & & \\
\hline
\end{tabular}


Table 3: Performance and change objectives for the behavioural outcome: young people motivate peers to get tested for Chlamydia (CT)



P02.1: Young people appraise peers to get tested

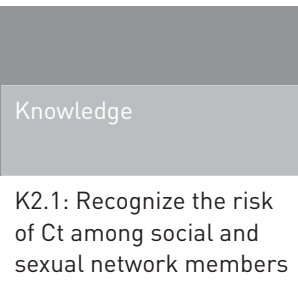

Determinants
Perceived social norms
P02.2: Young people

decide to motivate network

members for testing

P02.3: Young people

plan to motivate peers
A2.1: Feel responsible to

motivate high risk young

peers

A2.2: Express positive

attitude towards the

motivation of peers

to get tested

P02.4: Young people

motivate peers

SN2.1: Recognize social

acceptance among young people to motivate peers at high risk for $\mathrm{Ct}$

\section{Step 3: Selecting theory-informed intervention methods and practical applications}

As a result from the initial needs assessment and the matrices of change in step two, a webbased RDS was used to select peers to motivate young people and encourage them to attend CT testing, thereby motivating high-risk young people through their own social and sexual network. Web-based RDS was judged highly promising and feasible in high-risk young people, because it has been successfully used before in a group of young people [18]. The concept of using peer influence and chain-referral sampling has already worked well to target "those in need" in complex networks but never used in Ct control in young people $[19,45,46]$. In our strategy sampling begins with CT positive young people attending the South Limburg sexual health care centres and proceeds in waves recruiting more targeted contacts from hitherto-hidden sexual and social networks. Participants select friends based on their knowledge of the extent to which these friends need or use appropriate care. The person who begins the chain-referral sampling within a given high risk network is already tested for $\mathrm{CT}$, which increases perceived social norms. To improve the chance of the targeted contact to decide for testing, messages and home-based test kits will be used. Other supporting methods geared to improve testing and motivating include tailoring, personalize risk, modelling, consciousness raising, elaboration, mobilizing social support and self re-evaluation (i.e., Tables 4 and 5). 
Table 4: Methods and applications to get high-risk young people tested for Chlamydia (CT)

\begin{tabular}{|c|c|c|c|}
\hline & Methods & Parameters for use & Applications \\
\hline \multicolumn{4}{|l|}{ Knowledge } \\
\hline $\begin{array}{l}\text { K1.1: Describe different } \\
\text { STI and in particular } \\
\text { asymptomatic diseases }\end{array}$ & Tailoring & $\begin{array}{l}\text { Tailoring variables or } \\
\text { factors (e.g., socio- } \\
\text { economic status) }\end{array}$ & $\begin{array}{l}\text { AP1.1: Online tailored in- } \\
\text { formation about STI based } \\
\text { on current knowledge and } \\
\text { Socioeconomic Status (SES) }\end{array}$ \\
\hline $\begin{array}{l}\text { K1.3: Describe test proce- } \\
\text { dure and test options for CT }\end{array}$ & Elaboration & $\begin{array}{l}\text { Individuals with high } \\
\text { motivation, messages that } \\
\text { are personally relevant and } \\
\text { easily understandable }\end{array}$ & $\begin{array}{l}\text { AP1.2: Information about } \\
\text { the different CT test } \\
\text { options and procedures } \\
\text { using videos and images }\end{array}$ \\
\hline
\end{tabular}

\begin{tabular}{|c|c|c|}
\hline \multicolumn{3}{|l|}{ Attitude } \\
\hline $\begin{array}{l}\text { A1.1: Express positive } \\
\text { attitude towards self } \\
\text { assessment of CT risk }\end{array}$ & Self-re-evaluation & $\begin{array}{l}\text { Stimulation of both } \\
\text { cognitive and affective } \\
\text { appraisal of self-image }\end{array}$ \\
\hline
\end{tabular}

Modelling

A1.2: Express positive attitude towards test procedure and results
Attention and identification with model

Individuals with high motivation, messages that are personally relevant and easily understandable
AP1.3. Stimulation via visual effects (videos and images) and questions to self assess sexual behaviour

AP1.4: Messages from friends/sex partners to motivate young people to self assess their sexual behaviour

AP1.2: Information about the different CT test options and procedures using videos and images

Perceived social norms

SN1.1: Recognize social acceptance of CT testing among young people

\section{Modelling}

Mobilizing social

Support
Availability of social and sexual network
AP1.5: Via personalized or anonymous messages from peers young people are encouraged to get tested for CT. Information about CT test options and informs that a friend or sex partner already asked for a CT test

\section{Risk perception}

R1.1: Aware of the possibility of getting a CT infection
Personalize risk

Raising

Consciousness
Messages are personal and results are compared to absolute and normative standards

R1.2: Aware of the health risk of not getting tested
Can use feedback
AP1.6: Risk assessment questionnaire will be provided and a personalized report about the acquired CT risk and an advice about CT testing is provided to the person

AP1.7: Reminders will be send to young people who did not yet ask for a CT test

\begin{tabular}{|c|c|c|c|}
\hline \multicolumn{4}{|l|}{ Self-efficacy } \\
\hline $\begin{array}{l}\text { SE1.1: Express confidence } \\
\text { in ability to ask for testing } \\
\text { option (home-based test } \\
\text { kits or appointment STI } \\
\text { centre) }\end{array}$ & $\begin{array}{l}\text { Planning coping } \\
\text { responses }\end{array}$ & $\begin{array}{l}\text { Identification of potential } \\
\text { barriers and solutions }\end{array}$ & $\begin{array}{l}\text { AP1.8: Young people will } \\
\text { be informed about the } \\
\text { possibility and advantages } \\
\text { of home-based CT test } \\
\text { kits. These test kits are } \\
\text { free, anonymous and easy } \\
\text { to use. }\end{array}$ \\
\hline
\end{tabular}


Table 5: Methods and applications for young people to motivate peers to get tested for Chlamydia (CT)

\begin{tabular}{|c|c|c|c|}
\hline & Methods & Parameter of use & Applications \\
\hline \multicolumn{4}{|l|}{ Knowledge } \\
\hline \multirow[t]{2}{*}{$\begin{array}{l}\text { K2.1: Recognize the } \\
\text { transmission of CT among } \\
\text { social and sexual network } \\
\text { members }\end{array}$} & Tailoring & $\begin{array}{l}\text { Tailoring variables or } \\
\text { factors le.g., socio- } \\
\text { economic status }\end{array}$ & \multirow[t]{2}{*}{$\begin{array}{l}\text { AP2.1: Online information } \\
\text { about the transmission } \\
\text { of CT among social and } \\
\text { sexual network via videos } \\
\text { and images }\end{array}$} \\
\hline & Elaboration & $\begin{array}{l}\text { Messages that are } \\
\text { personally relevant, easily } \\
\text { understandable and } \\
\text { include direct instructions }\end{array}$ & \\
\hline \multicolumn{4}{|l|}{ Attitude } \\
\hline $\begin{array}{l}\text { A2.1: Feel responsible to } \\
\text { motivate high-risk young } \\
\text { peers }\end{array}$ & Elaboration & $\begin{array}{l}\text { Messages that are } \\
\text { personally relevant, easily } \\
\text { understandable and } \\
\text { include direct instructions }\end{array}$ & $\begin{array}{l}\text { AP2.1: Online information } \\
\text { about the transmission } \\
\text { of CT among social and } \\
\text { sexual network via videos } \\
\text { and images }\end{array}$ \\
\hline $\begin{array}{l}\text { A2.2: Express positive } \\
\text { attitude towards the } \\
\text { motivation of peers to } \\
\text { get tested }\end{array}$ & Modelling & $\begin{array}{l}\text { Attention and identification } \\
\text { with model }\end{array}$ & $\begin{array}{l}\text { AP2.2: Via personalized } \\
\text { or anonymous messages } \\
\text { from peers young people } \\
\text { will be encouraged to } \\
\text { motivate their own friends/ } \\
\text { sex partners }\end{array}$ \\
\hline \multicolumn{4}{|l|}{ Perceived social norms } \\
\hline \multirow[t]{2}{*}{$\begin{array}{l}\text { SN2.1: Recognize social } \\
\text { acceptance among young } \\
\text { people to motivate peers } \\
\text { at high-risk for CT }\end{array}$} & Modelling & $\begin{array}{l}\text { Attention and identification } \\
\text { with model }\end{array}$ & \multirow{2}{*}{$\begin{array}{l}\text { AP2.2: Via personalized } \\
\text { or anonymous messages } \\
\text { from peers young people } \\
\text { will be encouraged to } \\
\text { motivate their own friends/ } \\
\text { sex partners }\end{array}$} \\
\hline & Mobilizing social support & $\begin{array}{l}\text { Availability of social and } \\
\text { sexual network }\end{array}$ & \\
\hline
\end{tabular}

\section{Step 4: Producing program components and materials}

As a result of the selected methods and practical applications the deliverable will be an outreach CT screening strategy based on a secure web-based RDS engine, with an online interface specially written for young people to recruit and motivate peers. This website is named www.SafeFriend.nl. The use of the web was judged promising during this IM process, because many young individuals have an email address and/or mobile phone to reach them. Using messages via email and/or mobile phone young people can motivate their sex partners and/or friends. The message will be brief and contains carefully worded text to alert the receiver of possible CT risk, provide options for CT testing and modelling (i.e., peers who test). To increase the likelihood of use the exact content of this message can be partly adapted (i.e., name or anonymous, level of language) by the user who sends it. After login and system user verification the person is offered tailored information on sexual health and likely CT risk. They will be prompted with a brief questionnaire and the answers are automatically assessed to decide to offer him or her a home-based CT test kit. Home-based testing has proven feasible and effective 
in other screening programs, however, such internet-delivered testing is yet to be included in regular care in public sexual health care centres or other care settings. The new recruit is then encouraged to motivate at that moment or at a later stage others who will then go through the same procedure. It should be noted that within the website in some cases a young individual will be asked to visit the sexual health care centre as they are likely to require more sexual health care than CT testing alone. Necessary facilities like computers and home-based CT test kits will be in place at the moment the intervention is implemented in practice. Overall, the use of the SafeFriend website by young people is self-initiated and not guided by the health care professionals. The exception is the first recruitment step where the CT positive young people at the sexual health care centre are motivated and supported by the nurses to use the intervention. For this, a second designed interface is accessed by the nurse during the consultation visit (the moment that in routine care PN is discussed). This interface enables the nurse to start the recruitment-chain and to oversee the process of further home-test requests. The young CT positive client can motivate others during the consultation (like in provider-referral) and/or at a later moment at home (like in patient-referral). Of course the clients may choose not to motivate others, without any further consequences for their own care. As the actions on motivating others are standardly registered (coded) the intervention yields systematic data on PN, data that are currently lacking.

\section{Discussion}

Intervention Mapping has been used to develop a web-based outreach strategy, named SafeFriend, for CT testing in young people at risk. The intervention will be used to target highrisk young people as opposed to the current wider web-based CT screening strategies which have used a more opportunistic $[6,9]$ or population approach $[8,10]$. It is believed that the current research project is the first web-based outreach screening strategy that combines a web-based RDS method with the delivering of targeted CT screening to high-risk young people using peer influence, starting from young CT positive sexual health care centre clients. The sexual health care setting acts as a sustainable source of CT positive young people and thereby provides continued access to more hard-to-reach group of high-risk young people in their networks. Specifically, this strategy aims to extend CT prevention beyond sexual networks by also recruiting high-risk young people within social networks.

The attitudes and behaviours of young people in respect of sexual behaviour and STIs are strongly influenced by their peers $[15,17,32]$. Peer influence regarding STI screening is therefore an important strategy to reach high-risk young people for STI testing. The CT positive young people, who begin the web-based chain-referral sampling in the proposed intervention, will 
have experiences with $\mathrm{CT}$ testing and treatment. Their specific knowledge and positive attitudes about CT testing could make them ideal peers to communicate messages within their sexual and social networks. However, the reliance on the success of motivation and engaging peer networks using peer influence could be reason for some concern. Personal and social sensitivities regarding STI (i.e., stigmatization, confidentiality and privacy) can be important barriers and can counter the success of peer influence. To ensure medical confidentiality and provide a secure web-based screening strategy, we enable persons to decide for themselves which personal information they reveal to their own chosen sex partners and/or friends; personal information will, in all cases, be completely invisible to all other peers. Having said this, STI is a sensitive and personal topic, especially if a STI is diagnosed; still other studies have found that youngsters did share their results with peers (i.e., 93\% in CSI) [31].

The use of online CT testing of larger populations and associated home-based test kits is increasing worldwide and proved already feasible and acceptable among young people $[7,9,40,41,47]$. It creates easy access to testing and overcomes barriers such as the time required for travelling, transportation and fear of anonymity loss [48]. Despite these advantages, the cost per case detected and treated is high due to low participation and Ct positivity rates $[8,10]$, caused by targeting sexual networks only (i.e., thereby missing non-sexual high-risk contacts) or by taking a population based approach (i.e., including lower risk individuals). The developed strategy is expected to be more targeted and cost-effective for CT control starting from high-risk young people (i.e., Ct positive sexual health care clients) and also including social networks (i.e., non sexual high-risk individuals).

In addition, the intervention should increase re-infection control by facilitating also web-based PN. Using a web-based RDS method will respectively reduce the delay of sex partner's testing and increases the number of detected $\mathrm{Ct}$ infections among sex partners and friends [41]. For an actual reduction of CT transmission and re-infection effective CT treatment is necessary. In two previous studies, more than $90 \%$ of sex partners and positive patients being tested with homebased test kits received treatment $[40,41]$.

Although web-based PN systems are emerging [43,49], comprehensive evaluations to determine the effectiveness of these systems are limited: data regarding socio-demographics and actual outcomes (i.e., testing and treatment of partners) are not systematically collected. To obtain more insight into infection patterns and partner management, sexual and social contacts should be linked with socio-demographics at the individual and network level. The proposed intervention will yield systematic data on infections patterns and PN. The methodology in this paper (i.e., web-based RDS) in combination with social network techniques can structurally identify network clusters and the socially prominent characteristics associated with the clusters. Identifying and 
understanding the boundaries and bridges within a network will also be possible and can provide useful information about the extent of network penetration. Furthermore, available data show that current PN practices, which are mainly by patient-referral $[50,51]$, could be improved significantly when there is more provider-oversight and support $[34,42,47]$, a strategy that is also accommodated in our intervention.

The intervention will be developed, tested and implemented within a public health care service involved in STI control. An important pillar of public healthcare is the support of vulnerable groups in society. If a patient is less capable to warn his/her partner, due to low self-efficacy or misperceived severity, public health care professionals may be inclined to take responsibility in the interest of both the patient and his/her sex partner (i.e., prevention and re-infection control). However, tension exists between achieving benefits for whole populations and protecting the individual's rights [52]. The intervention therefore facilitates both patient- and provider-referral, creating a digital environment where clients can voluntarily, but with the support and oversight of sexual health care nurses motivate peers to get tested.

\section{Conclusion}

In conclusion, IM was a useful tool in developing an intervention for targeted CT testing among high-risk young people. The proposed intervention SafeFriend will be the first web-based outreach $\mathrm{CT}$ screening strategy for high-risk young people which includes web-based chain-referral sampling to motivate peers (i.e., sex partners and fiends) to get tested for CT. The intervention will complement existing sexual health care, by introducing the Internet to targeted CT screening. It builds on lessons learned from a large-scale Dutch population based CT screening programme using home-based test kits and adds to current initiatives to strengthen web-based PN. We hope it can become an integral part in sexual health care for reaching high-risk populations with CT screening and treatment that is important for both the individual and public health level. 


\section{References}

1. National Institute for Public Health and the Environment: Nationaal soa/hiv-plan 2012-2016: 'bestendigen en versterken. 2011:13,14, 18,19. Report 215111001/2011 Bilthoven http://www.rijksoverheid.nl/ documenten-en-publicaties/rapporten/ 2011/12/05/nationaal-soa-hiv-plan-20122016-bestendigen-en-versterken.html

2. Soetens LC, Koedijk FDH, van den Broek IVF, Vriend HJ, Op de Coul ELM, van Sighem Al, Stirbu-Wagner I, van Benthem BHB: STI, including HIV, in the Netherlands in 2012. 2011:3-51. Annual Report 150002003 Bilthoven http://www.rivm.nl/Documenten_ en_publicaties/Wetenschappelijk/Rapporten/ 2013/juni/Sexually_transmitted_infections_ including_HIV_in_the_Netherlands_in_2012

3. Geisler WM: Duration of Untreated, Uncomplicated Chlamydia trachomatis Genital Infection and Factors Associated with Chlamydia Resolution: a Review of Human Studies. JID 2010, 201(Suppl 2):s104-s113.

4. Wand H, Guy R, Donovan B, McNulty A: Developing and validating a risk scoring tool for chlamydia infection among sexual health clinic attendees in Australia: a simple algorithm to identify those at high risk of chlamydia infection. BMJ Open 2011, 1:e000005. Doi:10.1136/bmjopen-2010-000005.

5. Haggerty CL, Gotliebb SL, Taylor BD, Low N, Xu F, Ness RB: Risk of Sequelae after Chlamydia trachomatis Genital Infection in Women. JID 2010, 201(Suppl2):s134-s155.

6. Novak DP, Karlsson BR: Simplifying chlamydia testing: an innovative Chlamydia trachomatis testing approach using the
Internet and a home sampling strategy: population based study. Sex Trans Infect 2006, 82:142-147. doi: 10.1136/ sti.2005.016832.

7. Novak D, Novak M: Use of the Internet for home testing for Chlamydia trachomatis in Sweden: who are the users? Int J of STD AIDS 2012, 23:83-87. Doi:10.1258/ijsa.2011.011030.

8. Bracebrigde S, Bachmann MO, Ramkhelawon K, Woolnough A: Evaluation of a systematic postal screening and treatment service for genital Chlamydia trachomatis, with remote clinic access via the internet: a cross-sectional study, East of England. Sex Trans Infect 2012, 88(5):375-381. Doi:10.1136/sextrans-2011050267.

9. Gaydos CA, Dwyer K, Barnes M, Rizzo-Price PA, Wood BJ, Flemming T, Hogan MT: Internet-Based Screening for Chlamydia trachomatis to Reach Nonclinic Populations With Mailed Self-Administered Vaginal Swabs. Sex Trans Dis 2006, 33(7):451-457. doi: 10.1097/01.olq.0000200497.14326.fb.

10. Van Den Broek IVF: Chlamydia Screening Implementation Netherlands, Impact evaluation and cost-effectiveness. National Institute for Public Health and the Environment (RIVM). 2010:22,113. Report 210261008 Bilthoven http://www.rivm.nl/bibliotheek/ rapporten/210261008.html

11. Jenkins WD, Weis $R$, Campbell $P$, Barnes $M$, Barnes P, Gaydos C: Comparative effectiveness of two self-collected sample kit distribution systems for Chlamydia screening on a university campus. Sex Trans Infect 2012, 88:363-367. 
12. Mishra S, Sgaier SK, Thompson LH, Moses S, Ramesh BM, Alary M, Wilson D, Blanchard JF: HIV epidemic appraisals for assisting in the design of effective prevention programmes: shifting the paradigm back to basic. Plos One 2012, 7(3):e32324. doi: 10.1371/journal. pone.0032324.

13. Aral SO, Leichliter JS, Blanchard JF: Overview: the role of emergent properties of complex systems in the epidemiology and prevention of sexually transmitted infections including HIV infection. Sex Trans Infect 2010, 86(Suppl3):iii1-iii3.

14. Robinson K, Cohen T, Colijn C: The dynamics of sexual contact networks: effects on disease spread and control. Theor Pop Biol 2012, 81(2). Doi:10.1016/j.tpb.2011.12.009.

15. Drumright LN, Frost SDW: Rapid social network assessment for predicting HIV and STI risk among men attending bars and clubs in San Diego California. Sex Trans Infect 2010, 86(3):iii17-iii23.

16. Rothenberg R: The tranformation of Partner Notification. CID 2002, 35(2):S138-S145.

17. Youm Y, Laumann EO: Social Network Effects on the Transmission of STI. Sex Trans Dis 2002, 29(11):689-697.

18. Wejnert C, Heckathorn DD: Web-Based Network Sampling: efficiency and Efficacy of RDS. Soc Meth Res 2008, 37:105-134.

19. Malekinejad M, Johnston LG, Kendall C, Kerr LRFS, Rifkin MR, Rutherfors GW: Using Respondent-Driven Sampling Methodology for HIV Biological and Behavioral Surveillance in International Settings: a systematic review. AIDS Behav 2008, 12:S105-S130.
20. Heckathorn DD, Semaan S, Broadhead RS, Hughes JS: Extensions of respondent-driven sampling: A new approach to the study of injection drug users aged 18-25. AIDS Behav 2002, 6:55-67.

21. Johnston LG, Whitehead S, Simic-Lawson M, Kendall C: Formative research to optimize respondent dirven sampling surveys among hard-to-reach populations in HIV behavioral and biological surveillance: lessens learned from four case studies. AIDS Care 2010, 22(6):784-792.

22. Bartholomew LK, Parcel GS, Kok G, Gottlieb $\mathrm{NH}$, Fernandez ME: Planning health promotion programs: an intervention mapping approach. United States of America: John Wiley \& Sons; 2011.

23. van Oostrom SH, Anema JR, Terluin B, Venema $A$, de Vet HCW, van Mechelen W: Development of a workplace intervention for sick-listed employees with stress-related mental disorders: intervention Mapping as a useful tool. BMC Health Serv Res 2007, 7:12. doi: 10.1186/1472-6963-7-127.

24. Wolfers MEG, van den Hoek C, Brug J, de Zwart O: Using Intervention Mapping to develop a programme to prevent sexually transmittable infections, including HIV, among heterosexual migrant men. BMC Public Health 2007, 7:141. doi: 10.1186/14712458-7-141.

25. van Empelen $P$, Kok G, Schaalma HP, Bartholomew LK: An AIDS Risk Reduction Program for Dutch Drug Users: An Intervention Mapping Approach to Planning. Health Promot Pract 2003, 4(4):402-412. doi: $10.1177 / 1524839903255421$. 
26. Green LW, Kreuter MW: Health Program Planning: An Educational and Ecological Approach. 4th edition. NY: McGraw-Hill Higher Education; 2005.

27. Central Committee on Research inv. Human Subjects (CCMO). http://www. ccmo-online. $n l /$ main.asp?pid=43\&thid $=57 \&$ catid $=2$.

28. Weinstein ND, Sandman PM: A model of the Precaution Adoption Process: Evidence From Home Radon Testing. Health Psychol 1992, 11(3):170-180.

29. van Bergen J, Gotz HM, Richardus JH, Hoebe CJPA, Broer J, Coenen AJT: Prevalence of urogenital Chlamydia trachomatis increases significantly with level of urbanisation and suggests targeted screening approaches: results from the first national population based study in the Netherlands. Sex Trans Infect 2005, 81:17-23. doi: 10.1136/ sti.2004.010173.

30. Trienekens SCM, Vriend HJ, Koedijk FDH, Van Den Broek IVF, Vriend HJ, Op De Coul ELM, Van Veen MG, Van Sighem Al, Stirbu Wagner I, Van Der Sande MAB: Sexually transmitted infections, including HIV, in the Netherlands in 2011. National Institute of Public Health and the Environment (RIVM). 2012:39-49. Annual Report 201051001 Bilthoven http:// www.rivm.nl/Documenten_en_publicaties/ Wetenschappelijk/Rapporten/2012/juni/ Sexually_transmitted_infections_including_ HIV_in_the_Netherlands_in_2011

31. Greenland KE, Op De Coul ELM, Van Bergen JEAM, Brouwers EEHG, Fennema HJSA, Gotz HM, Hoebe CJPA, Koekenbier RH, Pars LL, Van Ravesteijn SM, Van Den Broek IVF: Acceptability of the Internet-Based Chlamydia
Screening Implementation in the Netherlands and Insights Into Nonresponse. Sex Trans Dis 2011, 38:6.

32. Potard C, Courtois R, Rusch E: The influence of peers on risky sexual behaviour during adolescence. Eur J Contracept Reprod Health Care 2008, 13(3):264-270.

33. Fichtenberg $C M$, Muth $S Q$, Brown $B$, Padain NS, Glass TA, Ellen JM: Sexual network position and risk of sexually transmitted infections. Sex Trans Dis 2009, 85:493-498. doi: 10.1136/sti.2009.036681.

34. Brewer D: Case-finding effectiveness of partner notification and cluster investigation for sexually transmitted diseases/HIV. Sex Trans Dis 2005, 32(2):78-83.

35. Samkange-Zeeb FN, Spallek L, Zeeb H: Awareness and knowledge of STIs among school-going adolescents in Europe: asystematic review of published literature. BMC Public Health 2011, 11:727.

36. Centers for Disease Control and Prevention: Summary of a review of the literature: Programs to Promote Chlamydia Screening. http://www.cdc.gov/ STI/HealthComm/ ChlamydiaLitReview2008.pdf

37. Tilson EC, Sanchez V, Ford CL, Smurzynski M, Leone PA, Fox KK, Irwin K, Miller WC:

Barriers to asymptomatic screening and other STD services for adolescents and young adults: focus group discussions. BMC Public Health 2004, 21(4):1-8.

38. Barth KR, Cook RL, Downs JS, Switzer GE, Fischhoff B: Social Stigma and Negative Consequences: Factors That influence College Students' Decisions to Seek Testing for Sexually Transmitted Infections. J of Am Coll Health 2003, 50(4):153-159. 
39. Blake D, Kearney M, Oakes JM, Druker S, Bibace R: Improving participation in chlamydia screening programs: perspectives of high-risk youth. Arch Pediatr Adolesc Med 2003, 157:523-529.

40. Gotz HM, Veldhuijzen IK, van Bergen JEAM, Hoebe CJPA, de Zwart O, Richardus JH: Acceptability and Consequences of Screening for Chlamydia trachomatis by Home-Based Urine Testing. Sex Trans Dis 2005, 32(9):557562. doi: 10.1097/01.olq.0000175416.15905.db.

41. Østergaard L, Andersen B, Møller JK, Olesen F, Worm AM: Managing partners of people diagnosed with Chlamydia trachomatis: a comparison of two partner testing methods. Sex Transm Infect 2003, 79:358-362.

42. Temple-Smith M, Hopkins C, Fairley C, Tomnay J, Pavlin N, Parker R, Russell D, Bowden F, Hocking J, Pitts M, Chen M: The right thing to do: patients' views and experiences of telling partners about chlamydia. Fam Pract 2010, 27:418-423. doi: 10.1093/fampra/cmq028.

43. Bilardi JE, Fairley CK, Hopkins CA, Hocking JS, Temple Smith MJ, Bowden FJ, Russell DB, Pitts M, Tomnay JE, Parker RM, Pavlin NL, Chen MY: Experiences and Outcomes of Partner Notification Among Men and Women Recently Diagnosed With Chlamydia and Their Views on Innovative Resources Aimed at Improving Notification Rates. Sex Trans Dis 2010, 37:4.

44. Burnet Institute: Partner Notification of Sexually Transmitted Infections in New South Wales: an informed literature review. http:// www.stipu.nsw.gov.au/content/Document/ NSW_STI_PN_PDF.pdf.
45. Rothenberg RB, Sterk C, Toomey KE, Potterat JJ, Johnson D, Schrader M, Hatch S: Using Social Network and Ethnographic Tools to Evaluate Syphilis Transmission. Sex Trans Dis 1998, 25(3):154-160.

46. Choi KH, Ning Z, Gregorisch SE, Pan QP: The Influence of Social and Sexual Networks in the Spread of HIV and Syphilis Among Men Who Have Sex With Men in Shanghai. Epidemiol Soc Sci 2007, 45(1):77-84.

47. Trelle S, Shang A, Nartey L, Cassell JA, Low $\mathrm{N}$ : Improved effectiveness of partner notification for patients with sexually transmitted infections: systematic review. BMJ 2007, 334(7589):354.

48. Jenkins WD, Wold B: Use of the Internet for the surveillance and prevention of sexually transmitted diseases. Microbes Infect 2012, 14:427-437.

49. Levine D, Woodruff AJ, Mocello AR, Lebrija J, Klausner JD: inSPOT: The First Online STD Partner Notification System Using Electronic Postcards. Plos Med 2008, 5(10):213

50. Alam N, Chamot E, Vermund SH, Streatfield $\mathrm{K}$, Kristensen S: Partner notification for STI in developing countries: a systematic review. BMC Public Health 2010, 10(19):1471-2458.

51. Hogben M, Kissinger P: A Review of Partner Notification for Sex Partners of Men Infected With Chlamydia. Sex Trans Dis 2008, 35(11):S34-S39.

52. Rogers WA: Ethical issues in public health: a qualitative study of public health practice in Scotland. J Epidemiol Community Health 2004, 58:446-450. Doi:10.1136/ jech.2003.013417 


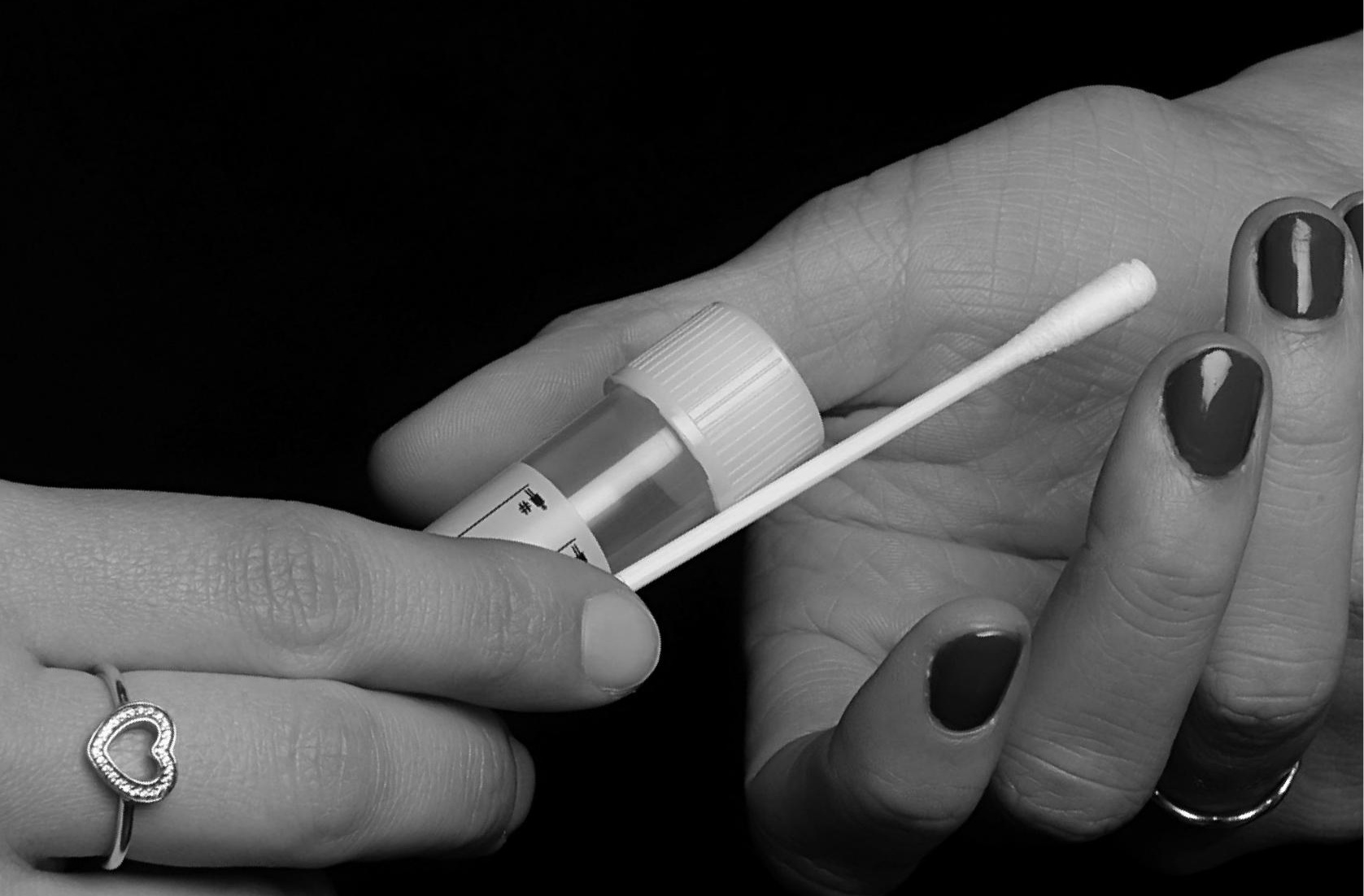




\section{Chapter 3}

\section{A web-based respondent driven sampling pilot targeting young people at risk for Chlamydia trachomatis in social and sexual networks with testing: a use evaluation}

Kevin A.T.M. Theunissen, Christian JPA Hoebe, Gerjo Kok, Rik Crutzen, Chakib Kara-Zaïtri, Nanne K. de Vries, Jan E.A.M. van Bergen, Robert Hamilton, Marianne A.B. van der Sande and Nicole H.T.M. Dukers-Muijrers

Int. J. Environ. Res. Public Health 2015, 12, 9889-9906 


\section{Abstract}

\section{Background}

With the aim of targeting high-risk hidden heterosexual young people for Chlamydia trachomatis (CT) testing, an innovative web-based screening strategy using Respondent Driven Sampling (RDS) and home-based CT testing, was developed, piloted and evaluated.

\section{Methods}

Two STI clinic nurses encouraged 37 CT positive heterosexual young people laged $16-25$ years), called index clients, to recruit peers from their social and sexual networks using the web-based screening strategy. Eligible peers (young, living in the study area) could request a home-based CT test and recruit other peers.

\section{Results}

Twelve (40\%) index clients recruited 35 peers. Two of these peers recruited other peers ( $n=7$ ). In total, 35 recruited peers were eligible for participation; ten of them $(29 \%)$ requested a test and eight tested. Seven tested for the first time and one (13\%) was positive. Most peers were female friends (80\%). Nurses were positive about using the strategy.

\section{Conclusions}

The screening strategy is feasible for targeting the hidden social network. However, uptake among men and recruitment of sex-partners is low and RDS stopped early. Future studies are needed to explore the sustainability, cost-effectiveness, and impact of strategies that target people at risk who are not effectively reached by regular health care.

\section{Keywords}

Chlamydia trachomatis; web-based respondent driven sampling; peer-referral; social networks; sexual networks; partner notification; home-based test kits 


\section{Introduction}

Screening of (a)symptomatic patients is considered an important strategy for controlling wthe transmission of Chlamydia trachomatis (CT) among young people [1]. Early detection and treatment prevents the infection from spreading and causing further morbidity. Most CT infections are found among young heterosexual people [1-3].

The number of reported cases of CT has increased worldwide in the past years [1-3]. With approximately 100 million new cases of CT every year, many CT infections still remain hidden to health care [3]. Approximately 30,000 infections are diagnosed in Sexually Transmitted Infections (STI) clinics and General Practitioner (GP) practices amongst young people each year in The Netherlands [2]. However, there are an estimated 60,000 new CT infections among young people [4] suggesting that half of the CT infections remain hidden, i.e., invisible to health care, in The Netherlands. Many young people at risk for CT may not seek sexual health care [3] due to the asymptomatic nature of the bacterial infection and other barriers such as fear for the sampling methods, a positive test result, and associated stigmatization and privacy concerns [1,5-8].

Several attempts have been made nationally and internationally, beyond regular sexual health care, to increase CT testing among young people at risk for CT. Initiatives in The Netherlands, United States, Canada, Sweden, Norway and the United Kingdom focused on population-based screening using the Internet and home-based testing to engage young people in CT testing [9-14]. Although such screening methods are appreciated amongst their users $[13,15]$, both participation and CT positivity rates in such population-based initiatives are generally low $[9-12,16]$. Furthermore, this method is not found to be cost-effective in The Netherlands [17].

Other approaches have been developed with the aim to reach out to the hidden CT positives by specifically targeting sexual partners of young CT positive people. Such partner notification approaches use a combined web-based system and/or home-based testing, building on the understanding that partner-notification is essential in the management of CT [18-22]. This is because timely notification, testing and treating of partners prevents transmission and (re)-infections. Web-based partner notification is complementary to standard face-to-face or telephone notification by providers (provider referral) and/or patients (patient referral) and can be used to send personal or anonymous emails, e-cards or mobile text messages (SMS) to motivate sexual partners to test for CT $[6,19,20,22]$. Web-based partner notification is well accepted among its users to notify others, but information about its actual use and its outcomes is scarce, especially with respect to the proportion of partners actually seeking testing and care $[6,20,23]$. A comparison was made between test uptake among partners by using home-based test kits compared to the regular testing by a health care provider in a randomized controlled 
trial. Results showed that more partners were tested and found to be CT positive with homebased test kits [21].

Other approaches $[24,25]$ have explored the use of social networks to access hidden high-risk young people for CT testing. These approaches use peer-led testing whereby young people recruit their social networks to test for CT using home-based test kits. Peers influence each other's attitudes and actions with respect to sexual behaviour and STI testing [26]. In reality therefore, not only sexual partners but also friends, i.e. the social network, of a CT positive person may be at higher risk for CT, although they do not share a sexual relationship $[6,26]$. Interestingly, approaches based on CT testing using social networks suffered from poor test kit uptake. Additionally, they have not explored using CT positives as recruiters of social network members [24,25].

Respondent driven sampling (RDS) is another method that has been used for many years, with some success, to reach out a targeted hidden population [27]. RDS initiates the search by using index clients (e.g., a person with an infection) to recruit and motivate network members to test (first wave). These members can motivate their own network members to get tested (second wavel and so on [27]. RDS has been demonstrated successful in finding new cases through social network members (non-sexual relationships) in studies with HIV [28] and syphilis [29]; cases who otherwise would not be reached when only sexual partners had been targeted (i.e., partner notification). Limited human and economic resources led to Internet based methodologies for conducting RDS in networks, which have shown effective in several studies. Until now, web-based RDS has been applied to infectious diseases [30] and drug and alcohol use [31] with some success. We hypothesize that web-based RDS may also be a potential novel strategy to reach young people at risk for CT who are not reached by regular care efforts, using their sexual and social networks and home-based test kits.

To test this hypothesis, we developed a novel web-based RDS outreach screening strategy, using a systematic approach, i.e., the Intervention Mapping (IM) protocol [32]. The strategy combines recruitment of the social and sexual network members starting with CT positive young people, and home-based CT testing. We piloted this strategy to test and evaluate its use luptake and usabilityl. Such evaluations have rarely been described for most other similar projects, yet are hoped to provide the necessary learning points for future CT control strategies that target social and sexual networks of high-risk young people, in particular those not reached by existing regular care. 


\section{Methods}

\section{Setting and intervention development}

The intervention was piloted at the STI clinic of the Public Health Service South Limburg, The Netherlands. This clinic provides about $6500 \mathrm{STI}$ consultations annually, offering free examination and treatment. The development of the intervention has been described in detail in Theunissen et al. [32]. In short, the intervention program components and specific materials were determined, based on existing theories and evidence, using the Intervention Mapping (IM) protocol [33].

\section{Intervention pilot implementation}

From November 2013 to March 2014, two sexual health care nurses piloted the intervention in their daily practice among CT positive young people and their social and sexual network members. Initially, the intervention was developed to consist of two interfaces: (1) a public website (online interface) for young people to recruit peers (i.e., https://www.SafeFriend.nl) and (2) a secure private interface which enables nurses to invite, motivate and support index clients to start a recruitment-chain during the treatment consultation at the STI clinic. Index clients were CT positive young people who were aged between 16 and 25 years, lived in South Limburg and visited the STI clinic for CT treatment. Young men who reported having sex with men (MSM) were excluded from participation, because according to national guidelines they are recommended to serologically test for other STI as well (i.e., HIV). The nurses asked all eligible index clients during the treatment consultation to participate and recruit anonymous or non-anonymous their sexual and/or social network members (peers) via the web-based screening strategy using email. They could login at the website (https://www.safefriend.nl) with their personalized credentials. The recruited peers (first wave) were then able to login and A) request a home-based urogenital CT test kit for themselves and B) recruit their social and sexual network members. The newly recruited peers then followed the same procedures, and so on; with a maximum of five waves. Peers in the pilot were eligible if they were aged 16-25 years; they were living in South Limburg and were not a man reporting having sex with a man. Excluded peers were advised to visit their GP. Home-based test kits could be requested to be sent to home addresses or collected at the STI clinic and were then mailed by the peers to the laboratory. Index clients and peers who did not finish the online process of the screening strategy or who did not return a home-based test kit received an email reminder two weeks after the first login. The nurse informed all CT positive peers by telephone and recommended treatment at the STI clinic South Limburg. The selection of the study population and the recruitment of peers is depicted graphically in Figure 1. 
Figure 1: Flowchart of the selection of the study population and recruitment of their peers

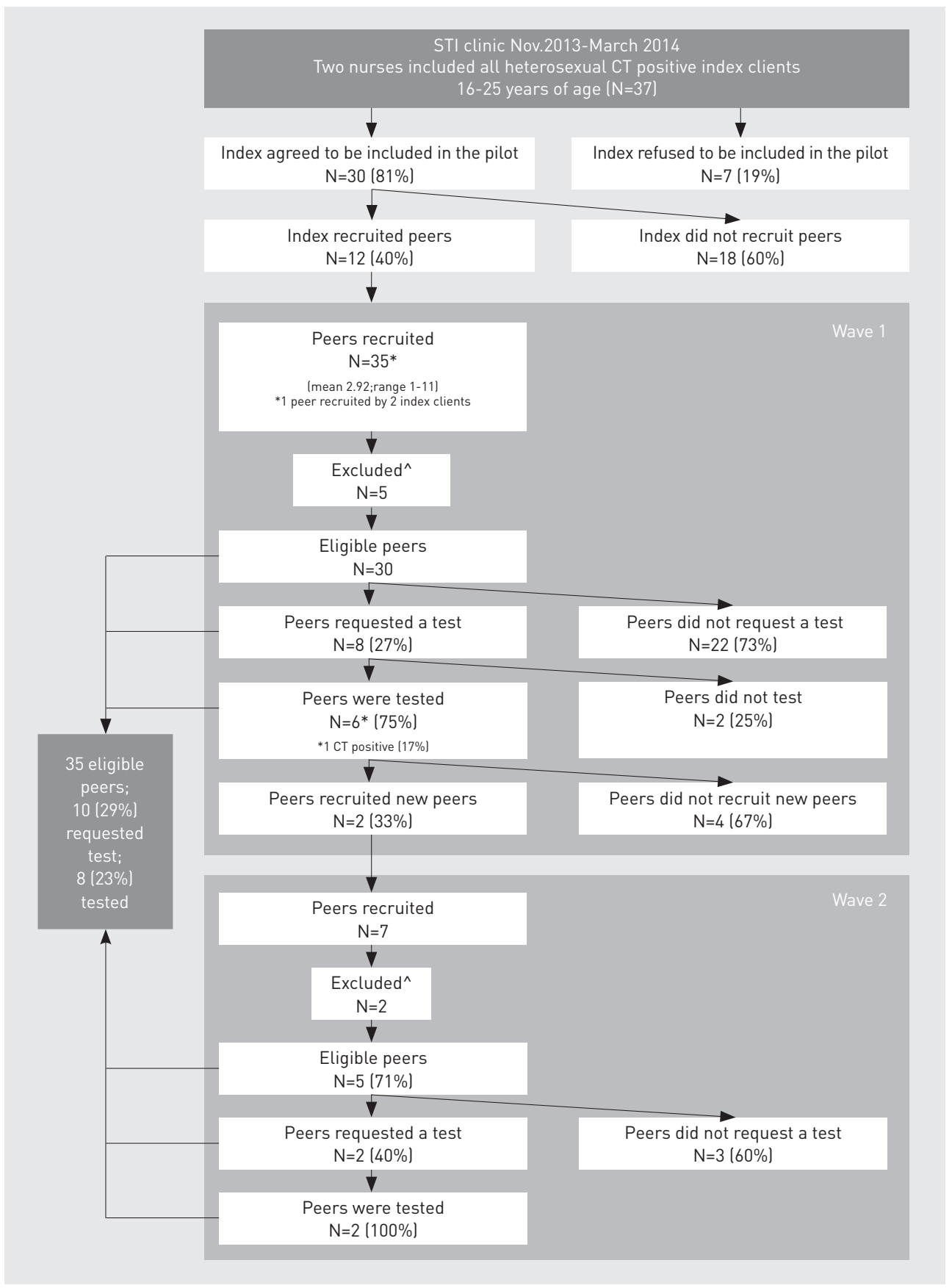

^ outside study region, or older than 25 years of age 


\section{Pilot evaluation}

The evaluation study was approved by the Ethics Committee of the Psychology Department of Maastricht University (ECP-13-4-054) prior to implementation. The evaluation comprised five steps of the intervention process: 1) technical development, 2) inclusion of index patients by nurses, 3) participation of index clients, 4) participation by peers, and 5) the treatment of CT positives.

\section{(1) Technical development}

To evaluate the technical part of the screening strategy, the functionalities used during the pilot were compared to those described in the IM protocol (which had been written before the pilot) [32]. The following functionalities were evaluated: the interfaces for nurses and young people, request of home- based test kits, recruitment process via email and SMS, and anonymous and non-anonymous recruitment.

\section{(2) Inclusion of index patients by nurses}

The percentage of index clients included was calculated and basic characteristics lage, sex, education level and number of sex partners during the last six months) were compared between included and not included clients using chi-square analyses. The number of clients who refused to participate, and reasons for refusal were analysed from a structured paper questionnaire which the two nurses filled in for eligible index clients. This questionnaire was used by the nurses for the partner notification and to invite index clients for the pilot. Information registered included the number of sexual partners in the past six months, partners already notified, and reasons for non-participation. Also the additional time needed to explain the pilot was included to estimate the workload for providers. To evaluate the providers' acceptability and workload, two weekly appointments of one hour were held with a researcher during the time of the pilot. During these appointments the researcher systematically recorded all comments lincluding positive and negative experiences) of the providers with the screening strategy and index clients.

\section{(3) Participation of index clients}

To evaluate index participation, i.e. recruitment, we used process observations (coded online collected data i.e., login dates, email addresses, birth dates, postcode area, sexual behaviour, actual recruitment, type of message sent, and type of relation between participants). The participation rate was calculated as the ratio of index clients who actually participated (recruiting peers from their social and/or sexual networks) by the number of index clients who were included by the two nurses in the pilot. Basic characteristics lage, sex and type of relationship with index, education level and number of sex partners last six months and test historyl of participants and non-participants were compared using chi-square analyses. 


\section{(4) Participation by peers}

Peer participation data, i.e. recruitment of network members, the type of relationships (i.e., best friend, friend, acquaintance, steady partner, casual partner, steady casual partner) and the number of waves reached, were retrieved from the process data and the PN questionnaires.

\section{(5) The treatment of CT positives}

The proportion of diagnosed CT was based on the biological assessment of the urogenital homebased self-taken samples (urine for men and vaginal swab for women) using a nucleic acid amplification test (NAAT: PCR, Cobas 4800, Roche, Pleasanton, CA, USA). The treatment status of positives was assessed by reviewing the medical records for tested cases.

\section{Results}

\section{Technical development}

The nurse interface, to invite index clients at the treatment consultation for our website, could not be used. Therefore nurses could not start the recruitment of peers by index clients at the STI clinic. Instead, the nurses sent the index clients an email containing a personal link to the website to use the online facility at home to recruit their peers.

Further, there were technical problems with the online interface for young people whereby only email as a method for participation could be used. The originally designed text messaging function was lacking. Moreover, in the first two weeks of the pilot six participants could not use their personal links to login (technical error). These participants were sent a second personal link. Finally, the website was offline during two weeks (server problems). In spite of the technical problems several technical features designed to increase usability were included in the strategy, i.e., providing the option to request home-based test kits and to recruit peers anonymous or non-anonymous.

\section{Inclusion of index clients}

During five months two female nurses served 37 eligible index clients who were all invited to participate and who filled in the structured paper partner notification questionnaire. The additional time that nurses needed for this inclusion and registration was between five to 15 minutes per index. Index clients were mostly women, between 21 and 25 years of age, highly educated and had had no more than two sex partners in the past six months (Table 1).

Eventually, 30 of 37 eligible index clients agreed to be included in the pilot; thereby the intended uptake was $81 \%$. They all received an invitation email with a personal link to login on the 
Table 1: Characteristics of index clients who recruited peers and non-recruiters.

\begin{tabular}{|c|c|c|c|c|c|}
\hline \multirow{2}{*}{\multicolumn{2}{|c|}{$\begin{array}{l}\text { All eligible index } \\
\text { clients }\end{array}$}} & \multirow[b]{2}{*}{$\begin{array}{l}\text { Eligible index } \\
\text { clients refused }\end{array}$} & \multirow[b]{2}{*}{$\begin{array}{l}\text { Eligible Index } \\
\text { Clients Included }\end{array}$} & \multicolumn{2}{|c|}{ Index Included } \\
\hline & & & & $\begin{array}{l}\text { Index Clients } \\
\text { Non-Recruiter }\end{array}$ & $\begin{array}{l}\text { Index Clients } \\
\text { Recruiter }\end{array}$ \\
\hline & $(n=37)$ & $(n=7) *$ & $(n=30) *$ & $(n=18) *$ & $(n=12) *$ \\
\hline & $\%(n)$ & $\%(n)$ & $\%(n)$ & $\%(n)$ & $\%(n)$ \\
\hline \multicolumn{6}{|l|}{ Age (years) } \\
\hline $17-20$ years & $43.2(16)$ & $71.4(5)$ & $36.7(11)$ & $38.9(7)$ & $33.3(4)$ \\
\hline $21-25$ years & $56.8(21)$ & $28.6(2)$ & $63.3(19)$ & $61.1(11)$ & $66.7(8)$ \\
\hline \multicolumn{6}{|l|}{ Sex } \\
\hline Female & $83.8(31)$ & $100.0(7)$ & $80.0(24)$ & $77.8(14)$ & $91.7(11)$ \\
\hline Male & $16.2(6)$ & $0.0(0)$ & $20.0(6)$ & $22.2(4)$ & $8.3(1)$ \\
\hline \multicolumn{6}{|c|}{ Education level ${ }^{\wedge}$} \\
\hline $\begin{array}{l}\text { University } \\
\text { and Higher } \\
\text { Professional } \\
\text { Education }\end{array}$ & $68.6(24)$ & $57.1(4)$ & $71.4(20)$ & $62.5(10)$ & $83.3(10)$ \\
\hline $\begin{array}{l}\text { Intermediate } \\
\text { Vocational } \\
\text { Education }\end{array}$ & $31.4(11)$ & 42.9 (3) & $28.6(8)$ & $37.5(6)$ & $16.7(2)$ \\
\hline \multicolumn{6}{|c|}{ Number of sex-partners past six months } \\
\hline $1-2$ & $64.9(24)$ & $85.7(6)$ & $60.0(18)$ & $61.1(11)$ & $58.3(7)$ \\
\hline 3 or more & 35.1 (13) & $14.3(1)$ & 40.0 (12) & 39.9 (7) & 41.7 (5) \\
\hline
\end{tabular}

^ 2 missing, *non-significant

web-based intervention at home and recruit peers to test for CT. No statistically significant differences (all $p>0.2$ ) were observed between clients who refused to be included ( $n=7 ; 19 \%$ ) and index clients who accepted to be included (Table 1). Reasons reported by eligible index clients to not be included in the pilot were shame, the unavailability of an email address of a sex partner, a sex partner had already been notified and friends were in a steady relationship and/ or already tested. The seven index clients who refused to be included reported a total of 19 sex partners and said that they already had notified nine of them.

During the weekly evaluation sessions, the nurses stated that the structured partner notification questionnaire that was used in this pilot helped them to systematically discuss the notification of sex partners with their clients. They felt also more motivated to encourage index clients to notify their sexual networks. The nurses also said that they were more aware of the CT risk among social network members of CT positive clients and emphasized the importance of their 
recruitment. The web-based strategy also provided them with previously lacking and important feedback on the effectiveness of their work process (i.e., visual notification of sex partners and friends). Nurses also noted shortcomings. The lack of an online nurse interface was a missed opportunity to provide support and to persuade index clients during their treatment consultation to use the web-based strategy and recruit peers. Index clients mentioned to the nurses that they preferred receiving and sending text messages instead of email.

\section{Index participation: recruitment of peers}

Of the 30 index clients who received a personal link to login on the website 18 persons did not recruit their peers (Table 1). The actual uptake was therefore $40 \%$ with 12 index clients participating by recruiting peers. No statistically significant differences (all $p>0.2$ ) were found between index clients who did not recruit peers and those who did (Table 1).

Figure 2: Recruitment among index clients and first wave peer

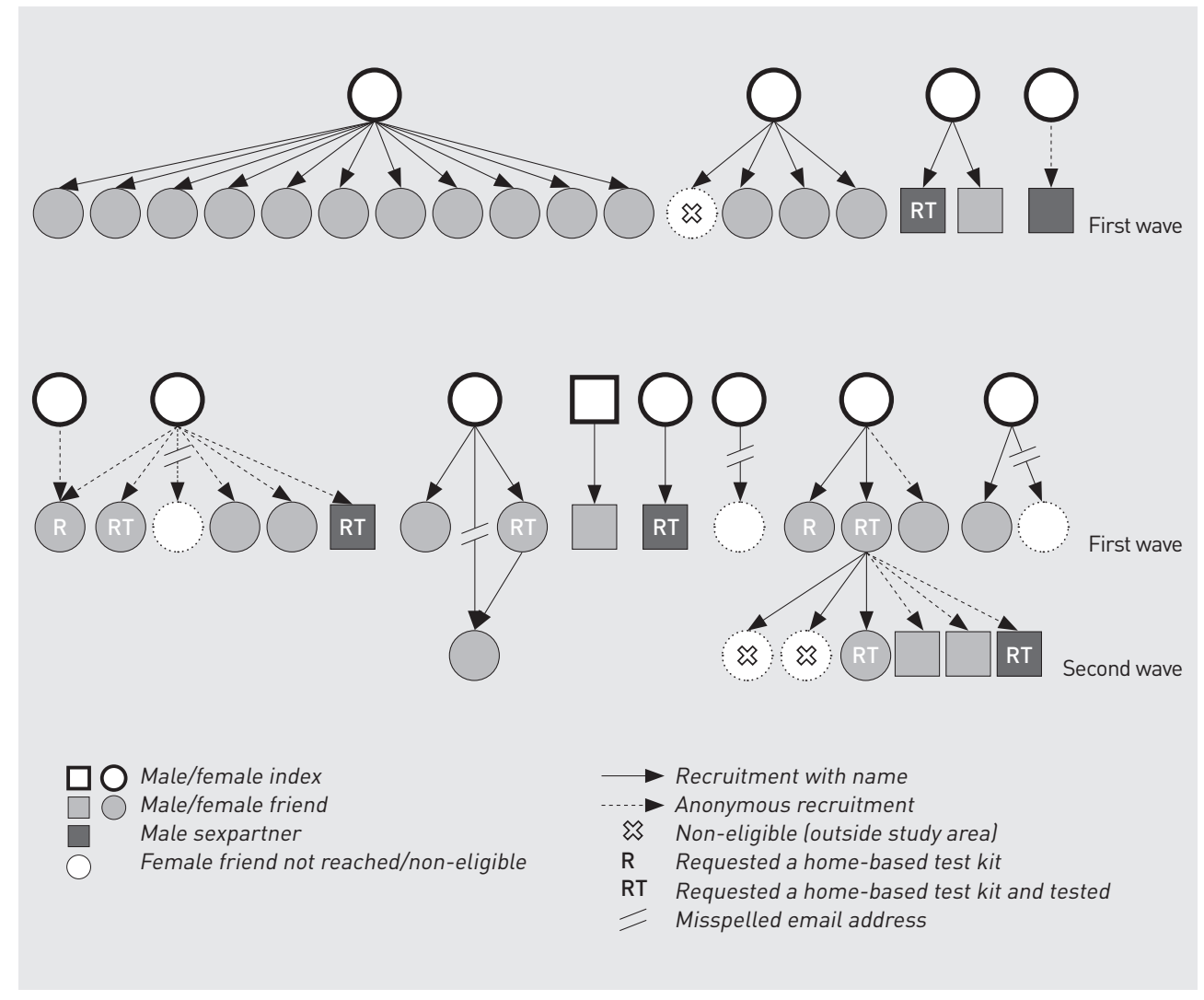


Table 2: Characteristics of eligible peers

\begin{tabular}{|c|c|c|c|}
\hline & $\begin{array}{l}\text { Eligible peers who not } \\
\text { requested a test/not } \\
\text { recruited another peer } \\
(n=25)\end{array}$ & $\begin{array}{l}\text { Eligible peers who } \\
\text { requested a home- } \\
\text { based test but not } \\
\text { recruited other peers } \\
(n=8)^{*}\end{array}$ & $\begin{array}{l}\text { Eligible peers who } \\
\text { requested a home- } \\
\text { based test and } \\
\text { recruited other peers } \\
(n=2) *\end{array}$ \\
\hline & $\%(n)$ & $\%(n)$ & $\%(n)$ \\
\hline \multicolumn{4}{|l|}{ Age lyears) } \\
\hline $17-20$ & $\mathrm{~N} / \mathrm{A}$ & $50.0(4)$ & $0.0(0)$ \\
\hline $21-25$ & N/A & $50.0(4)$ & $100.0(2)$ \\
\hline \multicolumn{4}{|c|}{ Sex and relationship with the index } \\
\hline Female Friends & $80.0(20)$ & $50.0(4)$ & $100.0(2)$ \\
\hline Male Friends & $16.0(4)$ & $0.0(0)$ & $0.0(0)$ \\
\hline Male sex partner & $4.0(1)$ & $50.0(4)$ & $0.0(0)$ \\
\hline \multicolumn{4}{|l|}{ Educational level } \\
\hline $\begin{array}{l}\text { University and Higher } \\
\text { Professional education }\end{array}$ & $\mathrm{N} / \mathrm{A}$ & $100.0(8)$ & $100.0(2)$ \\
\hline $\begin{array}{l}\text { Intermediate Vocational } \\
\text { Education }\end{array}$ & $\mathrm{N} / \mathrm{A}$ & $0.0(0)$ & $0.0(0)$ \\
\hline \multicolumn{4}{|c|}{ Number of partners past six months ${ }^{\wedge}$} \\
\hline $1-2$ & N/A & $71.4(5)$ & $100.0(2)$ \\
\hline 3 or more & N/A & $28.6(2)$ & $0.0(0)$ \\
\hline \multicolumn{4}{|l|}{ Test history } \\
\hline Tested before for CT & $\mathrm{N} / \mathrm{A}$ & $0.0(0)$ & $50.0(1)$ \\
\hline Never tested for CT & $\mathrm{N} / \mathrm{A}$ & $100.0(8)$ & $50.0(1)$ \\
\hline
\end{tabular}

$\wedge 1$ missing, *non-significant

In total, the 12 participating index clients recruited four sexual (two anonymous) and 31 social (only six anonymous) network members during the first wave (Figure 2). Of the sexual partners two were casual male partners and two were steady male partners. The 31 social network members included four best friends and 27 friends; 29 were women. The 12 index clients that recruited their peers reported in total 29 contactable sex partners of whom one was already tested and $15(52 \%)$ had been notified. Of the 14 sex partners (48\%) that were not yet notified, four $(29 \%)$ were recruited via our screening strategy In total this resulted in only $9 \%$, of all sex partners mentioned by the 30 included index clients, that were reached by our screening strategy. 


\section{Peer participation: requesting a CT test and recruitment of other peers}

Of the 35 recruited peers, four email addresses of social network members were misspelled; these peers were therefore not reached by the intervention. The 31 effectively recruited peers were offered to login to the website to request a home-based CT test kit and also recruit their peers. One social network member was not eligible to participate in the pilot. Of the 30 eligible recruited first wave peers most $(n=28)$ did not recruit their peers. The remaining two eligible first wave peers (female friends) logged in and eventually recruited one steady male sex partner (anonymous) and six friends (two anonymous; two men). Two recruited friends were not eligible to participate. None of the five eligible peers in the second wave recruited new peers (Figure 2).

Of all ( $n=14)$ recruited peer networks in the first and second wave, 43\% $(n=6)$ included three or more persons. Of the 30 eligible first wave peers $27 \%(n=8)$ requested a home-based test kit. Most of these peers were female, and never tested before (Table 2). The test kit return rate was $75 \%$ ( $n=6 ; n=3$ female friends, $n=3$ male sex partners). One (13\%) peer (male sex partner) was found CT positive. Of the five eligible second wave peers $40 \%(n=2)$ requested a test kit, one female friend and one male sexual partner who were both CT negative.

Of all index clients who recruited peers $(n=12), 50 \%(n=6)$ did so after they had received a reminder. Twenty-six reminders were sent to finish the online process (recruiting others or requesting a home test) to peers in the first wave. None of these peers who received a reminder recruited peers and only one female requested a home-based test kit. Six reminders to finish the online process were sent to peers from wave two. None of them encouraged peers or requested a test kit.

\section{Treatment of CT positive peers}

One peer was CT positive. He visited the STI clinic for treatment, additional testing and routine partner notification.

\section{Discussion}

We report the evaluation of the first CT outreach screening strategy that combined web-based social and sexual peer-referral (i.e., Respondent Driven Sampling) and home-based sampling to reach hidden high-risk young people for testing. We found several positive factors and some shortcomings that should be taken into account in future CT (re)-screening strategies for young people (Table 3). Positive factors included substantial recruitment of peers among index clients $(40 \%)$ with a mean number of 3 peers recruited. Mainly non-sexual friends were recruited who would otherwise be missed in conventional partner notification. The strategy reached a hidden population as most tested peers (88\%) were never tested before. In theory these friends are at 
higher risk, because their sexual behaviour is influenced by their friends and sex partners who are CT positives (index clients). However, this influence could neither be confirmed nor rejected by our study. Health care providers experienced more feedback on their daily work, were more aware of the CT risk in networks and were more motivated to encourage networks to recruit each other for CT testing. The strategy also provided information on the proportion of friends and sex partners actually seeking testing and care; valuable information that is scarce in current evaluation studies. The shortcomings included technical difficulties, peer-referral chains that were small, low number of sexual partners reached and few participating men.

Table 3: An evaluation of use of the web-based screening strategy; a summary of the positive factors and shortcomings.

\begin{tabular}{|c|c|c|}
\hline & Positive factors & Shortcomings \\
\hline \multirow[t]{5}{*}{$\begin{array}{l}\text { Usability by } \\
\text { health care } \\
\text { providers }\end{array}$} & $\begin{array}{l}\text { (2) Providers feel more motivated (compared } \\
\text { to before the pilot) to encourage index clients } \\
\text { to recruit their social and sexual networks }\end{array}$ & $\begin{array}{l}\text { (1) Lack of an online interface for providers (this } \\
\text { would allow to start recruitment during STI } \\
\text { clinic consultation avoiding delay) }\end{array}$ \\
\hline & (2) Structured partner notification process & \\
\hline & $\begin{array}{l}\text { (2) Feedback on partner notification result } \\
\text { (which provides information on the proportion } \\
\text { friends and sex partners actually seeking test- } \\
\text { ing and care; to evaluate care effectiveness) }\end{array}$ & \\
\hline & (1) Secure, fully automated system & \\
\hline & $\begin{array}{l}\text { (5) Automated link with referral of CT positives } \\
\text { to further health care and actual treatment } \\
\text { and care }\end{array}$ & \\
\hline \multirow{3}{*}{$\begin{array}{l}\text { Usability by } \\
\text { young people }\end{array}$} & $(3,4)$ Personal messages & (1) Online and login problems (technical) \\
\hline & (4) Home-based test kits & $\begin{array}{l}\text { (1) Misspelling of email addresses. } \\
\text { No system (technicall feedback to recruiting } \\
\text { peer of email error }\end{array}$ \\
\hline & $(3,4)$ System reminders & $\begin{array}{l}\text { (1) Lack of availability of short message service } \\
\text { (SMS) texts to recruit peers (this is likely to be } \\
\text { the most used communication method) }\end{array}$ \\
\hline \multirow[t]{4}{*}{$\begin{array}{l}\text { Uptake by } \\
\text { young people }\end{array}$} & $\begin{array}{l}\text { (3,4) Recruitment of social network members } \\
\text { (peer-referral) }\end{array}$ & $(3,4)$ Low number of recruited waves \\
\hline & $(3,4)$ Moderate network sizes & $(3,4)$ Few men reached \\
\hline & & $(3,4)$ Few sex-partners reached \\
\hline & & $\begin{array}{l}\text { (3) A number of indexes with intended uptake } \\
\text { still did not actually participate }\end{array}$ \\
\hline
\end{tabular}

1-5 refers to the steps of the evaluation process (1) technical development, (2) inclusion of index patients by nurses,

(3) participation of index clients, (4) participation by peers, (5) treatment of positives 
Several positive factors were noted. It was encouraging to learn that the strategy was highly acceptable among the providers involved in the pilot. They stated that it helped them better structure their consultation, and that it increased their awareness about the CT risk among social network members of CT positive young people. Therefore, they felt more motivated to encourage and support index clients to recruit their network members. Also, they stated that the strategy provided them with important feedback on the effectiveness of their work process, feedback that so far had been lacking [34].

Another finding that we consider promising is the substantial recruitment of peers among index clients $(40 \%)$ with a mean number of three peers recruited. Index clients and first wave peers almost exclusively recruited friends to test for CT. In conventional partner notification, such social network members are not targeted hence remain hidden to care. The strategy could potentially enhance current STI outreach work. This outreach work aims to increase testing in high-risk populations outside STI clinic walls. A comparison with other studies that use peer referral via Internet is difficult to make, because they have either focused on the recruitment of sex partners $[19,20,22]$ or only studied the acceptability among its users $[19,20]$. Studies that have focused solely on the recruitment of non- sexual contacts (friends) did not use the Internet and CT positive young people to recruit peers $[24,25]$.

The recruitment of young people is aimed at testing and treating them when needed, which is fundamental to decreasing the transmission. Home-based test kits were requested and returned by $23 \%$ of all eligible recruited peers (social and sexual). This return rate is somewhat higher compared to a Dutch population-based screening strategy, where $16 \%$ of the invited young people between 16 and 29 years old requested online a CT home-based test kit and returned it for testing [9]. However, more importantly to note is that our intervention reached young people who were hidden to care, as $88 \%$ had never been tested before and of whom $13 \%$ was CT positive lone sex partner).

Shortcomings of the strategy included technical problems. Due to a lack of funding, the webbased screening strategy in the pilot was not fully developed, lacking some of the components that were originally designed to increase usability. This limited its effectiveness to some extent, as providers could not start a recruitment-chain at the STI clinic (where they could oversee and support actual peer-recruitment). Such combination of patient and provider referral could increase the notification of sex partner, as discussed in several studies [6]. Further, messages could only be sent by email instead of SMS, while the latter is frequently used by young people. In a study about web-based partner notification among STI clinic clients only $15 \%$ chose emails and $84 \%$ mobile text messages to notify their sexual partners of a possible STI infection [22]. Additionally, email addresses were misspelled. However, the same issue could occur with 
mobile phones. In both cases, it is very difficult to know if messages have been received or not and to inform the sender of the mistake. A possible solution may be to automatically retrieve mobile numbers of a person's contacts, which however may be difficult to achieve in a secure web-facility.

Furthermore, even though recruitment by index clients was substantial, it was also selective in that mostly female social networks were reached. The aim of using the strategy to recruit sexual partners (as in web-based partner notification) is thereby clearly not reached as only few sex partners were recruited. Of all contactable sex partners, more than half of them had not yet been notified by the eligible index clients during the CT treatment consultation. Furthermore, only four index clients (13\%) recruited a sex partner via our strategy. This low recruitment rate agrees with $14 \%$ recruitment of sex partners observed in another study, where STI positive clients received a personal code for online recruitment of their sex partners for testing [22]. Reasons for the poor recruitment of their sex partners as opposed to social networks could be the intimate history persons have had with sexual partners which can lead to anticipated negative reactions (i.e., blame and aggression towards or from partners) [7] and stigma surrounding disclosure and encouragement of others to test [34]. Overall, females were better represented in our study, which is in line with an earlier study [25] that showed that men were more reluctant to distribute kits to their peers and were more embarrassed to discuss sexual health-related issues. Women have been found more likely to recruit men in other web-based RDS approaches, addressing respiratory infections, as well [30].

Although, peer-referral combined with a web-based RDS method was judged highly promising and feasible during the development of the intervention [32], only two waves were created in this pilot study. We know that stigma plays an important role in the process of disclosure to and encouragement of friends and sexual partners [35-37]. In a study among CT tested and never tested young people between 16-24 years, participants used selective disclosure and encouragement as an effective strategy to manage stigma. They stated that they only disclosed their testing experience to a small and selective group that provides them with emotional support and empathy. They fear stigmatizing reactions from others [37]. To overcome this stigma the screening strategy already had embedded the option to notify friends and sex partners anonymous. Still, people did not often use this option. More than two third of all peers in this study were recruited with personal messages (40\% among sex partners and $78 \%$ among friends). Factors other than stigma may be at play. For example, a web-RDS study addressing much less stigmatized infections (respiratory infections) in young people, also achieved only few waves [30]. Future interventions should explore how to reach high-risk network members outside the small networks. A possible method to combine with our screening strategy could be Motivational Interviewing (MI). MI is a client-centered approach for eliciting behaviour changes by helping 
people to feel confident to perform a particular behaviour according to their needs and abilities [38]. When applied in partner notification training for sexual health care providers MI has been shown to improve skills and behaviour in dealing with patients' resistance towards PN [39]. This way, clients may also be more motivated to encourage peers outside their trusted sexual and social networks. Messages could be send to encourage index clients to remind their peers to mail their CT test to the laboratory.

Some limitations of our study design need to be considered when interpreting our results. Firstly, the number of included nurses and eligible CT positive index clients was small. This may hamper generalizability of our results to respectively the broader population of STI clinic health care providers and CT positive young people. Secondly, only heterosexual young people at risk for CT were eligible to participate in the pilot. Therefore, it is unknown whether the results can be extrapolated to other target groups such as young MSM or other STIs (e.g., syphilis or HIV). Thirdly, the cost-effectiveness and sustainability of the screening strategy was not evaluated. However these factors will influence future implementation of a screening strategy in daily practice.

Other limitations concern the study findings. Firstly, non-participation of index clients and peers in semi-structured interviews was high. This limited the assessment of usability of the screening strategy developed and indicated how difficult it is to conduct interviews with this hard-to-reach group. Secondly, the assumption that recruited clients' friends are at higher risk for CT las they are in the same network as a CT positive person), the actual higher risk could neither be confirmed nor rejected by the data. None of the reached friends tested CT positive, friends included few lower educated persons and relatively few persons with a high number of partners. Further evaluation to assess the CT risk of reached social networks is therefore needed.

\section{Conclusions}

With pretty reasonable recruitment and test rates among respectively index clients and peers who have never been tested previously we feel that the intervention provided proof-of-concept and succeeded to reach young people who are currently not accessing CT testing. Most of the recruited peers were social contacts that would normally be missed through conventional partner notification processes. A positive impact of the strategy was experienced by nurses in daily STI care practice. However, it should be noted that only two RDS waves were created. Also, penetration in the sexual network was poor and it is unclear whether the social network accessed with testing did comprise high- risk persons. Other shortcomings included technical problems, which however could be resolved (i.e., using SMS instead of email). The use of peerreferral in combination with home-based test kits seems promising, but its combined use with 
online RDS should be studied and developed further to explore if more waves, sex partners and men can be reached. Learning points as identified here can help to inform health care strategies that aim to increase CT testing in high risk populations, especially those that employ social and sexual networks. Future studies are needed to also explore the sustainability and costeffectiveness of these approaches. 


\section{References}

1. European Centre for Disease Prevention and Control. Chlamydia Control in Europe:

Literature Review. Available online: http:// ecdc.europa.eu/en/publications/Publications/ chlamydia-control- europe.pdf laccessed on 20 June 2015).

2. National Institute for Public Health and the Environment. Sexually Transmitted Infections, Including HIV, in the Netherlands in 2014. Annual Report National Institute for Public Health and the Environment: Bilthoven, The Netherlands, 2014.

3. Senior, K. Chlamydia: A much underestimated STI. Lancet 2012, 12, 517-518.

4. Van Bergen, J.; Gotz, H.M.; Richardus, J.H.; Hoebe, C.J.P.A.; Broer, J.; Coenen, A.J.T. Prevalence of urogenital Chlamydia trachomatis increases significantly with level of urbanisation and suggests targeted screening approaches: Results from the first national population based study in the Netherlands. Sex. Trans. Infect. 2005, 81, 17-23.

5. Newby, K.V.; Wallace L.M.; French, D.P. How do young adults perceive the risk of chlamydia infection? A qualitative study. Br. J. Health Psychol. 2012, 17, 144-154.

6. Centers for Disease Control and Prevention. Summary of a Review of the Literature: Programs to Promote Chlamydia Screening. Available online: http://Www.cdc.gov/STI/ HealthComm/ laccessed on 20 June 2015).

7. Pavlin, N.L.; Gunn, J.M.; Parker, R.; Fairley, C.K.; Hocking, J. Implementing chlamydia A systematic review of the literature. BMC Public Health 2006, 6, 221-231.
8. Farley, T.A.; Cohen, D.A.; Elkins, W. Asymptomatic sexually transmitted disease: The case for screening. Prev. Med. 2003, 36, 502-509.

9. van den Broek, I.V.F.; van Bergen, J.E.A.M.; Brouwers, E.E.H.G.; Fennema, J.S.A.; Götz, H.M.; Hoebe, C.J.P.A.; Koekenbier, R.H.; Kretzschmar, M.; Over, E.A.B.; Schmid, B.V.; Pars, L.L.; van Ravesteijn, S.M.; van der Sande, M.A.B.; de Wit, G.A.; Low, N.; Op de Coul, E.L.M. Effectiveness of yearly, register based screening for chlamydia in the Netherlands: Controlled trial with randomised stepped wedge implementation. BMJ 2012, 345, doi:org/10.1136/bmj.e4316.

10. Bracebrigde, S.; Bachmann, M.O.; Ramkhelawon, K.; Woolnough, A. Evaluation of a systematic postal screening and treatment service for genital Chlamydia trachomatis, with remote clinic access via the internet: A cross-sectional study, East of England. Sex. Trans. Infect. 2012, 88,375-381.

11. Kløvstad, H.; Grjibovski, A.; Aavitsland, P. Population based study of genital Chlamydia trachomatis prevalence and associated factors in Norway: A cross sectional study. BMC Infect. Dis. 2012, 12, 150, 1-7.

12. Novak, D.P.; Karlsson, B.R. Simplifying chlamydia testing: An innovative Chlamydia trachomatis testing approach using the internet and a home sampling strategy: Population based study. Sex. Trans. Infect. 2006, 82, 142-147.

13. Gaydos, C.A.; Dwyer, K.; Barnes, M.; Rizzo-Price, P.A.; Wood, B.J.; Flemming, T.; Hogan M.T. Internet-based screening for chlamydia trachomatis to reach nonclinic 
populations with mailed self-administered vaginal swabs. Sex. Trans. Dis. 2006, 33, 451-457.

14. Ten Hoor, G.A.; Hoebe, C.J.P.A.; van Bergen, J.E.A.M.; Brouwers, E.E.H.G.; Ruiter, R.A.C.; Kok, G. The influence of two different invitation letters on chlamydia testing participation: Randomized controlled trial. J. Med. Internet Res. 2014, doi:10.2196/ jmir.2907.

15. Greenland, K.E.; Op de Coul, E.L.M.; van Bergen, J.E.A.M.; Brouwers, E.E.H.G.; Fennema H.J.S.A.; Gotz, H.M.; Hoebe, C.J.P.A.; Koekenbier, R.H.; Pars, L.L.; van Ravesteijn, S.M.; van den Broek, I.V.F. Acceptability of the Internet-Based Chlamydia Screening Implementation in the Netherlands and Insights Into Nonresponse. Sex. Trans. Dis. 2011, 38, 467-474.

16. Ten Hoor, G.A.; Ruiter, R.A.C.; van Bergen, J.E.A.M.; Hoebe, C.J.P.A.; Houben, K.; Kok, G. Non-participation in chlamydia screening in the Netherlands: Determinants associated with young people's intention to participate in chlamydia screening. BMC Public Health 2013, 13, 1091, 1-10.

17. De Wit, G.A.; Over, E.A.B., Schmid, B.V.; van Bergen, J.E.A.M.; van den Broek, I.V.F.; van der Sande, M.A.B.; Welte, R.; Op de Coul, E.L.M.; Kretzschmar, M. Chlamydia screening is not cost-effective at low participation rates: Evidence from a repeated register-based implementation study in the Netherlands. STI 2015. Sex Transm. Infect 2014, doi:10.1136/ sextrans-2014-051677.
18. European Centre for Disease Prevention and Control. Public health benefits of partner notification for sexually transmitted infections and HIV. Available online: http://www.ecdc. europa.eu/en/publications/laccessed on 20 June 2015).

19. Bilardi, J.E.; Fairley, C.K.; Hopkins, C.A.; Hocking, J.S.; Temple-Smith, M.J.; Bowden, F.J.; Russell, D.B.; Pitts, M.; Tomnay, J.E.; Parker, R.M.; Pavlin, N.L.; Chen, M.Y. Experiences and outcomes of partner notification among men and women recently diagnosed with chlamydia and their views on innovative resources aimed at improving notification rates. Sex. Trans. Dis. 2010, 37, 253-258.

20. Levine, D.; Woodruff, A.J.; Mocello, A.R.; Lebrija, J.; Klausner, J.D. inSPOT: The first online std partner notification system using electronic postcards. Plose Med. 2008, 5, e213, 1428-1431.

21. Østergaard, L.; Andersen, B.; Møller, J.K.; Olesen, F.; Worm, AM. Managing partners of people diagnosed with chlamydia trachomatis: A comparison of two partner testing methods. Sex. Trans. Infect. 2003, 79, 358-362.

22. Götz, H.M.; van Rooijen, M.S.; Vriens, P.; Op de Coul, E.; Hamers, M.; Heijman, T.; van den Heuvel, F.; Koekenbier, R.; van Leeuwen, A.P.; Voeten, H.A. Initial evaluation of use of an online partner notification tool for STI, called' suggest a test: A cross sectional pilot study. Sex. Trans. Infect. 2014, 90, 195-200. 
23. Hogben, M.; Burstein, G.R.; Golden, M.R. Partner notification in the clinician's office: Patient health, public health and interventions. Curr. Opin. Obstet. Gynecol. 2009, 21, 365-370.

24. Rose, S.B.; Lawton, B.A.; Bromhead, C.; MacDonald, E.J.; Elley, C.R. Poor uptake of self- sample collection kits for Chlamydia testing outside primary care. Aust. N. Z. J. Public Health 2010, 34, 517-520.

25. Loaring, J.; Hickman, M.; Oliver, I.; Campbell, R.; Trotter, C.; Macleod, J.; Pye, K.; Crichton, J.; Horner, P. Could a peer-led intervention increase uptake of chlamydia screening? A proof of principle pilot study. J. Fam. Plann. Reprod. Health Care 2013, 39, 21-28.

26. Youm, Y.; Laumann, E.O. social network effects on the transmission of STI. Sex. Trans. Dis. 2002, 29, 689-697.

27. Heckathorn, D.D. Respondent-driven sampling: A new approach to the study of hidden Populations. Soc. Probl. 1997, 44, 174-199.

28. Rosenberg, N.E.; Kamanga, G.; Pettifor, A.E.; Bonongwe, N.; Mapanje, C.; Rutstein, S.E.; Ward, M.; Hoffman, I.F.; Martinson, F.; Miller, W.C. STI Patients Are Effective Recruiters of Undiagnosed Cases of HIV: Results of a Social Contact Recruitment Study in Malawi. J. Acquir. Immune Defic. Syndr. 2014, 65, e162-e169.

29. Rothenberg, R.B.; Sterk, C.; Toomey, K.E.; Potterat, J.J.; Johnson, D.; Schrader, M.; Hatch, S. Using Social Network and Ethnographic Tools to Evaluate Syphilis Transmission. Sex. Trans. Dis. 1998, 25, 154-160.
30. Stein, M.L.; van Steenbergen, J.E.; Buskens, V.; van der Heijden, P.G.; Chanyasanha, C.; Tipayamongkholgul, M.; Thorson, A.E.; Bengtsson, L.; Lu, X.; Kretzschmar, M.E. Comparison of contact patterns relevant for transmission of respiratory pathogens in Thailand and The Netherlands using respondent-driven sampling. PLoS ONE 2014, 9, e113711, doi: 10.1371/ journal.pone.0113711

31. Bauermeister, J.A.; Zimmerman, M.A.; Johns, M.M.; Glowacki, P.; Stoddard, S.; Volz, E. Innovative recruitment using online networks: Lessons learned from an online study of alcohol and other drug use utilizing a web-based, respondent- driven sampling (WEBRDS) strategy. J. Stud. Alcohol Drugs 2012, 73, 834-838.

32. Theunissen, K.A.T.M.; Hoebe, C.J.P.A.; Crutzen, R.; Kara-Zaïtri, C.; de Vries, N.K.; van Bergen, J.E.A.M; van der Sande, M.A.B.; Dukers-Muijrers, N.H.T.M. Using intervention mapping for the development of a targeted secure web-based outreach strategy named SafeFriend, for Chlamydia trachomatis testing in young people at risk. BMC Public Health 2013, 13, 1-11.

33. Bartholomew, L.K.; Parcel, G.S.; Kok, G.; Gottlieb, N.H.; Fernandez, M.E. Planning Health Promotion Programs: An Intervention Mapping Approach; John Wiley \& Sons: Hoboken, NJ, USA, 2011.

34. Theunissen, K.A.T.M.; Schipper, P.; Hoebe, C.J.P.A.; Crutzen, R; Kok, G.; Dukers-Muijrers, N.H.T.M. Care professionals' perceptions of barriers to and facilitators of partner 
notification for chlamydia trachomatis:

A qualitative study. BMC Health Serv. Res.

2014, 14, 1-10.

35. Balfe, M.; Brugha, R. Disclosure of STI testing activities by young adults: The influence of emotions and social networks. Soc. Health IIln. 2010, 32, 1041-1058.

36. Nack, A. Damaged goods: Women managing the stigma of STDs. Deviant Behav. 2000, 21, 95-121.

37. Theunissen, K.A.T.M.; Bos, A.E.R.; Hoebe, C.J.P.A.; Kok, G.; Vluggen, S.; Crutzen, R.; Dukers-Muijrers, N.H.T.M. Chlamydia trachomatis testing among young people: What is the role of Stigma? BMC Public Health. 2015, in press.

38. Rollnick, W.R.; Miller, S.R.; Butler, C.C. Motivational Interviewing in Health Care. Helping Patients Change Behavior. Available online: http://web.vu.lt/mf/r.viliuniene/ files/2014/10/Motivational-Interviewingin-Health-Care.-Helping-Patients-ChangeBehavior.pdf (accessed on 20 June 2015).

39. Op de C.E.L.; Spijker, R.; van Aar, F.; van Weert, Y.; de Bruin, M. With whom did you have sex? Evaluation of a partner notification training for STI professionals using motiva-tional interviewing. Patient Educ. Couns. 2013, 93, 596-603. 







\section{Chapter 4}

\section{Chlamydia trachomatis testing among young people: what is the role of stigma?}

Kevin A.T.M. Theunissen, Arjan E.R. Bos, Christian J.P.A. Hoebe, Gerjo Kok, Stan Vluggen, Rik Crutzen and Nicole H.T.M. Dukers-Muijrers 


\section{Abstract}

\section{Background}

To reach young people for Chlamydia trachomatis (CT) testing, new web-based strategies are used to offer testing via young people's sexual and social networks. The success of such peerdriven strategies depends on whether individuals disclose their own testing and encourage others to get tested. We assessed whether public- and self-stigma would hamper these behaviours, by comparing anticipations and experiences relating to these issues in young men and women who already tested or never tested for CT.

\section{Methods}

Participants were recruited at an STI clinic and two schools in the Netherlands. Semi-structured interviews were analysed from 23 sexually active heterosexual young people between 16-24 years using qualitative content analysis with a framework approach.

\section{Results}

Both tested and never tested participants perceived public stigma and anticipated shame and self-stigma in relation to testing. Maintaining good health was identified as main reason for testing. Never tested and tested participants anticipated that they would feel shame and receive stigmatizing reactions from people outside their trusted network if they would disclose their testing, or encourage them to test. From a selected group of trusted peers, they anticipated social support and empathy. When tested participants disclosed their testing to trusted peers they did not experience stigma. Due to the fact that no one disclosed their testing behaviour to peers outside their trusted network, stigma was avoided and therefore tested participants reported no negative reactions. Similarly, regarding the encouragement of others to test, most tested participants did not experience negative reactions from sex partners and friends.

\section{Conclusions}

Young people perceive public stigma and anticipate self-stigma and shame in relation to CT testing, disclosure and encouraging others to test. People do test for CT, including those who anticipate stigma. To avoid stigmatizing reactions, stigma management strategies are applied, such as selective disclosure and the selective encouragement of others to test (i.e. only in a small trusted peer network). Care strategies that deploy sexual and social networks of individuals can reach into small networks surrounding a person. These strategies could be improved by exploring methods to reach high-risk network members outside the small trusted circle of a person.

\section{Keywords}

Chlamydia, Stigma, Stigma management, Testing, Disclosure, Encouragement. 


\section{Background}

Chlamydia trachomatis (CT) is a much underestimated sexually transmitted infection (STI) and worldwide diagnoses of CT have increased in recent years [1-4]. CT is the most diagnosed bacterial STI among sexually active people, and has potential reproductive sequelae. A major risk group for CT are young heterosexual people below 25 years of age. They are targeted by health care professionals using key control strategies that encompass testing, treating, and partner notification (PN), to interrupt the inherent transmission chain $[5,6]$. Several associated factors, which influence the uptake of these strategies, have been identified. A systematic review on $\mathrm{CT}$ testing in young women revealed that the uptake of $\mathrm{CT}$ testing was impeded by ignorance and inaccurate information, denial, moral connotations, stigma, fear, anxiety, confidentiality and privacy concerns, and pragmatic factors such as cost and test discomfort [7]. Other barriers among women and men include the embarrassment and shame associated with seeking care $[8,9]$, the asymptomatic nature of the infection $[6,10]$, fear of a positive test result $[6,11]$, and perceived STI-related stigma (i.e., fear of being subjected to negative societal attitudes and discrimination) [12]. Facilitators included accurate knowledge, feelings of personal relevance, multiple test options (i.e., home-based test kits, self-administered swabs), free tests, and support with diagnosis [7]. The process of PN is also influenced by several factors. Barriers to notifying a sex partner, as revealed in a systematic review of PN, included stigma, guilt, blame, possible relationship breakdown, violence, and missing contact details [13]. Partner notification can be facilitated by using Patient-Delivered Partner Therapy (i.e., partners are treated via the patients by providing prescriptions or medications without a medical personal evaluation), online notification, and home-based test kits [13].

To overcome barriers and explore the facilitators of CT testing and PN among young people, innovative care methods have been developed in addition to the regular care provided by STI clinics and general practitioners in for instance Europe Australia, and US [13-20]. These new methods include web-based programmes that utilise email and text messaging, alongside home-based sampling [18-20]. These programmes aim to facilitate testing in high-risk groups of individuals who are connected in sexual networks and/or social networks. Peers from such networks surrounding CT positive individuals are important targets in CT control, as they typically show similar high risk, for example with respect to unprotected sex or sex with a CT positive person [21]. Communication in social networks is associated with the sexual behaviour among friends in these networks [22]. Modelling may also play a role; the actual behaviour of peers may influence a person's behaviour, for example regarding sexual behaviour, but also regarding CT testing [23]. Therefore, essential components of care methods that aim to reach high-risk networks include the disclosure of CT testing behaviour to sexual and social network members and the encouragement to get them tested using for example the internet and home- 
based sampling. Successful disclosure and encouragement could thus potentially lead to better partner notification and an increase in CT testing and emotional support among peers $[24,25]$.

Web-based CT care programs focus on utilising the factors identified as facilitators for CT testing and PN. However, factors that have been identified as barriers, especially stigma [15, 25-28], may still be of concern in the processes of disclosure and encouragement. A stigma is a deeply discrediting attribute that results in widespread social disapproval [29]. It consists of two fundamental components - the recognition of difference, and devaluation [30]. Stigmatization has different manifestations that can be overt (e.g. social rejection, avoidance) as well as subtle (e.g., lack of eye contact) [29]. Public stigma refers to the cognitive, affective and behavioural responses of other people towards an individual who possesses a stigmatized characteristic. Public stigma can lead to self-stigma which refers to an individual's awareness of his/her stigmatized condition, the social devaluation connected with his/her condition, and the possible internalization of this stigma [29]. Public stigma may shape anticipated stigma in persons with a stigmatized condition. However, anticipated stigma does not automatically translate into the actual experience of stigma.

Previous studies about stigma surrounding the disclosure of test behaviour have focused on anticipations or experiences with stigma by young men or women surrounding STI in general [25], HIV [31] and the Human Papilloma Virus [26]. Previous research on stigma surrounding CT was conducted in a UK population with a wide age-range [32], limiting the generalizability of the results to young populations. The present study assessed both anticipated stigma and experiences with stigma in young (16-24 years old) heterosexual men and women who had either never been tested (from here on referred to as "never tested") or who had been tested (referred to as "tested") for CT. By assessing the role of stigma in CT testing, disclosure of testing behaviour and encouragement of others to get tested, it is hoped that results will inform new care methods that aim to increase CT testing in high-risk groups, and thereby improve CT control.

\section{Methods}

\section{Design and setting}

A qualitative study was conducted using semi-structured interviews by researchers of the Public Health Service South Limburg and Maastricht University, the Netherlands. Participants provided written informed consent. According to national guidelines a Research Ethics Board reviewed and approved this study and gave permission to interview. 16 and 17 year olds without parental consent (Ethics Committee Psychology Maastricht University, reference number 13-4-054). This article adheres to the RATS guidelines on qualitative research [33]. 


\section{Recruitment of participants}

Sexually active heterosexual people between 16 and 25 years were eligible for participation. Between May and August 2013, both never CT tested ( $n=13$ ) and CT tested ( $n=10$ ) young people were recruited for participation. Tested young people were recruited during an STI clinic visit by nurses performing their sexual health consultations. Never tested young people were recruited during a sexual health education lesson at a secondary school and via leaflets at a University, both in the same region as the area served by the STI clinic.

\section{Data collection}

Semi-structured interviews lasting approximately $30 \mathrm{~min}$, were conducted over the telephone and tape-recorded. Data were collected using a semi-structured interview protocol, which was constructed in line with the opinion of experts in the field of social psychology and stigma and a review of the literature. All questions were related to CT and addressed topics related to the anticipations and experiences surrounding testing, disclosure, and the encouragement of peers to test (Table 1). Saturation occurred at around 20 interviews, and later interviews served to confirm themes identified earlier in the analysis.

\section{Analyses}

The audio-recorded interviews were transcribed verbatim in Dutch and analysed independently by two interviewers (SV and KT) using the "framework" approach [34], which involves structured stages of data management, descriptive accounts and explanatory accounts. Several transcripts were explored in detail, in order for SV and KT to become familiar with the data, after which open coding was applied using NVivo software. Codes were then applied to subsequent transcripts and grouped into categories: CT testing, disclosure of CT testing, and encouragement of peers to get tested. Furthermore, associations within categories were sought. Any disagreements found in the analysis were resolved through discussion, and consensus was reached by PS and KT consulting a third party (i.e. ND and $A B$ ).

\section{Results}

\section{Sample characteristics}

The sample consisted of 25 interviewed participants of whom two had to be excluded, because they were not eligible for participation. Of the remaining participants ( $n=23$ ), all were sexually active and heterosexual, 13 were female, 22 were of Dutch nationality, and the over- all mean age was 20 years old (age range 16-24 years). Of the 10 participants who had ever been tested, 7 had tested positive for CT. Participants who had been tested had undergone between 1 and 5 CT tests before participating in the current study. 
Table 1: Subject and topic list about Chlamydia testing, disclosure of own testing behaviour and encouragement of others to test, among tested and never tested young people.

\begin{tabular}{|c|c|}
\hline Subject & Topic \\
\hline General & Talking about sex and sexually transmitted infections with others \\
\hline CT testing & $\begin{array}{l}\text { Experiences of others with testing } \\
\text { Opinion about others who have tested } \\
\text { Opinion about others who are CT positive } \\
\text { Thoughts about testing } \\
\text { Feelings about testing } \\
\text { Reason(s) for testing } \\
\text { Feelings about test results }\end{array}$ \\
\hline Disclosure & $\begin{array}{l}\text { Experiences of others regarding the disclosure of testing and results } \\
\text { Disclosure of testing to others } \\
\text { Disclosure of test results to others } \\
\text { Reasons to disclose testing to others } \\
\text { Reasons to disclose test results to others } \\
\text { Reactions of others after disclosure }\end{array}$ \\
\hline Encouragement & $\begin{array}{l}\text { Encouragement of sex partners to test } \\
\text { Encouragement of friends to test } \\
\text { Reactions of sex partner and friends }\end{array}$ \\
\hline
\end{tabular}

\section{Anticipated stigma surrounding own testing}

Almost all tested and never tested participants perceived public stigma. In several cases this was based on what they had observed or what they heard had happened to other young people, i.e. those who had received stigmatized reactions after they went for STI testing or were found to be STI positive.

Interviewee: "Well, yes, I think that people do have certain ideas if someone has an STI, or get certain ideas about that person".

Interviewer: "OK, and what kind of ideas would they be?"

Interviewee: "That there are prejudices attached, so that you are maybe seen as easy, or that sort of thing... That you are more likely to have sex with others, and that you don't think about it so much."

(Tested, female no 2, 18 years)

"That people respond to it (CT infection) differently, react strangely, at school a girl had it and she was always being called names ... that girl was always called a slut or things like that."

(Never tested, female no 22, 16 years) 
The perception of public stigma among never tested participants was in line with the reported anticipated feelings of shame when going for a CT test, but differed from the good experiences with actual testing in tested participants. Most never tested participants thought testing would indicate unsafe sex or would be associated with a positive test result. Others were afraid of the testing procedure and the possibility of a positive test result. Despite these factors, most never tested participants said that they would test if they have had unsafe sex or experienced symptoms, because they valued their own health and that of their peers. Furthermore, some also mentioned certainty as a reason to be tested, which was also stated among most tested participants. Even though tested participants were nervous in the beginning, and did not know what to expect, both CT positives and CT negatives stated that they were glad to know their CT status.

Interviewee: "If I had to do a test like that then I would probably feel a bit ashamed, because then you, yes, you've maybe caught something, and then you're a bit ashamed" Interviewer: "And what exactly would you be ashamed of?"

Interviewee: "Yeah, that you just didn't pay attention really and that you haven't been safe" (Never tested, female no 9, 20 years)

"Um, if I had unsafe sex for some reason or another, I would like to know if I'd got anything, so for yourself it's sensible, and also for your health, to know if you have anything - and also for the other, should you have had sex"

(Never tested, male no 14, 21 years)

Never tested participants reported that they expected to feel bad if they would receive a positive test result. However, they would also be relieved, because at that moment they could act upon the test result and find appropriate care. Some tested participants who were CT positive expressed feelings of shame or anger towards their sex partners. Never tested participants would feel relieved if they received a negative test result, which was comparable with the feelings of most of the tested participants who indeed turned out to test CT negative. Similar responses were observed between male and female participants regarding stigma and own CT testing.

"Well, I was really ashamed... that I had caught something like that and hadn't taken better care" (Tested, female no 18, 21 years) 


\section{Disclosure of CT testing}

All participants who had never tested reported that they would disclose CT testing and test results only to parents, good friends and sex partners whom they trusted, and from whom they expected a positive reaction (social support and empathy). Likewise, all participants who had tested stated that they had only disclosed their test and its result to their trusted peers (parents, friends, sex partners), receiving only positive reactions. Tested participants reported that it was self-evident to them that they inform sex partners. Tested participants received positive reactions from their trusted peers (parents, friends, sex partners). Never tested and tested participants would not disclose to a broader network, because they anticipated shame and stigmatizing reactions, including gossiping and insulting language. For the never tested participants shame was associated with CT positivity and risky sexual behaviour. Due to the fact that no one disclosed their testing behaviour to peers outside the trusted network, experienced stigma from these people was avoided and tested participants reported no negative reactions. Similar responses were observed between men and women regarding their disclosure of test behaviour and results.

Interviewer: "And do you expect a reaction from them (good friends) when you tell them (about the test and results)?"

Interviewee: "Yes you could call it empathy what you expect, but also that they can help you or that they have gone through something similar that makes it easier for you to cope, as it were."

(Never tested, male no 17, 23 years)

"Yeah, I'm not someone who would just throw that out there. That's what I have my most trusted friend for, one or two. And with them I talk about it and then I ask advice and then for me it's fine, actually."

(Tested, male no 23, 20 years)

"It is something about myself, not everyone needs to know that I have it... Yeah, I won't be called a little slut, or have people think that I jump into bed with everyone or something."

(Tested, female no 21, 22 years)

\section{Encouraging others to get tested}

Most of the never tested participants indicated that, if they happened to be CT positive, they would encourage sex partners to test, because they want to prevent transmission or would be concerned about their own and their partner's health. Likewise, all tested participants had 
already, or would in the future personally encourage sex partners to test although they would find it difficult to do so. Some tested participants had themselves been encouraged by their sex partner or by someone within their trusted network to test for CT. A few tested participants and peers visited the clinic together for testing.

Interviewer: "And why do you find it important that she is also tested?"

Interviewee: "Yeah, if I have it then she can also have it and imagine that she has it and then we do it again, and l'll have it again."

(Never tested, male no 5, 17 years)

"The last time that I had myself tested was because I heard via a former sex partner that he had got Chlamydia and that I should also be tested."

(Tested, female no 1, 21 years)

Despite anticipated negative reactions such as anger or shock, never tested participants thought that their sex partners would go for a CT test once they had been encouraged by the participant to do so. This is in line with the positive experiences among tested participants where several sex partners they had talked to also got CT tested. Tested participants had not experienced negative reactions when encouraging others to test.

"I think that they (sex partners) would also be a bit angry, yeah, I would be too, like yeah, how can it have happened? But on the other hand I also really think that it's good that I tell him so that he can get himself tested."

(Never tested, female no 9, 20 years)

Most of the never tested and tested participants anticipated that they would also encourage a trusted network of good friends to test; friends with whom they already talk about sex or STIs or who they know have had unsafe sex or multiple sex partners. Some never tested participants anticipated negative reactions like laughing or anger if they would encourage a friend to get tested. Several never tested participants expressed the opinion that it was the responsibility of these friends to test for CT when necessary. Most tested participants did not anticipate negative reactions from friends and some had already encouraged friends to test. Similar responses were observed between men and women regarding the encouragement of others to test for CT. 
"Yeah, you could of course start talking about it, but if you haven't, for example, ever talked about sex or something like that with a person, that person's not a good friend, but a stranger or someone, then you're not going to suddenly say you should have a Chlamydia test done, anyway, that's not something I would do."

(Never tested, male no 11, 17 years)

"Yes, I expect that they would maybe also be slightly angry that I have the idea that they maybe have Chlamydia, but I think that they would probably take that on board and let themselves be tested after all, just to be sure."

(Never tested, female no 22, 16 years)

"I know in this case that my female friends... that it is the case that if someone said to me, well yes, I went to Spain last month on holiday and I had unsafe sex there, that I could just say, well yeah, I would go to the GGD [STI clinic], if I were you. In that sense our group is very straightforward about things like that and we are not ashamed about it."

(Tested, female no 25, 24 years)

\section{Discussion}

The present study explored the role of stigma in relation to CT testing, the disclosure of testing to peers, and the encouragement of peers to get tested, in a group of young never tested and tested heterosexual individuals.

Perceived public stigma and anticipated self-stigma were reported regardless of whether people had ever tested for CT or not. Nevertheless, all participants either intended to test when needed or had indeed tested already. This finding is in line with some other studies among tested and never tested young people in clinics, community based organizations, and household samples, where shame was not found to be a barrier to STI testing [12,35]. A study among young women in general practitioners settings and family planning clinics demonstrated that fear of stigmatization if they accepted screening did not lead to rejection of CT testing when it was offered to them [36].

Tested and never tested participants disclosed both their test behaviour and, when tested, their test result to a small, trusted network of peers. They anticipated positive reactions such as 
support and empathy from this small network. Similar results have been found in a study among young Irish adults who informed a few "key individuals" after their testing experience, because they helped them to feel normal and gave them emotional support [25]. Among the tested participants in this study, it was self-evident that they disclosed their CT testing and results to their sex partners, which is in line with previous studies about PN and STIs [13]. Despite the potential self-stigma and public stigma associated with notifying sex partners, many young people consider partner notification in practice "the right thing to do", and people's experiences with PN were much better than they had initially expected $[13,27,37]$. Stigmatizing reactions and shame were anticipated among all participants when disclosing details of their CT testing and results to a "non- trusted" broader network of peers. However, it has been shown that people try to minimize or regulate the negative psychological and social impact of stigma by using problem-focused and emotion-focused coping strategies $[38,39]$. In the present study, participants used selective disclosure as such stigma management strategy, and indeed no tested participants in this study had experienced stigmatizing reactions. Fear of stigmatization and the selective disclosure to a few key individuals has also been found in other studies regarding the disclosure of STI testing and test results $[25,26]$, and moreover in studies investigating stigma associated with mental illnesses [40].

Disclosure does not automatically lead to the encouragement of peers to test for CT. Novel approaches that deploy social and sexual networks in order to get high-risk individuals tested for CT place importance on proactive encouragement among young people [17]. Never tested participants reported that they would encourage sex partners to get tested if they themselves tested CT positive. This finding is in line with the experience of tested participants who were either encouraged by peers or who themselves had encouraged friends or sex partners to get tested. Again, stigma management strategies resulted in the encouragement only of a select trusted circle of sex partners and friends to test for CT.

In contrast to findings in other studies [32, 41], in our study, men did not report less CT-related stigma or shame compared to women. No differences were observed between men and women regarding their stigma management strategies. 


\section{Recommendations}

People do test for $\mathrm{CT}$, including those who anticipate stigma. Despite anticipated stigma social and sexual networks can be reached for testing. Therefore, care strategies that deploy sexual and social networks to reach high-risk young people with CT testing are potentially effective. Yet, their effectiveness will potentially be limited by the small size of trusted networks reached due to people's stigma management strategies. With selective disclosure and encouragement (to get tested) young people protect themselves from anticipated stigma from peers outside their trusted peer networks. Nonetheless, a person outside an individual's trusted network may still be reached by such care strategies, because he or she may be a trusted peer in someone else's network. Care methods, such as web-based applications that already reach high risk trusted networks, will benefit from including ways to overcome anticipated stigma without increasing the impact of experienced stigma from outside these trusted networks. For example, via anonymous disclosure and encouragement, or by the use of home-based sampling kits, which have been shown to greatly facilitate the management of sexual partners [15, 42]. Sexual health care providers such as nurses and physicians have also an important role to play in the motivation and guidance of young people disclosing to their peers and encouraging them to get tested [43]. Care providers are generally trained in Motivational Interviewing (MI). MI targets the intrinsic motivation of people to change behaviour by supporting people to examine and resolve ambivalence to their needs and abilities [44]. MI is already used in PN, yet its use can be explored to reach trusted social networks but even more, to reach non-trusted networks.

\section{Strengths and weaknesses of the present study}

One of the strengths of this study is the inclusion of encouragement of peers. Several studies assessing stigma have been conducted regarding the disclosure of CT testing to sex partners and friends, but to our knowledge none of these have included encouragement of peers. A further strength of this study is the comparison between the hypothetical behaviour and anticipations among never tested young people with the real behaviour and experiences of tested young people. One possible limitation of our study is that all our tested participants were from Dutch STI clinics and all our never tested participants were from the general community (i.e., secondary school and university), and these groups might differ regarding STI knowledge and/ or sexual risk behaviour. Nevertheless, we found that perceived public stigma and behavioural intentions regarding testing, disclosing and encouragement were largely similar between our tested and never tested participants. By including tested and untested young people from different backgrounds and gender, we do consider it likely that the results of this study provide a general theoretical understanding of how stigma plays a role in testing and disclosure that 
may be exported to provide explanatory theory for the experiences of other individuals who are in comparable situations. It is unknown whether results can be extrapolated to other target groups (i.e. men having sex with men or commercial sex workers) and to other STIs (i.e. syphilis and HIV), because of differences in sexual risk behaviour and severity of the illness, and possible related differences in anticipated stigma. Therefore, caution is warranted with regard to the generalization of these findings to other target groups than young heterosexuals and other STIS than CT.

\section{Conclusion}

Young people perceive public stigma, they anticipate self-stigma and feelings of shame when they test for CT, disclose their test behaviour to peers, and encourage their peers to get tested. Nevertheless, despite these potential barriers, young people have been tested, or have expressed the intention to test for CT. As a protection against anticipated stigmatizing reactions, people use stigma management strategies such s selective disclosure and the encouragement of only a small trusted peer network to test for CT. Care strategies that deploy the sexual and social networks of individuals can reach into small networks surrounding a person. These strategies could be improved by exploring methods to reach high-risk network members outside the small trusted circle of a young person.

\section{Key messages}

- Young people perceive public stigma with Chlamydia testing

- Despite feelings of shame and anticipated self- stigma, young people would be willing to test for Chlamydia

- Stigma surrounding disclosure of testing behaviour and encouragement of others to test is anticipated. However the experience of stigma is effectively avoided by only disclosing to a small trusted peer group.

- Young people use stigma management strategies such as selective disclosure and selective encouragement of trusted others to protect themselves from stigmatizing reactions

- Care strategies that deploy social and sexual networks to invite young people to test for Chlamydia need to take into account the small size of these trusted peer networks. 


\section{References}

1. Senior K. Chlamydia: a much underestimated STI. The Lancet. 2012;12:517-8.

2. van Aar F, Koedijk FDH, van den Broek IVF, Op de Coul ELM, Soetens LC, Woestenberg PJ, et al. STI, including HIV, in the Netherlands in 2013. Bilthoven: Annual Report; 2014.

3. Geisler WM. Duration of untreated, uncomplicated chlamydia trachomatis genital infection and factors associated with chlamydia resolution: a review of human studies. JID. 2010;201 Suppl 2:s104-11.

4. Wand H, Guy R, Donovan B, McNulty A. Developing and validating a risk scoring tool for chlamydia infection among sexual health clinic attendees in Australia: a simple algorithm to identify those at high risk of chlamydia infection. BMJ Open. 2011. doi:10.1136/bmjopen-2010-000005.

5. National Institute for Public Health and the Environment. Nationaal soa/hiv-plan 2012-2016: 'bestendigen en versterken'. Bilthoven: Report; 2011.

6. Centers for Disease Control and Prevention: Summary of a review of the literature: Programs to Promote Chlamydia Screening; 2008. http://www.cdc.gov/std/healthcomm/ chlamydialitreview2008.pdf. [Accessed 19 Feb 2014].

7. Pavlin NL, Gunn JM, Parker R, Fairley CK, Hocking J. Implementing chlamydia screening: what do women think? A systematic review of the literature. BMC Public Health. $2006 ; 6: 221-31$.

8. Tilson EC, Sanchez V, Ford CL, Smurzynski M, Leone PA, Fox KK, et al. Barriers to asymptomatic screening and other STD services for adolescents and young adults: Focus group discussions. BMC Public Health. 2004;21(4):1-8.

9. Blake D, Kearney M, Oakes JM, Druker S, Bibace R. Improving participation in chlamydia screening programs: Perspectives of high-risk youth. Arch Pediatr Adolesc Med. 2003;157:523-9.

10. Farley TA, Cohen DA, Elkins W. Asymptomatic sexually transmitted disease: The case for screening. Preventive Med. 2003;36(4):502-9.

11. Barth KR, Cook RL, Downs JS, Switzer GE, Fischhoff B. Social stigma and negative consequences: factors that influence college Students' decisions to seek testing for transmitted infections. J Am Coll Health. 2010;4:153-9.

12. Cunningham $\mathrm{SH}$, Kerrigan DL, Jennings JM, Ellen JM. Relationships between perceived STD-related stigma, STD-related shame and STD screening among a household sample of adolescents. Perspect Sex Repord Health. 2009;41:225-30.

13. Burnet Institute. Partner Notification of Sexually Transmitted Infections in New South Wales: an informed literature review. http:// stipu.nsw.gov.au/wp-content/uploads/NSW_ STI_PN_PDF.pdf. Accessed 19 Feb 2014.

14. Levine D, Woodruff AJ, Mocello AR, Lebrija J, Klausner JD. InSPOT: the first online STD partner notification system using electronic postcards. Plose Med. 2008;5(10):213.

15. Østergaard L, Andersen B, Møller JK, Olesen F, Worm A-M. Managing partners of people diagnosed with Chlamydia tracho- 
matis: a comparison of two partner testing methods. Sex Trans Infect. 2003;79:358-61.

16. Loaring J, Hickman M, Oliver I, Campbell R, Trotter C, Macleod J, et al. Could a peer-led intervention increase uptake of chlamydia screening? A proof of principle pilot study. J Fam Plann Reprod Health Care. 2013;39:21-8.

17. Bilardi JE, Fairley CK, Hopkins CA, Hocking JS, Sze JK, Chen MY. Let Them Know: evaluation of an online partner notification service for chlamydia that offers E-mail and SMS messaging. Sex Trans Dis. 2010;37(9):563-5. doi:10.1097/OLQ.0b013e3181d707f1.

18. Bracebrigde S, Bachmann MO, Ramkhelawon K, Woolnough A. Evaluation of a systematic postal screening and treatment service for genital Chlamydia trachomatis, with remote clinic access via the internet: a cross-sectional study. East of England Sex Trans Infect. 2012. doi:10.1136/ sextrans-2011-050267.

19. Theunissen KATM, Hoebe CJPA, Crutzen $\mathrm{R}$, Kara-Zaïtri C, de Vries NK, van Bergen JEAM, et al. Using intervention mapping for the development of a targeted secure web-based outreach strategy named SafeFriend, for Chlamydia trachomatis testing in young people at risk. BMC Public Health. 2013;13:996. doi:10.1186/1471-2458-13-996.

20. Gaydos CA, Dwyer K, Barnes M, Rizzo-Price PA, Wood BJ, Flemming $T$, et al. InternetBased Screening for Chlamydia trachomatis to Reach Nonclinic Populations With Mailed Self-Administered Vaginal Swabs. Sex Trans Dis. 2006;33(7):451-7.
21. Youm Y, Laumann EO. Social network effects on the transmission of STI. Sex Trans Dis. 2002;689-697.

22. Busse $P$, Fishbein M, Bleakley A, Hennessy $M$. The role of communication with friends in sexual intention. Com Res. 2010;37(2):239-55.

23. Kotchick BA, Schaffer A, Forehand R, Miller KS. Adolescent sexual risk behavior: a multi-system perspective. Clinical Psych Rev. 2001;21(4):493-519.

24. Ferreira A, Young T, Mathews C, Zunza M, Low N. Strategies for partner notification for sexually transmitted infections, including HIV. Cochrane Database Syst Rev. 2013. doi:10.1002/14651858.CD002843.pub2.

25. Balfe M, Brugha R. Disclosure of STI testing activities by young adults: the influence of emotions and social networks. Social Health Illn. 2010;32:1041-58.

26. Nack A. damaged goods: women managing the stigma of STDs. Deviant Behavior. 2000;21:95-121.

27. Low N, Broutet N, Adu-Sarkodie Y, Barton P, Hossain M, Hawkes S. Global control of sexually transmitted infections. Lancet. 2006;368:2001-16.

28. Gorbach PM, Aral SO, Celum C, Stoner BP, Whittington WL, Galea J, et al. To notify or not to notify: STD patients' perspectives of partner notification in Seattle. Sex Transm Dis. 2000;27(4):193-200.

29. Bos AE, Pryor JB, Reeder GD. Stutterheim. Stigma: advances in theory and research. Basic Appl Soc Psych. 2013;35:1-9.

30. Dovidio JF, Major B, Crocker J. Stigma: Introduction and overview. In: Heatherton 
TF, Kleck RE, Hebl MR, Hull JG, editors. The social psychology of stigma. New York: Guilford Press; 2000. p.1-28.

31. Serovich J, Mosack K. Reasons for HIV disclosure or nondisclosure to casual sexual Partners. Aids Edu and Prev. 2003;15:70-80.

32. Mills N, Daker-White G, Graham A, Campbell R. Population screening for Chlamydia trachomatis infection in the UK: a qualitative study of the experiences of those screened. Fam Pract. 2006;23(5):550-7.

33. Clark JP. How to peer review a qualitative manuscript. In: Godlee F, Jefferson T, editors. Peer Review in Health Sciences. 2nd ed. London: BMJ Books; 2003. p. 219-35.

34. Ritchie J, Spencer L. Qualitative data analysis for applied policy research. In: Bryman A, Burgess R, editors. Analysing qualitative data. London: Routledge; 1994. p. 173-94.

35. Fortenberry JD, McFarlane M, Bleakley A, Bull S, Fishbein M, Grimley DM, et al. Relationships of Stigma and Shame to Gonorrhea and HIV screening. Am J Public Health. 2002;92:378-81.

36. Balfe M, Brugha R, O'Donovan D, O'Connell E, Vaughan D. Young women's decision to accept chlamydia screening: influences of stigma and doctor- patient interactions. BMC Public Health. 2010;10:425-35.

37. Bilardi JE, Fairley CK, Hopkins CA, Hocking JS, Temple-Smith MJ, Bowden FJ, et al. Experiences and outcomes of partner notification among men and women recently diagnosed with chlamydia and their views on innovative resources aimed at improving notification rates. Sex Trans Dis. 2010;37:253-8.
38. Miller CT, Kaiser CR. A theoretical perspective on coping with stigma. J of Soc Issues. 2001;57:73-92.

39. Stutterheim SE, Bos AER, Shiripinda I, de Bruin M, Pryor JB, Schaalma HP. HIVrelated stigma in African and Afro-Caribbean communities in the Netherlands: Manifestations, consequences, and coping. Psychology and Health. 2012;27:395-411.

40. Bos AE, Kanner D, Muris P, Janssen B, Mayer B. Mental illness stigma and disclosure: consequences of coming out of the closet. Issues Ment Health Nurs. 2009;30:509-13.

41. Balfe M, Brugha R, O'Connell E, Vaughan D, O'Donovan D. Men's attitudes towards chlamydia screening: a narrative review. Sex Health. 2012;9:120-30.

42. Trelle S, Shang A, Nartey L, Cassell JA, Low N. Improved effectiveness of partner notification for patients with sexually transmitted infections: systematic review. BMJ. 2007;334:354-9.

43. Theunissen KATM, Schipper P, Hoebe CJPA, Crutzen R, Kok G, Dukers- Muijrers NHTM. Care professionals' perceptions of barriers to and facilitators of Partner Notification for Chlamydia trachomatis: A qualitative study. BMC Health Serv Res. 2014;14:647.

44. Op de Coul EL, Spijker R, van Aar F, van Weert $Y$, de Bruin M. With whom did you have sex? Evaluation of a partner notification training for STI professionals using motivational interviewing. Patient Educ Couns. 2013;93(3):596-603. doi:10.1016/j.pec.2013.08.025. 


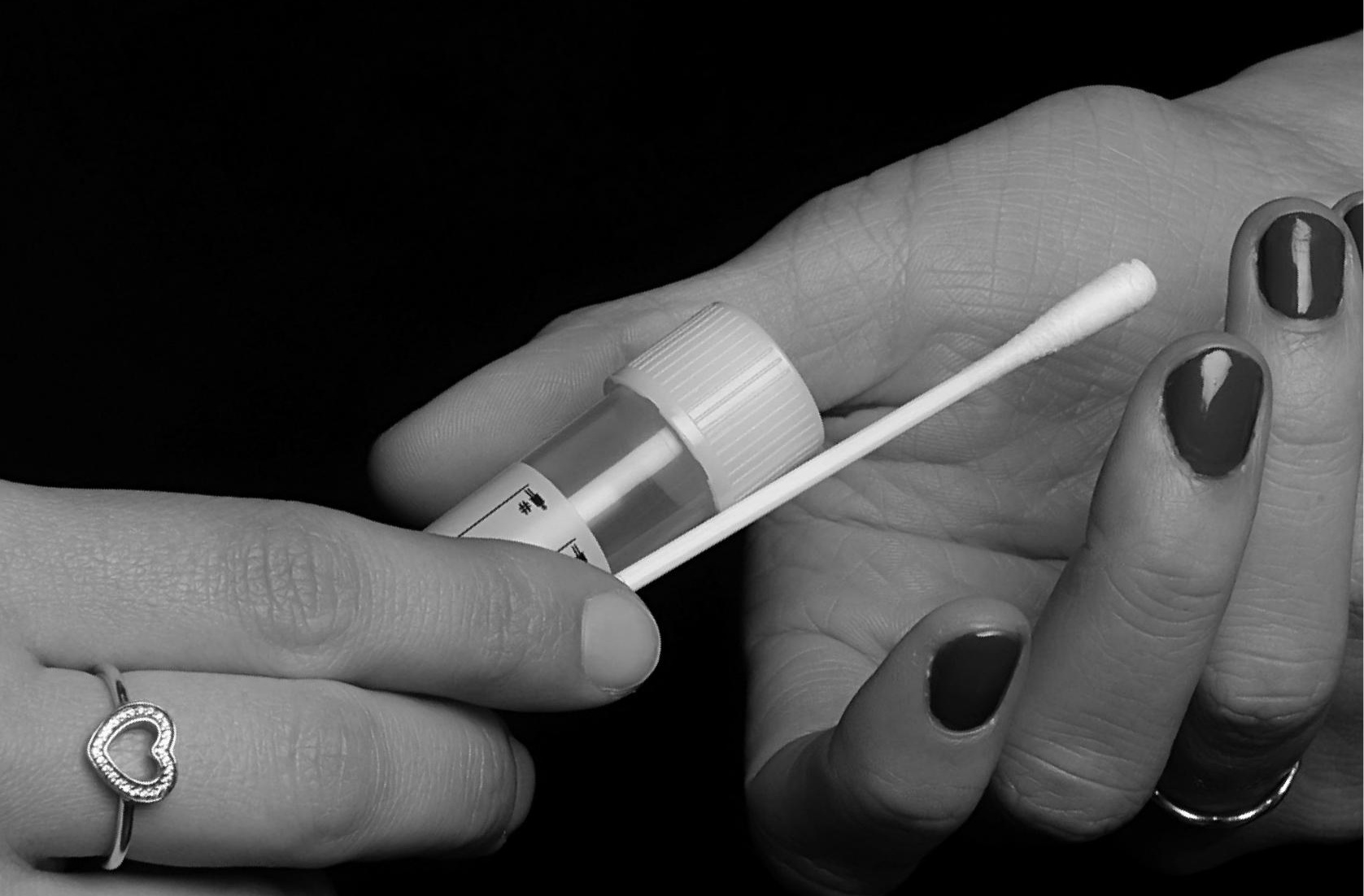




\section{Chapter 5}

\section{Barriers to and facilitators of partner notification for Chlamydia trachomatis among health care professionals}

Kevin A.T.M. Theunissen, Pim Schipper, Christian J.P.A. Hoebe, Rik Crutzen, Gerjo Kok and Nicole H.T.M. Dukers-Muijrers

BMC Health Services Research 2014, 14:647. 


\section{Abstract}

\section{Background}

Partner notification (PN) is an essential case-finding tool in the management of sexually transmitted infections (STIS). Yet, data on the effectiveness and factors impacting implementation of PN in the Netherlands are lacking. With the aim of further exploring and improving the PN process, the current study assessed perceived barriers and facilitators among health care professionals in the STI clinical setting. In particular, we explored the management of PN in young heterosexual patients diagnosed with Chlamydia trachomatis (CT).

\section{Methods}

We conducted semi-structured interviews among 22 health care professionals (response rate $52 \%$ ) from 5 of the 8 national STI clinics in the Netherlands. We carried out qualitative content analysis using a framework approach. All participants were nurses, aged mid $20 \mathrm{~s}$ to late $50 \mathrm{~s}$, and all but one were female.

\section{Results}

All health care professionals felt comfortable discussing PN. Other perceived facilitators for PN included: time, one-on-one consultations, interviewing skills (i.e. Motivational Interviewing) and a proactive helping style. Important barriers were identified as: sub-optimal guidelines, inaccurate sexual history, a lack of feedback regarding the motivational strategies that were used, and the lack of feedback regarding overall PN effectiveness. The health care professionals placed an emphasis on the care and treatment of the individual index patient rather than on discussion of $\mathrm{PN}$, or on motivating and helping patients to engage in $\mathrm{PN}$.

\section{Conclusions}

Health care professionals identified several barriers that need to be overcome, and facilitators which need to be maintained. Future efforts should concentrate on introducing PN protocols, providing feedback on both the effectiveness of strategies used by health care professionals, and on the PN process as a whole, and educating health care professionals about Motivational Interviewing strategies. Moreover, the possible implementation of an Internet-based PN system should be explored.

\section{Keywords}

Partner notification, Chlamydia trachomatis, Barriers, Facilitators, Public health. 


\section{Background}

Partner notification (PN) has an essential role to play in the management of sexually transmitted infections (STIs), both for the individual (i.e. in terms of the prevention of re-infection and complications) and the community (i.e. in terms of transmission interruption) [1,2]. The PN process entails four steps: 1) a health care professional discusses PN with an STI-positive patient and explains the possible infection risk for sex partners, 2) the sex partner is then identified, 3) notified, and is finally 4) tested, treated and educated [3]. The primary strategies used to notify partners include provider-referral and patient-referral. Provider referral involves the provider contacting the patients partner(s). Compared to patient referral where the patient notifies his/ her sex partners provider referral has been shown to be more effective at increasing the number of sex partners who are subsequently tested and treated [3-5].

When all 4 PN steps are carried out successfully, PN is an extremely effective tool in STI prevention, as it enables a high-risk population to be targeted, tested and treated. However, barriers at the health care professional, patient and organisational levels can disrupt the process at every step [1]. Data about PN barriers among public health care professionals (i.e. nurses) are scarce, and most research is conducted among General Practitioners (GPs). Previous research investigating PN barriers as perceived by GPs identified several important barriers at step 1 (i.e., discussing PN with the patient), including: time pressure, lack of financial reimbursement, and provider discomfort [6,7]. While GPs are generally supportive of PN, they can be unaware of, or misunderstand, their own role in $\mathrm{PN}$; for example, they may assume that PN will be performed by local health care services $[6,8,9]$. Most GPs prefer patient referral $[5,6]$, as provider referral is perceived as being both costly and time consuming $[2,5]$.

In the Netherlands, public health STI clinics are responsible for approximately $30 \%$ of STI care and the large majority of PN [10]. The organisational structure and scope differs between medical (i.e., among GPs and medical specialists) and public health care (i.e., STI clinics) settings. The latter are often described as being more concerned with populations than with individuals, and with prevention and care more than with cure $[11,12]$. There may well be different barriers to and facilitators of PN in medicine as compared to public health care, yet data on public health care professionals who perform PN in STI clinics are scarce, and any available data focuses on STI/ HIV in general [13].

This study examined the barriers to and facilitators of PN, as identified by public health care professionals, in relation to young heterosexual patients diagnosed with Chlamydia trachomatis (CT) who had visited an STI clinic for treatment. In the Netherlands, PN is not mandatory or enforceable by health care professionals. The role of the health care professional is to motivate 
and help CT positive patients to identify and notify their sex partners. PN can be initiated when a STI test is performed, when a patient is informed about a positive test result by telephone, or when a patient visits the STI clinic for treatment. In cases where a patient agrees that the health care professional may notify his or her sex partner(s), the health care professional will telephone or send a text message. Other tasks performed by STI clinic health care professionals include sexual health consultations, STI testing, treatment, and education. Their professional role description (as part of a public health service) includes the protection of the community as a whole (i.e. sex partners). In the current study, we focused on CT because it is the most common STI in patients younger than 25 years old, with an estimated prevalence of $17 \%$ in 2013 in the Netherlands [14]. Young patients have consistently high rates of risky sexual behaviour and, in terms of reproductive morbidity, potentially bear the largest burden of STI sequelae [15]. It is our intention that findings from the present study will inform a more effective PN process i.e., improve the prevention of re-infection and complications and interrupt transmission.

\section{Methods}

\section{Design and setting}

In order to study the perceptions of health care professionals, a qualitative method (i.e. semistructured interviews) was applied. Therefore, this article adheres to the RATS guidelines on qualitative research [16]. The study took place among health care professionals (i.e., trained STI clinic nurses) as they performed PN in public STI clinics. Participating health care professionals provided written informed consent, and the Medical Ethics Committee of Maastricht University reviewed and approved this study (reference number 13-4-054).

\section{Recruitment}

Between March and June 2012, an invitation letter with a short explanation of the study was sent to the email addresses of 42 nurses who had performed PN at their STI clinic for a period of at least six months. Email addresses were obtained from contact information that was available to the researcher, with contacts covering all 8 Dutch coordinating STI clinics. Within two weeks, 22 trained public sexual health care professionals (response rate of $52 \%$ ) from 5 of the 8 national STI clinics in the Netherlands had been recruited. As thematic saturation li.e., the point at which no new themes emerge) was reached within this sample, no email reminder was send to the nurses who did not respond to the first invitation email.

\section{Data collection}

Interviews were audio-recorded with the permission of the health care professionals, and conducted face-to-face $(n=11)$ or over the telephone $(n=11)$ by the interviewers. Both interviewers 
were affiliated to the Public Health Service South Limburg and the University of Maastricht, and had been trained in conducting semi- structured interviews and qualitative analyses. PS is a medical student and KT is an experienced researcher. The telephone and face-to-face interviews lasted, on average, 22 minutes. Recordings were assigned a number to ensure confidentiality. Numbers and corresponding names were kept in a locked file. Data were collected using a semistructured interview protocol consisting of 17 questions. This protocol was constructed in line with expert opinion, a comprehensive review of the literature, and (inter)national guidelines. At the beginning of each interview, the interviewers stated that all questions were related to Chlamydia diagnosis in young heterosexual people. Examples of questions are: At what stage in the process is PN carried ut, and how do you perform PN?; Which strategies do you apply during PN?; How do you feel when performing PN?; Which barriers do you experience during PN?; and Which facilitating factors do you experience during PN? The interview protocol was piloted among health care professionals before implementation. Saturation li.e. the point at which no new themes emerged in the interviews) occurred after approximately 17 interviews, and later interviews served to confirm themes identified earlier in the analysis.

\section{Analyses}

The audio-recorded interviews were transcribed verbatim in Dutch. Transcripts were analysed independently by PS and KT using the framework approach [17], which involves structured stages of data management, descriptive accounts and explanatory accounts. Furthermore, several transcripts were explored in detail, in order for PS and KT to become familiar with the data, after which open coding was applied. Codes were then grouped into categories in an iterative process, until no additional codes emerged. Eventually, categories and codes were applied to subsequent transcripts. A spreadsheet was used, which also included illustrative quotes, to find associations within categories and explanations for these associations were sought. Eventually, six categories were made: healthcare professional, patient, and organisational barriers and facilitators, respectively. Any disagreements found in the analysis were resolved through discussion, and consensus was reached by PS and KT consulting a third party (i.e. ND). Quotes that were used to illustrate the findings were translated into English and checked by the interviewers (PS and KT) to ensure accuracy.

\section{Results}

\section{Sample characteristics}

Twenty-one of the 22 participants were female, representing the sex ratio of staff in national STI clinics. The participants were aged between 24 and 55 years old. All had at least 6 months of experience, and all had received training in Motivational Interviewing (MI), which comprised part of their job education program. 
The barriers to and facilitators of PN (as perceived by health care professionals) are outlined below, using quotes to illustrate our findings. An overview of all barriers and facilitators is provided in Figure 1.

\section{Health care professional barriers}

Health care professionals primarily mentioned barriers in steps 2 and 3 of PN, i.e., the process of identifying and notifying sex partners. Some participants indicated awareness of the PN-

Figure 1: Care professionals' perceived barriers to and facilitators of partner notification derived from semi-structured interviews ( $n=22$ )

\section{Barriers}

Patient:

Patient does not attend treatment

\section{Care professional:}

Focus on curing the patient Lack of commitment when sex partner is a man

\section{Patient:}

Unreliable sexual history

Organisation:

No feedback on effectiveness of PN

\section{Patient:}

Lack of commitment to sex partner(s) Missing contact data of sex partner(s) Organisation:

No feedback on effectiveness of PN No feedback on effectiveness of care professionals strategies

Sub-optimal guidelines

\section{Facilitators}

\section{Care professional:}

Comfortable discussing sexual history and PN

\section{Discuss}

Partner Notification (PN)

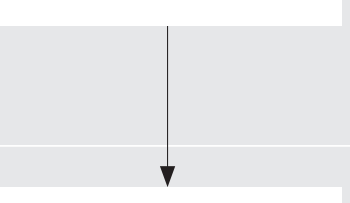

Step 2

Identify sex partner(s)

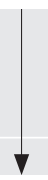

(1)

One-on-one sexual consultation Organisation:

Sufficient time

\section{Care professional:}

Experienced in motivational interviewing

\section{Care professional:}

Proactive helping style

\section{Patient:}

Access to sex partners' contact information

Commitment towards a sex partner

\section{Patient:}

Patient visits STI clinic together with sex partner(s)

Test, treat and educate sex partner(s) 
related goal of public health care, that is, the prevention of STIs in the community. However, nearly all health care professionals expressed a bigger commitment to curing the (index) patient rather than interviewing the patient about PN and helping him/her to notify (by themselves or with a staff member) sex partners of their exposure to an STI.

"My feeling is that it [notification of partners] is really the patient's own responsibility, although I do work at a Public Health Care Service, whose job it is to identity and treat as many people as possible".

(Female no. 13, mid 30 s, Region 5)

"For me, the patient and his questions come first, because he is sitting in front of me, he is top of the list."

(Female no. 16, late $50 \mathrm{~s}$, Region 1)

Health care professionals felt that placing too much pressure on PN could drive current patients away from future testing, in which case access to a high-risk population would be lost.

"The community is important, but you should not scare the patients away from public health care."

(Female no. 14, age unknown, Region 5)

Moreover, client-referral, as opposed to provider-referral, was preferred by almost all health care professionals. They viewed the notification of sex partners as the responsibility of the patient.

"My task is to convince and to inform, the actual notification is the client's responsibility."

(Female no. 22, mid 40 s, Region 3)

Some of the health care professionals were more committed to protecting female partners than male partners of patients, as females have a higher disease burden.

"It [PN] is important, because girls could become infertile. To be honest, because of this, I take a more active attitude with girls, as they may suffer more serious consequences than men."

(Female no.5, late 20 s, Region 1) 


\section{Health care professional facilitators}

All of the health care professionals felt comfortable assessing sexual history and discussing PN (i.e. PN step 1). Generally, PN was practised one-on-one, and the process was not disrupted by the presence of third parties.

"I think this [discussing PN] is a task that belongs to us. I do not have any problems with discussing it [PN]."

(Female no. 13, mid 30 s, Region 5)

"I try to see all my patients one-on-one without the presence of a partner so you know they will provide you with complete information. It will be easier to ask more in-depth questions about their sex partners from the past 6 months."

(Female no. 6, mid 20 s, Region 1)

Furthermore, all health care professionals had been trained in Motivational Interviewing, which they felt to be an advantage at moments in which a patient's willingness to identify sex partners was low. When a patient appeared reluctant to notify their partners themselves, for instance because they were afraid to do so, health care professionals contacted his/her partner(s). However, this happened only occasionally, because patients often indicated that they preferred to notify their sex partner(s) themselves.

Interviewer: "How often do you apply Motivational Interviewing techniques during a conversation?"

Health care professional: "Sometimes, because you do not need to apply it every time. when I have many doubts about someone's willingness to comply. In such moments it will help you to determine what someone thinks of it [Partner Notification], and it will indicate how far you can go with this person."

(Female no. 22, mid 40 s, Region 3)

The scope of public health care is to protect the community as a whole (i.e. sex partners) and not merely focus on the treatment of individuals. In line with this scope, it is notable that one health care professional mentioned that her professional role was to convince people to notify their partners and to use a more proactive helping style towards patients. As a result, she was often asked by patients to notify sex partners on their behalf. 
Health care professional; “When I started working here, I felt it [PN] was the client's responsibility. Meanwhile I think it is entirely our [health care professional and public health care] job to convince people to notify their partners."

Interviewer: "Is it only about informing partners, or is it more?"

Health care professional: "Of course informing that was also the case when I started here. But I mean more. I mean estimating whether you should take control in the interview and use a more directive style"

(Female no. 10, early 50s, Region 1)

Interviewer: "How many people request that you notify their partners, and how many people do it themselves?"

Health care professional: "I try my best to achieve 50 per cent, but so far this has proven impossible. No, I think 40 per cent request me to take over a big part. I convince them in an early phase, the best way in current practice."

(Female no. 10, early 50s, Region 1)

\section{Perceived patient-related barriers}

Some health care professionals mentioned that PN can be hindered when opportunities to discuss PN (PN step 1) are inadequate, especially when face-to-face contact is not possible.

"When a patient has tested positive for Chlamydia and refuses to return for treatment. That is, those patients who consider returning for treatment a nuisance. They just want a prescription, that $s$ it. It really annoys me, because I will have to discuss PN over the phone and make it quick at that."

(Female no. 3, mid 20 s, Region 1)

Even though health care professionals felt comfortable discussing PN, they were sometimes confronted with a lack of commitment among patients towards sex partners when discussing a Ct diagnosis. Reasons for this lack of commitment mentioned by the health care professionals included feelings of anger, fear and embarrassment among patients towards their sex partners. 
"It is difficult when a client in front of you does not feel any commitment towards the person they have to notify for example, because their partner was unfaithful and got infected with Chlamydia. This is an obstacle we face during Partner Notification."

(Female no. 19, late 30 s, Region 1)

In addition, health care professionals took into account that sexual history may be unreliable due to patients providing socially desirable answers. Health care professionals indicated that in such cases it is challenging to find opportunities to discuss PN optimally.

"Basically, a sexual history is unreliable. People pimp up their stories to appear more flattering. So, I always assume that they have more contacts than they reveal."

(Female no. 4, early 50 s, Region 1)

"It [dealing with socially desirable answers] is sometimes even harder than trying to persuade someone who frankly says I won't notify, because with the latter I can at least start the conversation."

(Female no. 3, mid 20 s, Region 1)

An additional barrier to PN included patients not having their partners contact information.

“Sometimes, it [PN] is impossible, because people had a one night stand or visited a disco and do not have a telephone number; in such instances, there is simply no room for PN."

(Female, no 22, mid 40 s, Region 3)

\section{Perceived patient-related facilitators}

Some health care professionals mentioned that, at the time of treatment, index patients often claim to have already notified their partners. Health care professionals stated this is often the case when patients have high feelings of responsibility toward their sex partners (i.e., are in steady relationships).

"When they [Chlamydia positive patients] visit us for treatment, they quite often indicate that they have already notified their partners."

(Female no. 15, age unknown, Region 3) 
Some health care professionals said that patients occasionally visit the STI clinic with a sex partner during a treatment consultation. In current practice, both the patient and the sex partner will receive treatment (i.e., $\mathrm{PN}$ step 4).

"When someone brings along a partner to a treatment consultation, both of them will be treated."

(Female no. 15, age unknown, Region 3)

\section{Perceived organisational barriers}

Health care professionals are not obliged to register the PN process in the Electronic Patient Record, and therefore no feedback on the effectiveness of PN outcomes and PN techniques used was available. The majority of the health care professionals did not know whether their $\mathrm{PN}$ techniques were effective, and some felt that their own contribution in PN was limited. In addition to this, health care professionals were unaware of whether patients sex partners were subsequently tested, treated, and educated (PN step 4).

"Often young people want to notify their partners themselves, and of course we do not have any idea whether they actually do so, or if they actually manage to get in touch. This makes the process difficult. Actually, you would like to count who [sex partners] is visiting you and if they are tested."

(Female no. 21, mid 30 s, Region 3)

"To be honest, I do not know, never measured this. I have never received feedback on it [Partner notification]."

(Male no. 12, late 40s, Region 4)

"Whether it [PN] works or not, we do not know. We do not monitor whether a sex partner has been notified or has actually been tested."

(Female no.1, mid 20 s, Region 1)

"There are many factors that play a role; my contribution [in the notification of partners] is only a small one."

(Female no.4, early 50s, Region 1) 
Health care professionals also stated that current guidelines do not specify in detail which motivational strategies to use, which PN procedure to follow, or which referral strategy is preferred; the guidelines only include a recommended recall period for tracing back sex partners. However, the health care professionals also mentioned variation in the use of these recall periods, suggesting that some staff members did not adhere to the guidelines.

"The recall period of sex partners is stated on paper, but the way you should do this [PN] is not. Everyone applies Motivational Interviewing their own way."

(Female no. 22, mid 40 s, Region 3)

"We do not strictly follow the national guidelines as stated during PN. We ask young people if they know who infected them. If they don t know, we ask them to recall sex partners from the past 6 months."

(Female no. 17, early 60 s, Region 2)

\section{Perceived organisational facilitators}

Almost all health care professionals reported that their STI clinics provide them with sufficient time to conduct and discuss PN (PN step 1).

"There is sufficient time! Sometimes you need 5 minutes and on other occasions you need half an hour."

(Female no. 18, early 50 s, Region 1)

\section{Discussion}

The semi-structured interviews we carried out among health care professionals in national public health STI clinics in The Netherlands revealed several barriers at the health care professional, patient, and organisational levels. These barriers may hinder the PN process (in which $\mathrm{PN}$ is discussed with the patient and sex partner(s) are subsequently identified, notified, tested, treated and educated). Important barriers were identified as: no-shows at the treatment stage (which was the most important moment to discuss PN), a focus on curing patients, less of a perceived need to conduct PN in male sex partners, a perceived lack of commitment among patients towards sex partners, missing contact data of partner(s), unreliable sexual history, a lack of feedback on the effectiveness of the PN process and on the strategies used by health care 
professionals, and suboptimal guidelines. In addition to these barriers, important facilitators of PN were identified as: feelings of being comfortable discussing sexual history and PN, oneon-one consultation, sufficient consultation time, a proactive helping style, being experienced in Motivational Interviewing, patient commitment towards sex partner(s), and having sex partners attend the clinic together with the patients.

While barriers among GPs concentrated on the discussion of PN (i.e. step 1 in the PN process), barriers among STI clinic professionals were mostly related to steps 2 and 3 (see Figure 1). Public health care is complementary to medicine, and has a different scope and organisational structure. Public health care aims to protect the community; it benefits individuals by providing treatment and preventing re-infection. Public STI clinics are non-profit organisations that provide free care and employ experienced health care professionals (i.e., staff who are experienced in Motivational Interviewing and sexual consultation). Contrary to the public health scope, most of the health care professionals in this study were more committed to curing patients than to preventing STIs in sex partners. Potentially, such a curative approach is maintained as the health care professionals do not have any information on the effectiveness of PN on the community, or any feedback on the PN process and the strategies they have implemented. As a possible result, health care professionals may feel less responsible for PN and the process of contacting and notifying sex partners on behalf of the patient. Currently, almost all notifications at Dutch STI clinics appear to be carried out by patients (i.e. patient referral) and not by health care professionals, as revealed during the interviews. Patient referral has generally been observed as the most common PN practice in patients with STIs [5]. However, its effectiveness is not known [18], due to the frequent absence of recorded PN outcome data (i.e. data regarding whether partners are notified, tested and treated] $[2,18,19]$. It is expected that patients will often fail to notify sex partners, because of the stigma surrounding STIS/HIV, and associated feelings of embarrassment or fear [20]. Therefore, barriers and facilitators surrounding PN, as identified by $\mathrm{Ct}$ positive patients and their partners, should also be considered when improving PN implementation in practice. While Motivational Interviewing was mentioned as a facilitator among health care professionals, there are differences in how well such techniques are applied; differences may be related to age, experience and/or personal attitude. Almost all health care professionals in our study merely informed the client about PN, while only one health care professional discussed PN and used a more proactive helping style in order to examine and resolve problems during PN. Notably, this health care professional was asked by almost half of the patients to notify sex partner(s) on their behalf (i.e. provider referral). Provider referral has been found to be more effective $[4,18]$ and is thus important in the management of re-infections and the screening and testing of sex partners. Professionals can use email, text messages, telephone and outreach approaches such as face-to-face conversations to inform sex partners. However, provider-referral is labour intensive, and a combination of different PN methods has therefore been recommended in the literature [18]. 
A low level of commitment towards sex partners (on the part of the patient) has previously been identified as a barrier in the PN process [21]. Health care professionals in our study identified low commitment as a barrier to the notification of patients sex partners. However, a previous study has demonstrated that young female and male patients who blamed their sexual partners for acquiring an STI infection still felt morally obliged to notify them [20]. The notification of sex partners may be hampered by patients under-reporting the number of sex partners in an attempt to provide socially acceptable answers or simply forgetting [22].

The results of this study underline the fact that national and international guidelines about PN contain only general recommendations $[23,24]$. Guidelines do not specify which motivational strategies to use, which PN procedures to follow, or which referral strategy is preferred and how exactly to implement it. This lack of specific instructions was also reported to be a barrier among GPs [7]. Sub-optimal guidelines may lead to misconceptions about best practice, job roles, and responsibilities [7].

A different approach towards partner management, called Expedited Partner Therapy (EPT), has recently gained attention in the literature [25]. In this approach, partners are treated without a personal assessment. Although EPT decreases the number of PN steps necessary, and could therefore potentially optimize the PN process, some barriers identified in this study could also hamper the implementation of EPT. Examples of such barriers include a focus on curing the patient and the lack of commitment among patients towards sex partner(s). Future studies are needed to map the barriers and facilitating factors in both providers and the public regarding EPT.

Since the results of this study became clear, discussions have taken place among health care professionals about their emphasis on patient care rather than public health, and also about the absence of outcome measures to determine effectiveness. Nationally, there is an ongoing

Table 1: Recommendations to improve partner notification

\begin{tabular}{|ll|}
\hline Topic & Recommendations \\
\hline PN Guidelines & $\begin{array}{l}\text { PN guidelines should provide concrete steps for health care professionals in terms } \\
\text { of how they can address public health goals }\end{array}$ \\
\hline PN training & Motivational Interviewing should be specifically addressed in training for PN \\
\hline Discussing PN & $\begin{array}{l}\text { Organisations should encourage and facilitate inter-professional discussions on best } \\
\text { practice regarding PN }\end{array}$ \\
\hline Feedback on PN & $\begin{array}{l}\text { Information systems should be created and implemented that provide feedback on PN } \\
\text { outcomes to health care professionals and policy makers }\end{array}$ \\
\hline
\end{tabular}


public debate about these issues, and the professional community has been informed. Currently, national PN protocols are being re-written and regional PN reporting systems have been developed, taking into account the findings presented in this study.

\section{Recommendations}

It is important to use, improve, and maintain current facilitators of PN. On the other hand, perceived barriers to PN should be tackled (see Table 1). From an organisational perspective, future efforts need to concentrate on addressing the public health care goals of public sexual health care professionals, focusing especially on their responsibility towards the community. For example, this could involve the development of PN protocols that encourage the notification of sexual, and possibly also social, networks. Furthermore, attention should focus on Motivational Interviewing, which has been shown to improve skills and behaviour of health care professionals in dealing with patients resistance towards PN [26]. PN training using MI as a useful tool should therefore be included in the education of health care professionals. In addition to this, recall of sex partners is likely to increase when professionals are better trained to motivate patients to contact sex partners, or when care professionals are more proactive in helping patients in the notification process (i.e., provider-referral) $[4,5,18,22,26]$. Since no feedback on the effectiveness of PN outcomes and PN techniques used is available, future efforts should also include developing ways to provide feedback to staff, which in turn could have a positive effect on their feelings of responsibility, and address their feelings of being ineffective. The frequent absence of recorded PN outcome data could be tackled by implementing a centralized and standardized collection of PN data. Regional and/or national PN reporting systems shared among all stakeholders who perform PN should be developed to determine, for instance, rates of notification, test, positivity and treatment among partners. One option, which was mentioned by some of the health care professionals, and has also been identified in the literature [27], would be to implement an internet-based PN system (i.e., e-mail and text messages), which can be used by both clients and health care professionals; this strategy would take advantage of a communication technology that is increasingly utilised [28]. An initiative of the Public Health Care Service South Limburg is to test and implement an internet-based system called SafeFriend [29]. Young people at risk for $\mathrm{Ct}$ will be motivated via their sexual and social networks (i.e. e-mail and text messages) to get tested for $\mathrm{Ct}$, and offered home-based test kits. As shown in a systematic review [5], home-based test kits improve the effectiveness of PN by increasing the number of partners tested. 


\section{Limitations}

Some limitations need to be considered when interpreting the data. First due to logistical reasons, we decided to conduct the interviews in participating clinics outside South Limburg via telephone rather than face-to-face linterviews were conducted face-to-face in participating South Limburg clinics). To minimize the difference between the verbal and non-verbal communication of the interviewers, a protocol was used for each of the interviews. Data showed that there were no notable differences in the themes raised by the interviewees across the face-to-face or telephone interviews. Second, to minimize the possibility of receiving only socially desirable answers, the interviewers emphasized the confidentiality of data be- fore and during the interview. Third, barriers and facilitators as perceived by health care professionals were studied only in relation to $\mathrm{PN}$ in young heterosexual people infected with $\mathrm{Ct}$ (i.e., the largest group of STI clinic patients in the Netherlands). Therefore, it is unknown whether results can be extrapolated to other target groups (i.e. men having sex with men, or commercial sex workers) and other STIs (e.g. Syphilis or HIV). Fourth, the experience that a health worker has (i.e. number of years working in a clinic) may play a role in the PN process. Positive and/or negative experiences over time could influence the attitudes and self-efficacy of health care professionals towards PN. Although we did not have exact data relating to employment years, all participants in the present study had at least six months PN experience in an STI clinic setting. Finally, the results of this study were not presented to the participants for confirmation. Nevertheless, at the end of each interview, participants were given the opportunity to ask questions and/or give comments concerning the interview.

\section{Conclusion}

The results of this study carried out among Dutch STI clinics provides insight into the challenges and facilitators at the health care professional, patient, and organisational levels. These applied mainly to steps 2 and 3 of PN, i.e., the identification and notification of sex partner(s). In order to overcome these barriers and maintain facilitators and thereby optimize PN efforts should be made to focus more on the public health care goals of STI clinical practice, especially on the aim of protecting the com- munity. Examples of ways in which these goals can be reached include: introducing PN protocols, providing feedback on the effectiveness of strategies used by health care professionals, and on the PN process as a whole, education in the use of Motivational Interviewing strategy and the possible implementation of an Internet-based PN system. 


\section{References}

1. Alam N, Chamot E, Vermund S, Streatfield K, Kristensen S. Partner notification for sexually transmitted infections in developing countries: a systematic review. BMC Public Health 2010, 10:19.

2. Bell G, Potterat J. Partner notification for sexually transmitted infections in the modern world: a practitioner perspective on challenges and opportunities. Sex Trans Infect 2011, 87:ii34 eii36.

3. Macke BA, Maher JE. Partner notification in the United States: an evidence-based review. Am J Prev Med 1999, 17:230 242.

4. Mathews C, Coetzee N, Zwarenstein M, Lombard C, Guttmacher S, Oxman A, Schmid G. A systematic review of strategies for partner of STD AIDS 2002, 13:285 300.

5. Trelle S, Shang A, Nartey L, Cassell JA, Low N. Improved effectiveness of partner notification for patients with sexually transmitted infections: systematic review. BMJ 2007. doi:10.1136/bmj.39079.460741.7c

6. Hogben M, St Lawrence JS, Montano DE, Kasprzyk D, Leichliter JS, Philips WR. Physicians opinions about partner notification methods: case reporting, patient referral, and provider referral. Sex Trans Infect 2004,80:30 34.

7. Pavlin NL, Parker RM, Piggin AK, Hopkins CA, Temple-Smith MJ, Fairley CK, Tomnay JE, Bowden FJ, Russell DB,

Hocking JS, Pitts MK, Chen MY. Better than nothing? Patient-delivered partner therapy and partner notification for chlamydia: the views of Australian general practitioners. BMC Inf Dis 2010, 10:274 281.

8. Bangor-Jones RD, McCloskey J, Crooks AML, Bastian LA: Attitudes of WA GPs to chlamydia partner notificationa survey. Australian family physician 2009, 38:448 452.

9. Burnet Institute: Partner Notification of Sexually Transmitted Infections In New South Wales: an informed literature review. Australia: Burnet Institute Centre for Population Health; 2010.

10. Dukers-Muijrers NHTM, van Liere GAFS, Hoebe CJPA. Re-screening chlamydia trachomatis positive subjects: a comparison of practices between an STI clinic, general practitioners and gynaecologists. Sex Trans Infect 2012, 89(1):25-27.

11. Rogers WA. Ethical issues in public health: a qualitative study of public health practice in Scotland. J Epidemiol Community Health 2004, 58:446 450.

12. Thomas JC, Sage M, Dillenberg J, Guillory VJ. A code of ethics for Public Health. Am J Public Health 2002, 92:1057 1059.

13. Edelman EJ, Col CA, Richardson W, Boshnack N, Jenkins H, Rosenthal MS. Opportunities for Improving Partner Notification for HIV: Results from a Community-Based Participatory 
Research Study. AIDS Behav 2014. doi:10.1007/s10461-013-0692-9.

14. National Institute for Public Health and the Environment. Sexually transmitted infections, including HIV, in the Netherlands in 2013. Annual report. Bilthoven: National Institute for Public Health and the Environment; 2014.

15. Haggerty CL, Gottlieb SL, Taylor BD, Low N, Xu F, Ness RB. Risk of Sequelae after Chlamydia trachomatis Genital Infection in Women. J Infect Dis 2010, 201:S134 S155.

16. Clark JP: How to peer review a qualitative manuscript. In Peer Review in Health Sciences. Secondth edition. Edited by Godlee F, Jefferson T. London: BMJ Books; 2003:219 235.

17. Ritchie J, Spencer L. Qualitative data analysis for applied policy research. In: Bryman A, Burgess R, eds. Analysing qualitative data. London: Routledge;1994:17394

18. Hogben M: Partner Notification for Sexually Transmitted Diseases. CID 2007, 44(suppl3):S160 S174.

19. Aar F, Schreuder I, Weert Y, Spijker R, Gotz H, Op de Coul E. The Partner Notification GroupCurrent practices of partner notification among MSM with HIV, gonorrhoea and syphilis in the Netherlands: an urgent need for improvement. BMC Infectious Diseases 2012, 12:114.

20. Temple-Smith M, Hopkins C, Fairley JT, Pavlin N, Parker R, Russell D, Bowden F, Hocking J, Pitts M, Chen M. The right thing to do: patients views and experiences of telling partners about chlamydia. Family Practice 2010, 27:418 423.

21. Darroch J, Myers L, Cassell J: Sex differences in the experience of testing positive for genital chlamydia infection: a qualitative study with implications for public health and for a national screening programme. Sex Transm Inf 2003, 79:372 374.

22. Brewer DD, Garrett SB, Kulasingam $S$ : Forgetting as a cause of incomplete reporting of sexual and drug injection partners. Sex Trans Dis 1999, 26(3):166 176.

23. European Centre for Disease Prevention and Control: Public health benefits of partner notification for sexually transmitted infections and HIV. Stockholm; 2013 http://www. ecdc.europa.eu/en/publications/ Publications/ Partner-notificationfor-HIV-STI-June-2013.pdf

24. Centers for disease control and prevention: Recommendations for Partner Services Programs for HIV Infection, Syphilis, Gonorrhea, and Chlamydial Infection. Atlanta; 2008 http://www.cdc. gov/mmwr/pdf/rr/rr5709.pdf

25. Centers for disease control and prevention: Expedited Partner Therapy in the Management of Sexually Transmitted Diseases: Review and Guidance. Atlanta; 2006 http://www.cdc.gov/std/ treatment/ eptfinalreport2006.pdf 
26. Op de Coul EL, Spijker R, van Aar F, van Weert $Y$, de Bruin $M$ : With whom did you have sex? Evaluation of a partner notification training for STI professionals using motivational interviewing. Patient Educ Couns 2013, 93(3):596-603. Doi: 10.1016/j. pec.2013.08.025.

27. Bilardi JE, Hopkins CA, Fairley CK, Hocking JS, Tomnay JE, Pavlin NL, Parker RM, Temple-Smith MJ, Bowden FJ, Russell DB, Pitts M, Chen MY: Innovative resources could help improve partner notification for chlamydia in primary care. Sex Trans Dis 2009, 36:779 783.

28. Bilardi JE, Fairley CK, Hopkins CA, Hocking JS, Temple-Smith MJ, Bowden FJ, Russell DB, Pitts M, Tomnay JE, Parker RM, Pavlin NL, Chen MY:Experiences and outcomes of partner notification among men and women recently diagnosed with chlamydia and their views innovative resources aimed at improving notification rates. Sex Trans Dis 2010, 37:253 258.

29. Kevin ATM T, Christian CJPA H, Rik C, Chakib K-Z, de Vries NK, van Bergen JEAM, van der Sande MAB, Nicole HTM D-M: Using intervention mapping for the development of a targeted secure web-based outreach strategy named SafeFriend, for Chlamydia trachomatis testing in young people at risk. BMC Public Health 2013, 13:996. doi:10.1186/1471-2458-13-996. 


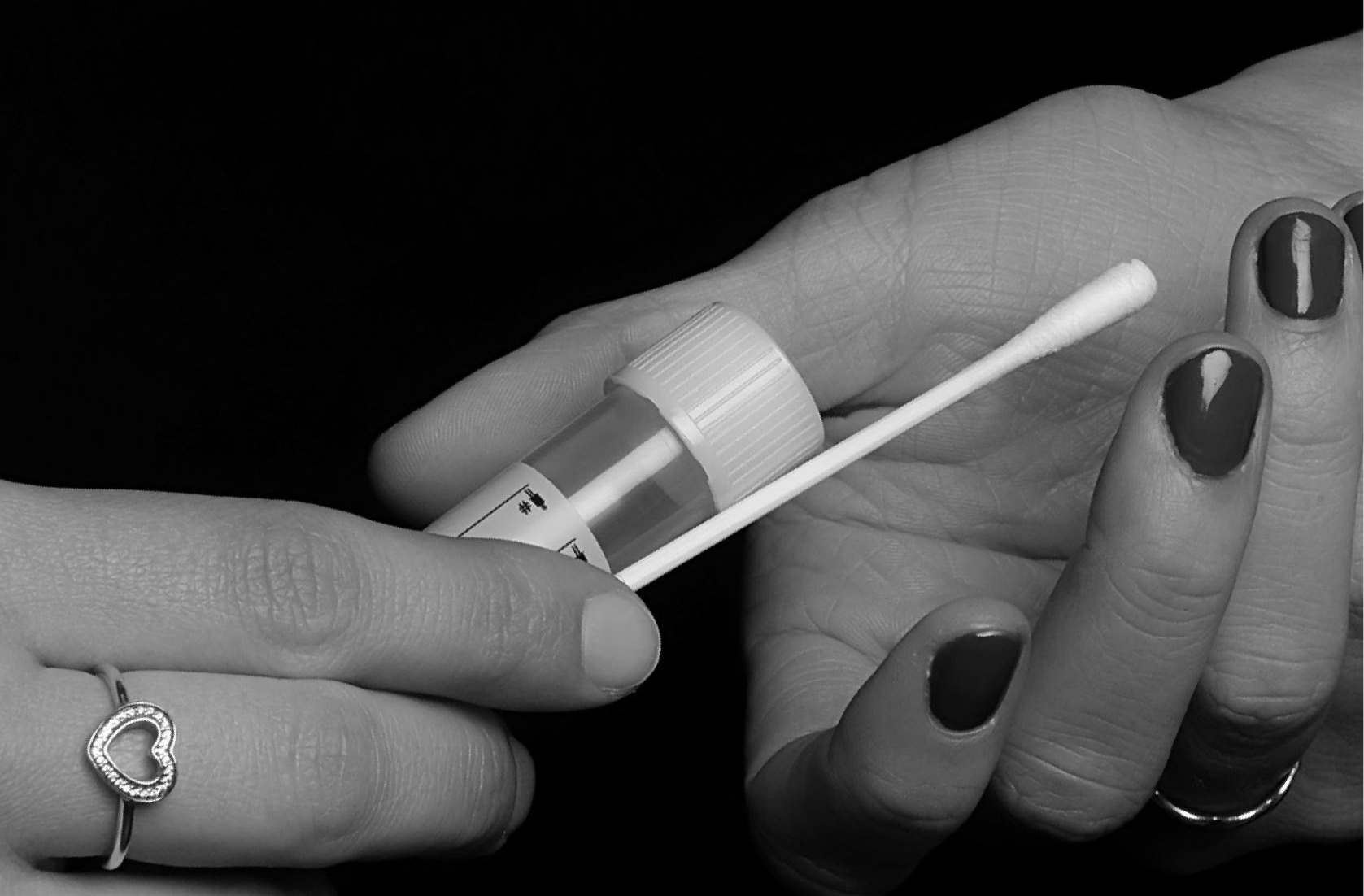




\section{Chapter 6}

\section{Acceptance of home-based chlamydia genital and anorectal testing using short message service (SMS) in previously tested young people and their social and sexual networks}

Kevin A. T. M. Theunissen, Nicole H. T. M. Dukers-Muijrers, Petra T. Wolffs, Gerjo Kok and Christian J. P. A. Hoebe

PLoS ONE 2015;10(7): e0133575 


\section{Abstract}

\section{Background}

Control strategies for Chlamydia trachomatis (CT) are most effective when targeting people at highest risk. We assessed test acceptance of home-collection test kits offered by short messaging services (SMS) texts, in high-risk young people, i.e. those who had previously tested CT positive (positive indices), or negative reporting more than 3 sex partners (negative indices), and their sexual and social networks.

\section{Methods}

Young ( 16 to 25 years old) heterosexuals who previously tested positive ( $n=536$ ) or negative ( $n=536$ ) in our STI clinic received, 3 to 20 months after their initial screening, an SMS inviting them to re-test. They were offered a free home-collection test kit including a genital (men and women) and anorectal (women only) test, and a test kit to pass on to a friend or sex partner (peer). SMS reminders were sent in case of non-response. We assessed pro- portions of tests requested and returned, peers tested, and positivity. Associations with the individual's initial screening result and other factors were explored using logistic regression.

\section{Results}

Of 1072 people invited to retest, $34.4 \%$ ( $n=369$ ) requested a test. Of these, $55.8 \%$ ( $n=206$ ) retested. Overall, retest participation was higher in positive $(22 \%)$ than in negative indices $(16 \%)(p<0.001)$; it was also higher in women and in those aged $>22$ years. Positivity was $13 \%$ and $7 \%$ in positive and negative indices, respectively. One in 3 retesters also had a peer tested. Of tested peers ( $n=87$ ), $84 \%$ were friends, $31 \%$ were first-time testers, and $7 \%$ tested positive.

\section{Conclusion}

Acceptance of a relatively low-cost strategy for genital and anorectal testing, i.e. using SMS and home-collection test kits, was highest in individuals who previously tested CT positive suggesting that implementation for this group may be considered. By further including a peer-led testing component, undetected CT positives can be identified in the social net- works surrounding a high-risk individual. 


\section{Introduction}

Internationally, the number of diagnoses of Chlamydia trachomatis (CT) among young people remains high, despite many efforts to reduce and manage the transmission of this infection [1-3]. Testing and treating positives is a key strategy for the interruption of CT spread. Yet testing is precluded by a range of barriers that can be CT-related le.g. it is an infection largely without symptoms), patient-related (e.g. patients may not feel at risk; may fear the testing method, a positive result, or stigmatization; may have privacy concerns) [4-10], or care-related (e.g. costs, time constraints). Evidence-based strategies designed to overcome some of these barriers and increase testing include the use of postal test kits for home-collection [11-15]. Such postal test kits include self-collected urine, vaginal and anorectal specimens, which are highly acceptable and being used by both men and women [16-18]. The samples derived from these kits can be tested with nucleic acid amplification tests (NAAT), yielding a similar accuracy level to that of clinically derived specimens [19]. Other promising techniques include the use of active recall systems to prompt testing (by letter, phone, email or short message service (SMS)), especially when used in combination with home-collection test kits [12,20,21]. The use of text messages, such as by SMS, has the advantage of being relatively cheap, convenient, and timely. SMS allows providers to interact with patients anywhere and anytime. This is particularly important as patient engagement is key to the effective management of sexual transmitted infections (STIs) [22]. The acceptability of text messages has already been demonstrated in the sexual health context [23]. It has been demonstrated that SMS reminders in combination with home- collection test kits can increase both the number of test requests and returns in young people who have already been invited by letter for testing [14]. Moreover, text messages sent to heterosexual individuals who had previously tested CT positive have been found to increase repeat CT testing at the clinic in some [20,24], but not in all [25], studies.

SMS technologies and home-collection kits are encouraging developments that can be used to overcome barriers and increase testing. Testing strategies are most effective when directed at $\mathrm{CT}$ infected people who are as yet untested and untreated, i.e. the hidden risk groups. Most international guidelines include retesting CT positives, and some also include annual rescreening of high-risk young people, regardless of their initial screening test result $[1,2]$. Individuals with a previous CT diagnosis show retest positive rates as high as $10 \%-30 \%[26,27$. Unfortunately, a large proportion of these people are not retested, and they remain hidden to care $[27,28]$. While home-based testing [15] or active recall by SMS $[20,24]$ have both been shown to increase retesting in some studies, to the best of our knowledge, data are lacking on the combination of SMS and home-based retesting. Contacting people for retesting may provide an excellent opportunity to also reach other hidden CT positives, i.e. in the individual's social and sexual networks. People in these networks typically show similar high risk, for example with 
respect to unprotected sex, or sex with a CT positive person [29]. The sexual behaviour, and potentially also the testing behaviour, within social networks has been associated with communication and modelling among friends in these networks [30-33]. Several innovative peer-led intervention programs aiming to reach high-risk social and sexual networks have been developed using home-collection and/or e-health technologies [34-37]. Moreover, a few studies have assessed peer-led CT screening using home-based testing [33, 38, 39]. Loaring et al. [33], showed that in a small study of 12 women and men, women were potentially more willing to provide their social network with test kits, yielding $34 \%$ of kits returned by peers for testing. This peer test return rate was $26 \%$ for the sexual partners of 637 diagnosed CT positive persons (general practitioner care) in a study by Ostergaard et al [38], while it was only $4.5 \%$ for social peers from 67 indices tested in a primary care setting in a study by Rose et al [39].

The use of SMS technologies and home-collection test kits in combination with retest strategies and peer-led testing may improve present control strategies and reach more hidden CT positives. We explored exactly this possibility in the current study, in people considered at risk for CT, i.e. young heterosexual men and women who had previously tested CT positive. This group was compared to a group of CT negative young heterosexual individuals at risk for CT, i.e. those who reported having three or more sex partners in the last six months [4]. All of these CT positive and CT negative young people (here called indices) were provided with an extra test kit to pass on to a member of their social or sexual network. Importantly, most strategies designed to increase retesting or peer testing have focused solely on genital infections, missing out on anorectal infections, which occur as frequently in women as do genital CT infections [40-42]. Therefore, in the current study, with the aim of providing a comprehensive screening package, we offered women both genital and anorectal testing. Findings contribute to existing evidence for the acceptance and yield of comprehensive home-collection test kits combined with SMS reminders on the retesting of CT positives as compared to CT negatives. Moreover, we further investigated test acceptance and yield in their social and sexual networks.

\section{Patients and Methods}

\section{Study design}

We used a controlled observational study design to assess the impact of SMS reminder systems and home-based CT genital and anorectal testing in young heterosexual individuals who had previously (1) screened CT negative or (2) CT positive, called indices, and (3) their social and sexual networks, called peers. The study was approved by the Psychology Research Ethics Board of Maastricht University, ECP-05-09-2012, who waived the need for the active consent of participants. The study was further approved by the Medical Ethical Committee of the University 
of Maastricht (METC 11-4-108), by using retrospective data originating from standard care (in which one can opt-out for the use of one's data for scientific research), and by analysing the data anonymously.

\section{Study population and procedures}

The study population was selected from clients attending the STI clinics of the Limburg Public Health Service, which provides approximately 6500 STI consultations annually, offering free examination and treatment. At these outpatient clinics, men who only had sex with women were screened for CT on genital sites only, and women were also screened anorectally on indication of anal sex and/ or symptoms and/or belonging to a high-risk group. The specimens tested consisted of self-collected vaginal swabs or urine (men), and anorectal swabs, and were processed at using nucleic acid amplification assays (NAATs) (PCR, Cobas 4800, Roche, California, USA). For each attendee, contact details (including mobile phone number), age, gender, and sexual orientation were registered.

Based on this registry, we selected the most recent test in 2013 from all 4414 unique clinic attendees (indices) who had been screened for CT, were heterosexual, and between 16 and 30 years of age (Fig 1). For the screened CT positive indices, we included those who had a valid mobile phone number registered. As a comparison group, we selected clients who had tested negative on their last CT test, who had reported having three or more partners in the past six months, who had not had a previous positive test in 2013, who did not object to using SMS for communication with the STI clinic, and who had a valid mobile phone number. From this remaining group, a random selection of $\mathrm{CT}$ negative indices was made to match the $\mathrm{CT}$ positive group in terms of number of males and females, and number of people aged 16-22 and 23-30 years (based on the median age of the CT positives).

The 536 CT positive indices and the 536 CT negative age- and sex-matched indices were sent an SMS containing an invitation to retest by offering a free home-collection CT test kit upon request. The text messages were sent in the period April-July 2014, which was three to 20 months after initial screening. Individuals invited to retest could respond directly, by SMS, or by email lusing a smart phone), to provide their contact details so that the test kit could be send to them. If no test was requested following the initial invitation, two extra SMS reminders were sent lafter two and four weeks) with a test invitation. When a person requested a test, the test kit was sent within two working days in an unmarked envelope with clear instructions for use. For men, the test kit consisted of a urine sampling kit. For women, the test kit contained a vaginal swab and an anorectal swab. It also contained a pre-paid return envelope addressed to the local laboratory responsible for routine NAAT testing. All men and women who requested a test kit for themselves (i.e. the index) were also sent a test-kit for a friend or sex partner (peer). The test 
kit for a peer was a separately marked unisex test kit comprising of a urine sampling kit for men, and a vaginal and an anorectal swab for women, also with a prepaid return envelope for testing.

A short questionnaire was also included in the index and peer packages, to be filled in and returned together with the samples. The questionnaire included questions about e.g. sex, date of birth, nationality, intention to give the extra test to a peer (for indices), or who gave them the extra test (for peers). In cases where the test of the index participant was not returned, up to four SMS reminders to return the kit were sent (after two, four, six and eight weeks). Study follow-up to return test kits ended six months after the first SMS invitation was sent. Upon return, the specimens were tested and the test results were communicated via telephone in case of a positive test result and via SMS in case of a negative test result. All CT positives then visited the STI clinic or their general practitioner where they received treatment.

\section{Statistical analyses}

The outcomes investigated: were the proportion of test requests among invited indices, samples returned for testing among both invited indices and among indices who requested a test, positivity among tested indices, and tested peers among indices who requested a test. The outcomes in tested peers further included CT positivity. Proportions were calculated for those who only received an initial invitation SMS and also for those who received extra reminders via SMS. Univariate and multivariate logistic regression were used to identify factors associated with the outcomes (except for the outcome peer positivity, due to low numbers for this outcome). The main focus of interest was the index group, i.e. those who had initially screened CT positive or CT negative. Other factors examined included: nationality (Dutch or non-Dutch), age (22 and $>22$ years), sex of the index, and time elapsed between index initial screening and the SMS invitation to retest (3-12 months and 13-20 months). For the outcomes associated with peer testing, additional factors evaluated included index testing, test result, and intention to pass on a test kit to a peer. A p-value of $<0.05$ was considered statistically significant. Analyses were performed using the SPSS package version 20 (IBM Inc. Somers, New York, USA).

\section{Results}

The study population comprised 536 CT positive and 536 CT negative young heterosexual individuals who were invited by SMS for retesting via a free home-collection test kit for genital CT and, for women, an additional test kit for anorectal CT (Fig 1). The test kit also contained a unisex test kit for a peer (friend/sex partner). The two groups invited for retest were similar regarding sex (women: $57.5 \%$ of negatives and $57.3 \%$ of positives), age (both median age 22 , 
interquartile range 20-24 years), and nationality (Dutch nationality: $95.5 \%$ of negatives and $97.4 \%$ of positives). The median number of days between initial screening and SMS retest invitation was 349 [IQR: 266-440] days for negatives (55.6\% between 3-12 months) and 287 [IQR: 201-391] days (69.2\% between $3-12$ months) for positive indices ( $p<0.001)$. At initial screening, all CT negatives and $39.0 \%(n=209)$ of CT positives reported having more than 3 partners in the past 6 months, and $61 \%(n=327)$ of CT positives reported having 3 or less sex partners in the last six months.

Figure 1: Flow chart of the selection of the study population

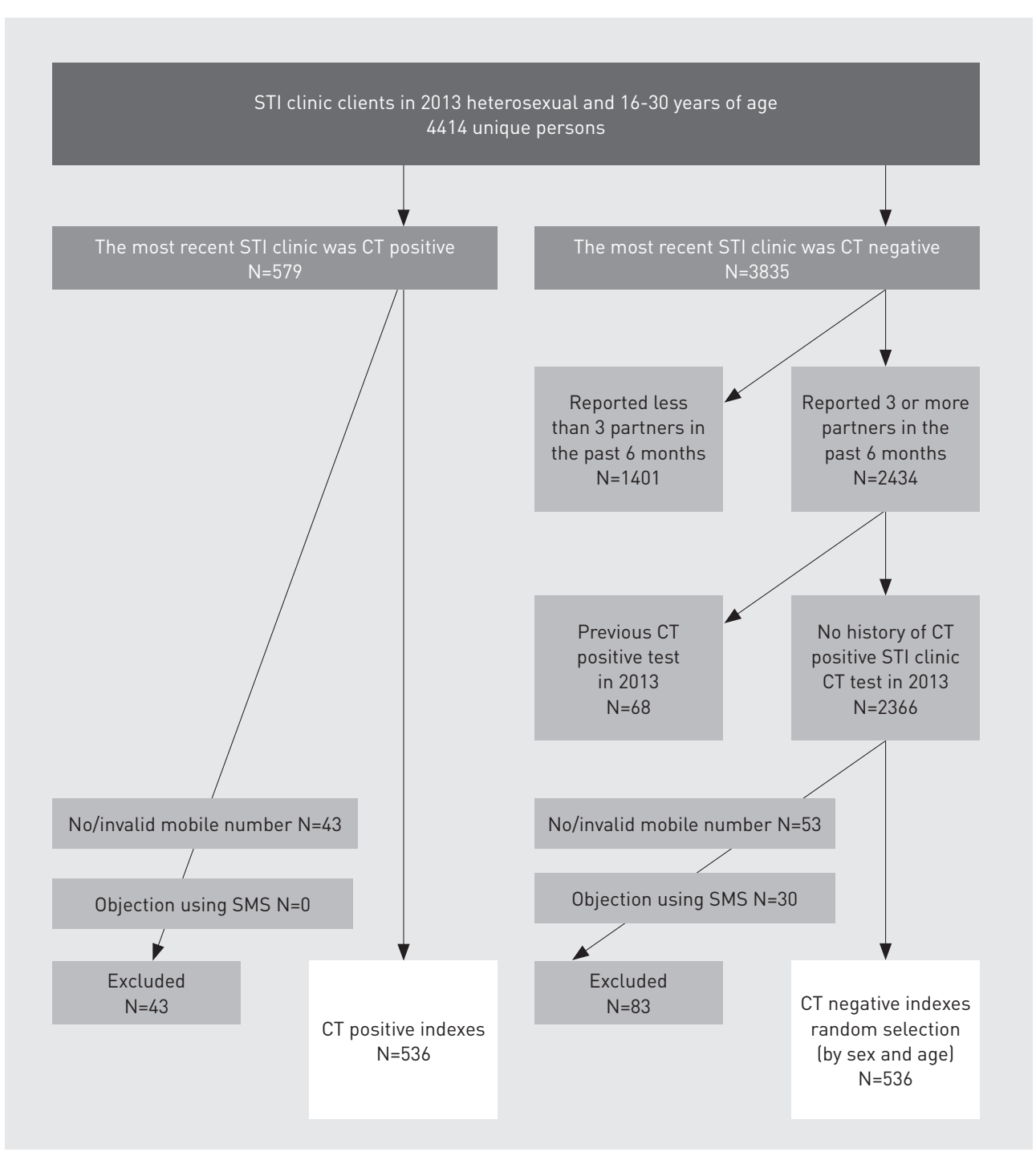


Invitations to retest, reminders, and test requests

In total, 369 (34.4\%) of all invited young people requested a test kit, i.e. $29.2 \%$ of CT negative indices and a significantly higher $39.9 \%$ of positive indices (Table 1 and Fig 2). Other factors found to be independently associated with requesting a test included age lthose in the older age bracket requested more tests) and sex (females requested more tests). Of the people who requested a test, the majority $171.3 \%$ of CT negative individuals and $76.9 \%$ of CT positive individuals) did so after the initial invitation SMS; most within a day. The remainder of those who requested a test responded only after one of the reminder SMS has been sent.

\section{Returning kits for laboratory testing, and reminders}

In total, 206 (55.8\%) of all young people who requested a kit returned it to the laboratory for testing. This proportion was similar between index groups with $54.8 \%$ for CT negatives and $55.6 \%$ for CT positives. The only factor found to be associated with returning the test kit was sex, with females returning significantly more test kits than males (Table 1). Of those who returned the test, about half (50.0\% of CT negative indices and $40.8 \%$ of CT positive indices) returned the test within two weeks. The rest did so after having been sent one or more SMS reminders to return the test kit.

\section{Overall retesting and associated factors}

In total, taking into account all persons invited to retest by SMS, $16.0 \%$ of CT negatives and a significantly higher proportion (22.4\%) of CT positives were retested for CT (Table 1). Other factors independently associated with retesting were sex (with more females retesting than males), and age (with those being in the older age bracket more likely to retest than those in the younger agebracket).

\section{Positivity upon retesting in indices}

In total, 21 indices (10.2\%) tested CT positive upon retesting. Positivity did not differ between CT positive and negative indices, or between other studied factors (such as age and sex) (Table 1). The majority of positives $(71.4 \%, n=15)$ had received extra SMS reminders to request/return the test kit in addition to the initial invitation SMS.

In women, positivity for genital CT was $6.9 \%(10 / 144) ; 86.8 \%$ of these women ( $n=125)$ also tested anorectally, of which $11.2 \%$ (14/125) were anorectal CT positive. Of anorectal cases, $42.9 \%(6 / 14)$ were single infections (i.e. not concurrent with genital CT). For most ( $\mathrm{n}=12$ ) of these anorectal CT positive women, it was the first time they had been anorectally tested. Five of these women with a single anorectal CT were again tested at the STI clinic treatment visit to rule out the possibility that there had been a home-collection sample mix-up and that the genital region was sampled instead of the anorectal region. All these women again tested positive for single anorectal CT. 


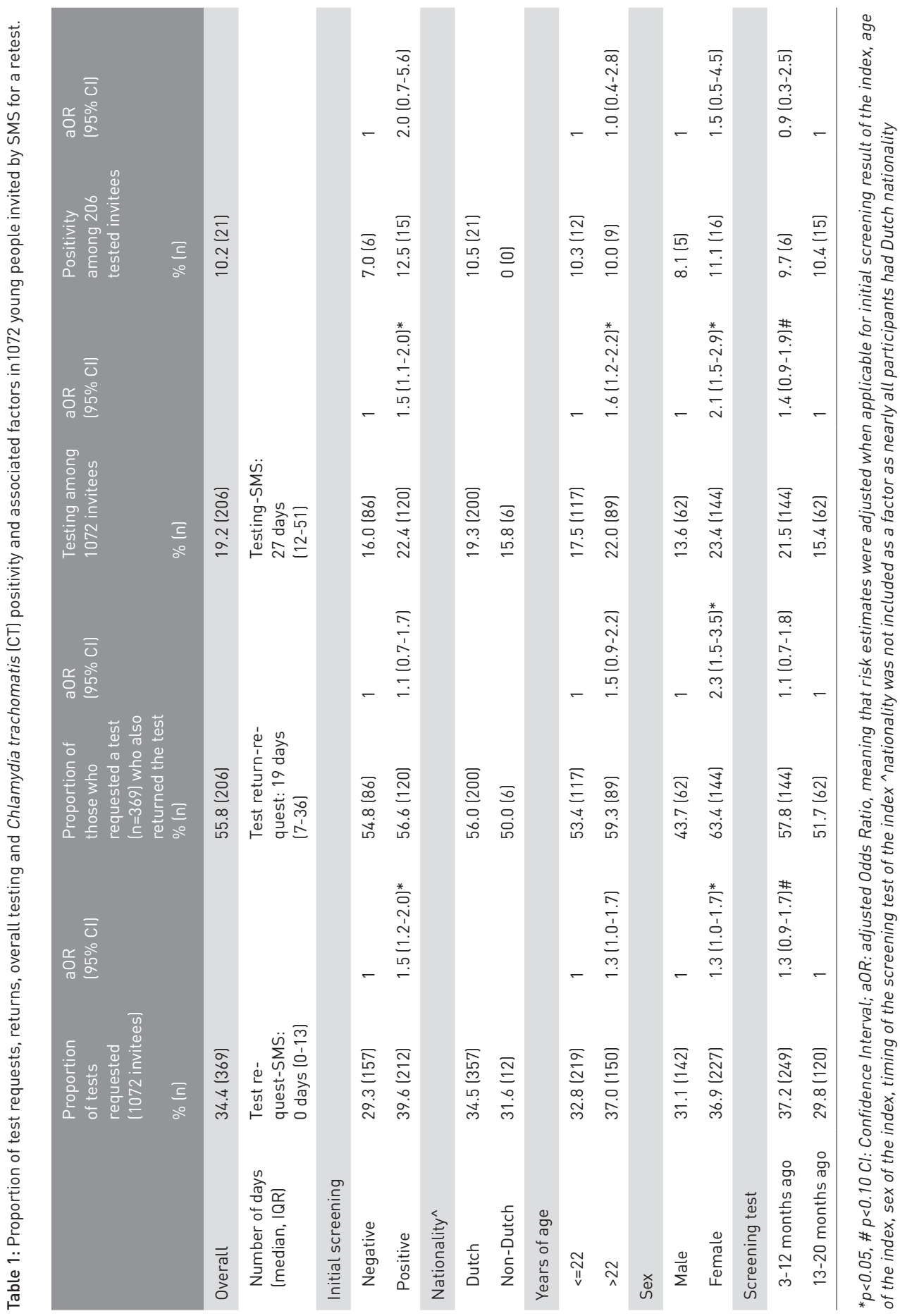


Figure 2: Number of test requests and tests by Chlamydia negative and positive indices.

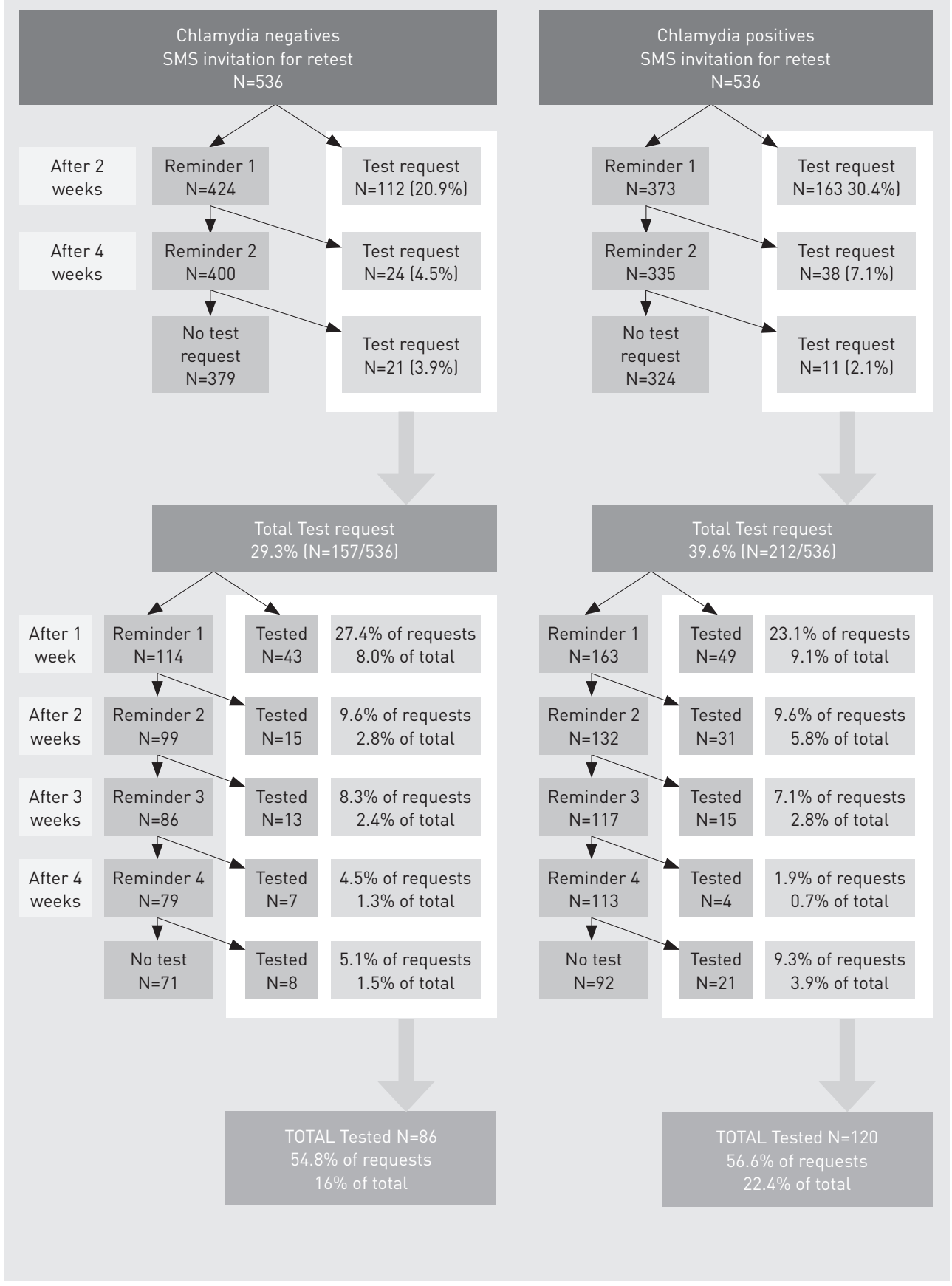




\section{Index-related factors associated with peer testing}

The proportion of peers that tested was similar across the two CT index groups who requested a test for themselves (Table 2). Peer testing was associated with the sex of the index (female indices were more likely than male indices to have a peer tested), whether the index was screened more recently, and whether an index retested. Further, in retested indices, peer testing was higher $(48.2 \% ; 43 / 110)$ for indices who expressed the intention to pass on the extra peer test kit. Peer testing was only $18.8 \%$ when no such intention was reported by the retested index; peer testing was $9.8 \%$ when the index had not retested (Table 2).

Of the 206 indices that retested themselves, $53.4 \%$ ( $n=110 / 206$ ) intended to pass on the extra test kit to a peer; this proportion did not differ between groups defined by indices' sex, age, or time elapsed since initial index screening (data not shown). Among the 110 indices who had the intention to pass on the extra test, $76.4 \%(n=84)$ mentioned that they would pass it on "to a friend' and $23.6 \%$ ( $n=26$ ) indicated that they would pass it on 'to a sex partner'. Intention to pass on 'to a friend' was higher in female indices $(87.0 \%)$ than male indices $(51.5 \%$; $p<0.001)$.

\section{Characteristics of tested peers and peer-index pairs}

Of the total number of 87 peers tested for CT; 62 (71.3\%) peers did so after their index had received a reminder SMS to request and/or return the test kit. About a third of tested peers had never been tested for CT before, and over two-thirds of the peer-index pairs were concordant in their age group, sex, and nationality (Table 3). Most peers received their test from a best friend $(39.1 \%, n=34)$, friend $(42.5 \%, n=37)$, or more distant friend $(4.6 \%, n=4)$, while a smaller number got the test from their steady sex partner $12.6 \%(n=11)$ or regular casual partner (1.1, $\mathrm{n}=1$ ). No one received the test from a casual partner.

Notably, all but one of the tested peers from indices that intended to pass the test on to a friend or did not know yet to whom to pass on the peer test' had indeed received the test from a friend. However, $28.6 \%$ of tested peers from indices that intended to pass on the test 'to a sex partner' reported that they had actually received the test from a friend.

\section{Positivity of the peers and peer-index pairs}

In total, six peers tested positive for CT (6.9\%). Of all six positives (100\%), the index had received an extra reminder SMS to request and/or return the test kit. Three of these positives had never been tested before. Positivity did not significantly differ by initial screening test result of the index or by other studied factors in Chi-square analyses (Table 3). Overall positivity in female peers was $7.7 \%$. Genital positivity in female peers was $5.8 \%(4 / 69)$ and in the $58(84.1 \%)$ women that were also anorectally tested positivity was $6.9 \%$ ( $n=$ four) for anorectal CT; one anorectal CT was a single infection (i.e. not concurrent with genital CT). All positives (one man and five women) got their test from a female friend. 
Table 2: Chlamydia trachomatis (CT) peer testing and associated factors among 369 indices who requested a CT test for themselves and got an extra test for a peer, and positivity among tested peers

\begin{tabular}{|c|c|c|c|}
\hline & $\begin{array}{l}\text { Peer testing } \\
\%(n)\end{array}$ & aOR $(95 \% \mathrm{CI})$ & $\begin{array}{l}\text { Positivity among } \\
87 \text { tested peers } \\
\%(n)\end{array}$ \\
\hline Overall & $23.3(87)$ & & $6.9(6)$ \\
\hline \multicolumn{4}{|l|}{ Initial screening result index } \\
\hline Negative & $23.6(37)$ & 1 & $5.4(2)$ \\
\hline Positive & $23.1(50)$ & $1.0(0.5-1.5)$ & $8.0(4)$ \\
\hline \multicolumn{4}{|l|}{ Nationality index^ } \\
\hline Dutch & $23.8(85)$ & & $7.1(6)$ \\
\hline Non-Dutch & $16.7(2)$ & & $0(0)$ \\
\hline \multicolumn{4}{|l|}{ Age index (years) } \\
\hline $16-22$ & $22.8(50)$ & 1 & $10.0(5)$ \\
\hline $22-30$ & 24.7 (37) & $1.2(0.7-2.0)$ & $2.7(1)$ \\
\hline \multicolumn{4}{|l|}{ Sex index } \\
\hline Male & $14.8(21)$ & 1 & $0(0)$ \\
\hline Female & $29.1(66)$ & $1.8(1.0-3.3)^{*}$ & $9.1(6)$ \\
\hline \multicolumn{4}{|l|}{ Screening test index } \\
\hline 3-12 months ago & $27.3(68)$ & $1.9(1.0-3.5)^{*}$ & $7.4(5)$ \\
\hline $13-20$ months ago & $15.8(19)$ & 1 & $5.3(1)$ \\
\hline \multicolumn{4}{|l|}{ Index re-tested } \\
\hline No & $9.8(16)$ & 1 & $6.3(1)$ \\
\hline Yes & $34.5(71)$ & $4.3(2.4-7.9)^{*}$ & $7.0(5)$ \\
\hline \multicolumn{4}{|l|}{ Among 206 tested indices } \\
\hline \multicolumn{4}{|l|}{ Index re-test result } \\
\hline Negative & $34.1(63)$ & 1 & $6.3(4)$ \\
\hline Positive & $38.1(8)$ & $1.1(0.4-3.1)$ & $12.5(1)$ \\
\hline \multicolumn{4}{|c|}{ Intention of index to pass on the peer test \# } \\
\hline Don't know yet & $18.8(16)$ & 1 & $0(0)$ \\
\hline Yes to social network member & $47.6(40)$ & $3.7(1.9-7.3)^{*}$ & $10.3(4)$ \\
\hline Yes to sexual network member & $57.7(15)$ & $6.9(2.5-19.2)^{*}$ & $7.1(1)$ \\
\hline
\end{tabular}

${ }^{*} p<0.05 \mathrm{Cl}$ : Confidence Interval; aOR: adjusted Odds Ratio, meaning that risk estimates were adjusted when applicable for initial screening result of the index, years of age of the index, sex of the index, timing of the screening test of the index, and whether the index retested. 'Nationality was not included as a factor as nearly all participants had Dutch nationality 
Table 3: Characteristics and positivity of 87 tested peers, concordance with the 87 indices that gave them the test

\begin{tabular}{|c|c|c|}
\hline & $\%(n)$ & $\begin{array}{l}\text { Positivity in tested peers } \\
\%^{\wedge}(\text { n) }\end{array}$ \\
\hline \multicolumn{3}{|l|}{ Peer age (years) } \\
\hline $16-21$ years & $32.2(28)$ & $7.1(2)$ \\
\hline 22-34 years & 67.8 (59) & $6.8(4)$ \\
\hline \multicolumn{3}{|l|}{ Peer-index pairs: concordance age } \\
\hline Both age $<=22$ years & $27.6(24)$ & $8.3(2)$ \\
\hline Both age $>22$ years & 37.9 (33) & $3.0(1)$ \\
\hline Discordant age & $34.56(30)$ & $10.0(3)$ \\
\hline \multicolumn{3}{|l|}{ Peer sex } \\
\hline Female sex & 78.3 (69) & $7.2(5)$ \\
\hline Male sex & $20.7(18)$ & $5.6(1)$ \\
\hline \multicolumn{3}{|l|}{ Peer-index pairs: concordance sex } \\
\hline Both female sex (friends) & $64.4(56)$ & $8.9(5)$ \\
\hline Both male sex (friends) & $6.9(6)$ & $0(0)$ \\
\hline Discordant sex (friends) & $12.6(11)$ & $9.1(1)$ \\
\hline Discordant sex (sex partners) & $16.1(14)$ & $0(0)$ \\
\hline \multicolumn{3}{|l|}{ Peer nationality } \\
\hline Dutch nationality & $90.8(79)$ & $7.6(6)$ \\
\hline Non-Dutch nationality & $9.2(8)$ & $0(0)$ \\
\hline \multicolumn{3}{|c|}{ Peer-index pairs: concordance nationality } \\
\hline Both have Dutch nationality & $88.5(77)$ & $7.8(6)$ \\
\hline Both have non-Dutch nationality & $1.1(1)$ & $0(0)$ \\
\hline Discordant nationality & $10.3(9)$ & $0(0)$ \\
\hline \multicolumn{3}{|l|}{ Peer history of CT testing } \\
\hline Never tested & $31.0(27)$ & $11.1(3)$ \\
\hline Previously tested & $69.0(60)$ & $5.0(3)$ \\
\hline
\end{tabular}

^ percentages were calculated excluding missing information for 18 indices that did not provide information as they were untested 


\section{Discussion}

To increase Chlamydia trachomatis testing in young heterosexual people at risk for CT, we combined several promising care methods including home-collection test kits for anorectal and genital CT testing, active recall by SMS technology, reminder systems, and peer-led testing. Home-collection testing following SMS invitation was moderately accepted, and rates of homecollection testing were higher in previously tested CT positives $(22 \%)$ than CT negatives (16\%). Peer-led testing was similar (23\%) across positive and negative indices, and as a result of implementing our system, several never-tested high-risk peers were reached. Acceptance and yield of anorectal CT testing in women-also outside the care setting-was high. Current standard care may well benefit from implementing and integrating these different components to existing CT control strategies.

Individuals with a previous CT diagnosis and those reporting behavioural risk le.g. a high number of partners, three or more partners in the current study) are well known risk groups for CT, and are specifically targeted in current testing guidelines [1,2]. Acceptance of CT retesting via home-collection test kits was highest in CT positive indices. Prior CT positives are considered more likely to be motivated to get rescreened [43]. Still, test return rates and peer testing rates were similar in CT positive indices as compared to high-risk CT negative indices. Notably, in CT positive indices, the number of partners reported at the time of initial screening was not associated with subsequent test requests, test returns or peer testing. Nevertheless, CT negative indices had a lower acceptance of home-collection testing and about half the number of new CT positive diagnoses as compared to positive indices. Thereby the impact of SMS invitations on reaching hidden CT positives is lowest in CT negative indices, despite them reporting having more than three partners.

Overall, the test rate can be considered moderate when compared with other studies that have used active recall or home-collection testing, with testing rates in these studies ranging from 3-48\% [11]. It should be noted that direct comparisons are difficult to make, as retest rates differ by sex, age and the approach taken. A comparison with historical data in the period 2006-2010 from our own clinic (a period when no active recall strategies were applied) showed in CT positive indices higher retesting rates (33\% versus $22 \%$ in the present study), and positivity rates (19\% versus $13 \%$ in the present study) [27]. Still, a thorough comparison is difficult to make, as rates may also be influenced by other factors potentially associated with retesting, such as time (e.g. testing policy), and sexual orientation (the current study only includes heterosexual individuals). It is unknown to what extent retesting rates were underestimated in the current study, as a proportion of patients may have undergone screening of their own volition, either at our clinic or at other health services. Previous studies have demonstrated a lower positivity rate 
in those who retest following active recall as compared to retesting without active recall, and it has been suggested that interventions to encourage rescreening may (also) reach patients at lower risk of re-infection [11].

People at risk for CT also include the sexual and social networks surrounding a person at risk, and these networks were effectively targeted in the current study. It is encouraging to note that young people who requested a test for themselves (following the offer of a home-collection test kit by SMS) were also quite often willing to pass on an extra test to their peers. This peer test was sent to all indices who requested a test for themselves (indices did not actively request an extra peer test). While the index's test result did not seem to influence peer testing, peer test- ing was associated with the index's own testing (35\% of peers tested when the index was tested). It was also associated with the intention of the tested index to pass on the test to a peer (peer testing was $46 \%$ when the intended peer was a friend, and $54 \%$ when the intended peer was a sex partner). Our study therefore demonstrates the potential these methods show in terms of reaching social and sexual peers for testing, confirming the findings of earlier studies $[33,38]$. Strikingly, most $(84 \%)$ of the tested peers were friends rather than sex partners, and CT positivity was highest among these peer friends (8\%). Even when indices intended to pass on the peer test to a sex partner, a quarter of their tested peers turned out to be friends, showing that indices tended to switch from the intended sexual to social peer type but not vice versa. Bearing in mind that a third of peers had never been tested before, peer-led CT testing appears to be a valuable tool that can be used to reach hidden young people at risk for $\mathrm{CT}$, especially in the social networks. This highly promising method could be incorporated into existing CT testing strategies. Actual peer-testing may have been even higher, as we were unable to determine how many of the kits provided to indices were not passed on to peers. Also we have not assessed what the reasons behind (not) passing on tests or (not) retesting might be. An accompanying publicity campaign about the kits could potentially increase both awareness and use of the kits by peers [39]. The rate of kit use might also be increased if different options for requesting (e.g. via SMS, internet, telephone and pick up from the clinic) and returning (e.g. dropping off at the clinic) the test kits were available, depending on the diverse needs and preferences of different risk groups, as suggested by Smith et al [44].

In line with the literature, women were more likely than men to be retested using homecol- lection test kits $[15,21]$ or have their peers tested $[33,38,39]$. In another study, women felt able to discuss home-collection CT testing among their close friends, whereas males experienced embarrassment and difficulty discussing and sharing home-collection testing amongst their social network members [33]. In the current study, as many as 22 of the (in total) 27 CT positive diagnoses originated from female indices. Although test acceptance in men is generally lower, it is notable that the intention to pass on the extra test to a peer was similar in tested male 
and female indices. Also, peer testing rates were similar for retested male indexes (38\%) and for retested female indices (27\%) (data not shown). Still most of the tested peers were women. It is unknown why male peers are less frequently tested. It may be that indexes are less likely to pass on their test to a male peer, or it may be that male peers do receive a kit but for some reason do not test. More research is needed to understand these reasons for not testing and to improve care strategies targeted at men. Other methods evaluated in the current study include the use of extra SMS reminders, which were shown to positively influence the numbers of tests and diagnoses made, in line with previous findings [14]. In general, SMS is cheap, can be largely automated, but still allows prompt and personal communication. Our experience was that in several cases, invitees phoned back to check for confidentiality and to ensure that the invitation was 'real and reliable'. We recommend having a nurse available to answer such calls, whereas the SMS process itself can be fully automated. Importantly, this is the first time that acceptance of anorectal CT testing in women has been demonstrated outside the care set- ting [40-42]. In line with studies investigating women attending STI clinics, anorectal CT positivity in women outside the clinic setting is at least as high as genital CT positivity. While anorectal infections are largely concurrent with genital CT, they also do occur as single infections [40-42].

Although different aspects of our methodology were shown to be successful, there is room for improvement in terms of how they are implemented. For example, the loss of test kits that were sent out but not returned is a waste of resources. In our current routine care, we no longer immediately send out the extra peer test, but only do so after the index has expressed his or her intention to pass on the peer test kit. To decrease loss of test kits and improve return rates, we also added a fifth and sixth SMS reminder. It should be noted that the test return rate of the indices is in line with the overall return rate in a systematic review of studies that also used home-collection test kits for the active recall and retesting of Ct positives [21].

Our study also has several limitations. The first is that we did not have a randomized control group who received standard care only. Consequently we do not know whether our combined approach using SMS and home-based testing is more effective than an approach with no active recall. The second limitation is that, as mentioned above, all participating indices were pro- vided with an extra test kit to pass to a peer without first ascertaining their willingness to do so. Had these extra test kits for peers only been provided to indices who indicated that they were willing to pass on an extra test kit to a peer, return rates might well have been higher.

In conclusion, acceptance of a relatively low cost, feasible strategy for genital and anorectal CT retesting-i.e. using SMS technology, reminder systems and home-collection test kits-is higher in previously CT positive than negative indices. Those who retest are willing to provide tests to their sex partners, and especially friends. By including this peer-led testing component, un- 
detected CT positives can be identified in the social networks surrounding a high-risk individual. However, patients at risk for CT may choose different ways in which to test and it is important for programs to provide different options offering integrated CT control strategies. 


\section{References}

1. Torrone E, Papp J, Weinstock H; Centers for Disease Control and Prevention (CDC). Prevalence of Chlamydia trachomatis genital infection among persons aged 14-39 years-United States, 2007-2012. MMWR Morb Mortal Wkly Rep. 2014 Sep 26; 63(38):834-8. PMID: 25254560.

2. European Centre for Disease Prevention and Control. Chlamydia control in Europe: literature review. Stockholm ECDC. 2014. Available: http://ecdc.europa.eu/en/publications/ Publications/chlamydia- controleurope.pdf.

3. Senior K: Chlamydia: a much underestimated STI. The Lancet 2012, 12: $517-518$

4. Newby KV, Wallace LM, French DP. How do young adults perceive the risk of chlamydia infection? A qualitative study. Br J Health Psychol. 2012 Feb; 17(1):144-54. doi: 10.1111/j.20448287.2011.02027. x Epub 2011 May 5 PMID: 22233107

5. Centers for Disease Control and Prevention. Summary of a review of the literature: Programs to Pro- mote Chlamydia Screening. Available: http:// www.cdc.gov/STI/HealthComm/ ChlamydiaLitReview2008.pdf

6. Pavlin NL, Gunn JM, Parker R, Fairley $\mathrm{CK}$, Hocking J. Implementing chlamydia screening: what do women think? A systematic review of the literature. BMC Public Health 2006, 6:221-231.
7. Tilson EC, Sanchez V, Ford CL, Smurzynski M, Leone PA, Fox KK, et al. Barriers to asymptomatic screening and other STD services for adolescents and young adults: Focus group discussions. BMC Public Health 2004, 21(4): 1-8

8. Blake D, Kearney M, Oakes JM, Druker S, Bibace R. Improving participation in chlamydia screening programs: Perspectives of high-risk youth. Arch Pediatr Adolesc Med 2003, 157:523-529

9. Farley TA, Cohen DA, Elkins W. Asymptomatic sexually transmitted disease: The case for screening. Preventive Medicine 2003 36(4), 502-509.

10. Cunningham $S H$, Kerrigan $D L$, Jennings JM, Ellen JM. Relationships Between Perceived STD-Related Stigma, STD-Related Shame and STD Screening Among a Household Sample of Adolescents. Per- spect Sex Repord Health 2009, 41:225-230

11. Guy R, Hocking J, Low N, Ali H, Bauer HM, Walker J, et al. Interventions to increase rescreening for repeat chlamydial infection. Sex Transm Dis. 2012 Feb; 39(2):136-46. doi: 10.1097/ OLQ. Ob013e31823ed4ec Review. PMID: 22249303

12. Jamil MS, Hocking JS, Bauer HM, Ali $\mathrm{H}$, Wand $\mathrm{H}$, Smith $\mathrm{K}$, et al. Home-based chlamydia and gonorrhoea screening: a systematic review of strategies and outcomes. BMC Public Health. 2013 
Mar 4; 13:189. doi: 10.1186/1471-245813-189 PMID: 23496833

13. Odesanmi TY, Wasti SP, Odesanmi OS, Adegbola 0, Oguntuase 00, Mahmood S. Comparative effectiveness and acceptability of home-based and clinic-based sampling methods for sexually transmissible infections screening in females aged $14-50$ years: a systematic review and meta-analysis. Sex Health. 2013 Dec; 10(6):559-69. doi: 10.1071/SH13029 PMID: 24160747

14. Dokkum NF, Koekenbier RH, van den Broek IV, van Bergen JE, Brouwers EE, Fennema JS, et al. Keeping participants on board: increasing uptake by automated respondent reminders in an Internet- based chlamydia screening in the Netherlands. BMC Public Health. 2012 Mar 9; 12:176. doi: 10.1186/14712458-12-176 PMID: 22404911

15. Gotz HM, Wolfers MEG, Luijendijk A, van den Broek IVF. Retesting for genital Chlamydia trachomatis among visitors of a sexually transmitted infections clinic: randomized intervention trial of home- versus clinic-based recall. BMC Infect Dis. 2013; 13: 239. Published online May 24, 2013. doi: 10.1186/14712334-13-239 PMCID: PMC3666896

PMID: 23705624

16. Doshi JS, Power J, Allen E. Acceptability of chlamydia screening using self-taken vaginal swabs. Int J STD AIDS. 2008 Aug; 19(8):507-9. doi: 10.1258/ijsa.2008.008056 PMID: 18663033
17. van der Helm JJ, Hoebe CJ, van Rooijen MS, Brouwers EE, Fennema HS, Thiesbrummel HF, et al. High performance and acceptability of self-collected rectal swabs for diagnosis of Chlamydia trachomatis and Neisseria gonorrhoeae in men who have sex with men and women. Sex Transm Dis. 2009 Aug;36(8):493-7. doi: 10.1097/ OLQ.0b013e3181a44b8c PMID: 19617869

18. Hoebe CJ, Rademaker CW, Brouwers $E E$, ter Waarbeek HL, van Bergen JE. Acceptability of self-taken vaginal swabs and first-catch urine samples for the diagnosis of urogenital Chlamydia trachomatis and Neisseria gonorrhoeae with an amplified DNA assay in young women attending a public health sexually transmitted disease clinic. Sex Transm Dis. 2006 Aug; 33(8):491-5. PMID: 16547452

19. Masek BJ, Arora N, Quinn N, Aumakhan B, Holden J, Hardick A, et al. Performance of three nucleic acid amplification tests for detection of Chlamydia trachomatis and Neisseria gonorrhoeae by use of self-collected vaginal swabs obtained via an Internetbased screening program. J Clin Microbiol. 2009 Jun; 47(6):1663-7. doi: 10.1128/JCM.02387-08 Epub 2009 Apr 22. PMID: 19386838

20. Guy R, Wand H, Knight V, Kenigsberg A, Read P, McNulty A. SMS reminders improve re-screening in women and 
heterosexual men with chlamydia infection at Sydney Sexual Health Centre: a before-and- after study. Sex Transm Infect 2013; 89:11-15. doi: 10.1136/sextrans-2011-050370 PMID: 22517890

21. Desai M, Woodhall SC, Nardone A, Burns F, Mercey D, Gilson R. Active recall to increase HIV and STI testing: a systematic review. Sex Transm Infect. 2015 Mar 10. pii: sextrans-2014-051930. doi: 10.1136/ sextrans-2014-051930 [Epub ahead of print] Review.

22. Lunny C, Taylor D, Memetovic J, Wärje O, Lester R, Wong $T$, et al. Short message service (SMS) inter-ventions for the prevention and treatment of sexually transmitted infections: a systematic review protocol. Syst Rev. 2014 Jan 16; 3:7. doi: 10.1186/20464053-3-7 Review. PMID: 24433348

23. Kegg S, Natha M, Lau R. Communication with patients: Are e-mail and text messaging the answer? Int J STD AIDS 2004; 15(46).

24. Downing SG, Cashman C, McNamee H, Penney D, Russell DB, Hellard ME. Increasing chlamydia test of reinfection rates using SMS reminders and incentives. Sex Transm Infect.2013; 89(1):16-19. Doi:10.1136/sextrans-2011-050454 PMID: 22728911

25. Burton J, Brook G, McSorley J, Murphy $\mathrm{S}$. The utility of short message service (SMS) texts to remind patients at higher risk of STIs and HIV to reattend for testing: a controlled before and after study. Sex Transm Infect.2014 Feb; 90(1):11-3. doi: 10.1136/ sextrans-2013-051228 Epub 2013 Sep 24 PMID:24064987

26. Hosenfeld CB, Workowski KA, Berman S, Zaidi A, Dyson J, Mosure D, et al. Repeat infection with Chlamydia and gonorrhea among females: a systematic review of the literature. Sex Transm Dis 2009;36:478-89. doi: 10.1097/ OLQ.0b013e3181a2a933 PMID: 19617871

27. Dukers-Muijrers NH, van Liere GA, Hoebe CJ. Re-screening Chlamydia trachomatis positive subjects: a comparison of practices between an STI clinic, general practitioners and gynaecologists. Sex Transm Infect 2013; 89(1):25-27. doi: 10.1136/sextrans-2011-050467 PMID: 22941863

28. Guy R, Wand H, Franklin N, Fairley CK, Chen MY, O'Connor CC, et al. Re-testing for chlamydia at sexual health services in Australia, 2004-2008. Sex Health 2011; 8:242-247 doi: 10.1071/SH10086PMID: 21592440

29. Youm Y, Laumann EO. Social Network Effects on the Transmission of STI. Sex Trans Dis 2002, 689-697

30. Busse P, Fishbein M, Bleakley A, Hennessy $M$. The role of communication with friends in sexual intention. Com Res 2010, 37(2):239-255 
31. Kotchick BA, Schaffer A, Forehand R, Miller KS. Adolescent sexual risk behavior: a multi-system per- spective. Clinical Psych Rev 2001, 21(4): 493-519

32. Balfe M, Brugha R. Disclosure of STI testing activities by young adults: the influence of emotions and social networks. Social Health Illn 2010, 32:1041-1058

33. Loaring J, Hickman M, Oliver I, Campbell R, Trotter C, Macleod J, et al. Could a peer-led intervention increase uptake of chlamydia screening? A proof of principle pilot study. J Fam Plann Reprod Health Care 2013, 39:21-28

34. Theunissen KATM, Hoebe CJPA, Crutzen R, Kara-Zaïtri C, de Vries NK, van Bergen JEAM, et al. Using inter-vention mapping for the development of a targeted secure web-based outreach strategy named SafeFriend, for Chlamydia trachomatis testing in young people at risk. BMC Public Health 2013,13:996. doi: 10.1186/14712458-13-996 PMID: 24148656

35. Götz HM, van Rooijen MS, Vriens P, Op de Coul E, Hamers M, Heijman T, et al. Initial evaluation of use of an online partner notification tool for STI, called 'suggest a test': a cross sectional pilot study. Sex Transm Infect.2014: 90(3):195-200. doi: 10.1136/sextrans-2013-051254

36. Gaydos CA, Barnes M, Jett-Goheen M, Quinn N, Whittle P, Hogan T, et al. Characteristics and predictors of women who obtain rescreening for sexually transmitted infections using the www.iwantthekit.org screening programme. Int J STD AIDS. 2013 Sep; 24(9):736-44. doi: 10.1177/0956462413483252 Epub 2013 Jul 15 PMID: 23970594

37. Bilardi JE, Fairley CK, Hopkins CA, Hocking JS, Sze JK, Chen MY. Let Them Know: evaluation of an online partner notification service for chlamydia that offers E-mail and SMS messaging. Sex Transm Dis. 2010 Sep; 37(9):563-5. doi: 10.1097/OLQ.0b013e3181d707f1 PMID: 20351621

38. Østergaard L, Andersen B, Møller JK, Olesen F, Worm AM. Managing partners of people diagnosed with Chlamydia trachomatis: a comparison of two partner testing methods. Sex Transm Infect 2003;79:358-362 PMID: 14573827

39. Rose SB, Lawton BA, Bromhead C, MacDonald EJ, Elley CR. Poor uptake of self-sample collection kits for Chlamydia testing outside primary care. Aust N Z J Public Health. 2010 Oct; 34(5):517-20. doi: 10.1111/j.17536405.2010.00600.x PMID: 21040182

40. van Liere GA, Hoebe CJ, Wolffs PF, Dukers-Muijrers NH. High co-occurrence of anorectal chlamydia with urogenital chlamydia in women visiting an STI clinic revealed by routine universal testing in an observational study; a recommendation towards a better anorectal chlamydia control in 
women. BMC Infect Dis. 2014 May 19;

14:274. doi: 10.1186/1471-2334-14-274

PMID: 24885306

41. Peters RP, Dubbink JH, van der Eem L, Verweij SP, Bos ML, Ouburg S, et al.

Cross-sectional study of genital, rectal, and pharyngeal Chlamydia and gonorrhea in women in rural South Africa. Sex Transm Dis. 2014 Sep;

41(9):564-9. doi: 10.1097/ OLQ.0000000000000175 PMID: 25118973

42. Trebach JD, Chaulk CP, Page KR, Tuddenham S, Ghanem KG.

Neisseria gonorrhoeae and Chlamydia trachomatis Among Women Reporting Extragenital Exposures. Sex Transm Dis. 2015 May; 42(5):233-9. doi: 10.1097/OLQ.0000000000000248 PMID: 25868133

43. Gotz HM, Veldhuijzen IK, van Bergen JE, Hoebe CJ, de Zwart O, Richardus JH, et al. Acceptability and consequences of screening for chlamydia trachomatis by home-based urine testing. Sex Transm Dis 2005; 32:557-62 PMID: 16118604

44. Smith KS, Hocking JS, Chen M, Fairley CK, McNulty A, Read P, et al. Rationale and design of REACT: a randomised controlled trial assessing the effectiveness of home-collection to increase chlamydia retesting and detect repeat positive tests. BMC Infect Dis. 2014 Apr 24; 14:223. doi: 10.1186/1471-233414-223 PMID: 24758169 


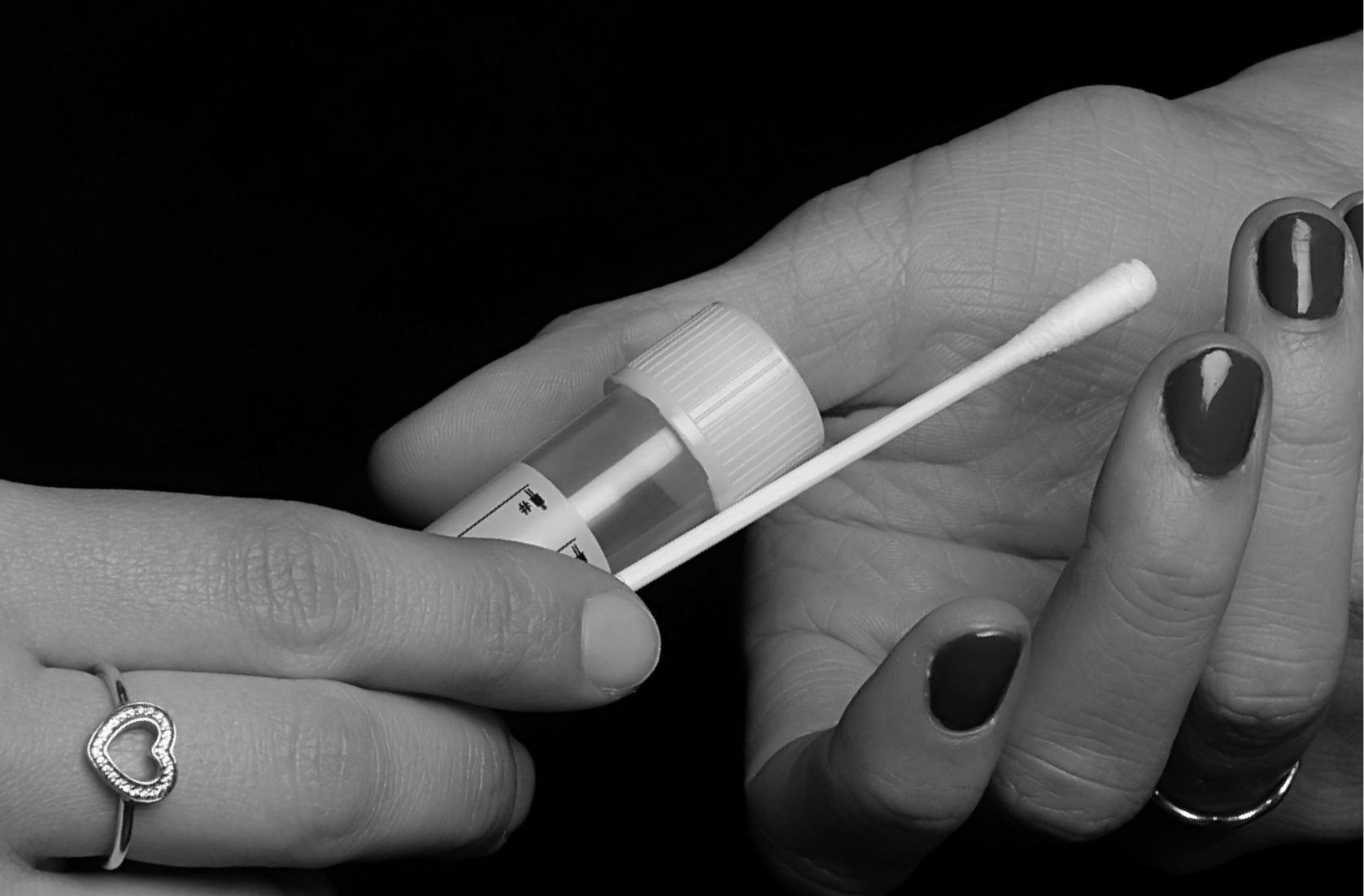




$$
\text { Chapter } 7
$$

General discussion 
Chlamydia trachomatis (CT) is the most frequently diagnosed bacterial sexual transmitted infection (STI) among young people and numbers are still increasing. Despite standard sexual health care and additional testing strategies such as population-based testing many young people with CT are hidden to standard health care since the majority may not experience symptoms and underestimate their own risk, preventing them from getting tested. New testing strategies need to be developed to improve access beyond standard care and increase testing among hidden young people; those sexual active who never tested before. Peer-driven testing was found promising in finding hidden infections, because of the scientific evidence of high STI prevalence in social and sexual networks surrounding STI positive people $[1,2]$

In this thesis we evaluated peer-driven CT testing strategies for young people to recruit social and sexual networks using home sampling test kits. The main aim was to determine the value of peer-driven testing in terms of number of recruited peers, number of hidden peers (who had never been tested beforel and number of CT infections.

In this general discussion we will first focus on the added value of introducing peer-driven CT testing in social and sexual networks. Second, we discuss the value of web-based RDS, a form of peer-driven testing. Third, we evaluate the role of sexual health care professionals in peerdriven testing. Fourth, we discuss the role of stigma in peer-driven testing. At last recommendations are given for sexual health care practice and future research.

\section{Value of peer-driven testing in social networks}

Friends potentially influence each other's behaviours and attitudes regarding testing. Information and cultural norms are shared and social networks create opportunities to meet new sex partners and could thereby overlap with sexual networks [3]. Therefore, young people who show risky behaviour and/or are CT positive will have others in their networks that are similar in behaviour and are therefore at risk for CT. Recruitment within social networks has already been successful in finding hidden cases of HIV and Syphilis [1,2]. Surprisingly the value of social network recruitment in CT testing has been studied less and evidence about its use and effectiveness is limited. In this thesis we developed and piloted peer-driven testing strategies that encouraged young people to recruit their peers to test for CT via home sampling test kits. In the first strategy young people recruited their peers via email and offered them the option to request online a home sampling test kit (chapter 3). In the second strategy, young people received a home sampling test kit for retesting and an additional test kit for a peer, after replying to an SMS of the STI clinic. They recruited a peer by providing them in person with a home sampling test kit (chapter 6). 
To find hidden CT infections in social networks recruitment is the first step. In the first strategy $40 \%$ of young people who participated emailed a peer; $89 \%$ were friends compared to $11 \%$ of sex partners. In the second strategy at least $23 \%$ of young people who requested a retest gave the additional test to a peer; $84 \%$ were friends compared to $16 \%$ of sex partners. In the latter strategy, the actual number of peers who received a test may have been higher, as we were unable to determine how many test kits were actually passed on to peers. Also, we did not assess the reasons behind (not) passing on a test kit to a peer or (non) testing among peers.

The recruitment of friends is substantial looking at the recruitment rate in chapter 3 and the number of test kits returned by friends in chapter 6 . Our studies and those of others $[1,4,5]$ show that recruitment of friends via peer-driven testing is feasible. However, the next question would be if we recruit the right persons considering their risk behaviour (CT positivity) and test history (never tested before).

Besides recruitment we also studied CT testing and treatment among friends. In chapter 3, of all returned test kits $50 \%$ were friends of which $75 \%$ never tested before. All tested friends were CT negative. In chapter 6 , of all returned home sampling tests $84 \%$ were friends of which $32 \%$ never tested before (data not presented in this thesis). Among these tested friends $8 \%$ were CT positive and received treatment, $50 \%$ never tested before.

We succeeded in our aim to reach never tested young people. Next to this, positivity in chapter 6 is almost two times higher compared to a large population-based study in three regions of the Netherlands in 2008, which showed an overall prevalence of $4,2 \%$ of CT among 41.638 tested young people aged 15-29 years [6]. This could indicate that we reached young people that were more at risk for acquiring CT than the general population. However we did not study actual sexual risk behaviour and our percentage is lower compared to the Dutch STI clinics $(17 \%$; 2014) [7]. Our studies show that with peer-driven testing it is possible to recruit the right persons to a certain extent. Tested friends showed moderate rates of CT positivity and a substantial part $75 \%$ in chapter 3 and $32 \%$ in chapter 6 was not previously tested and thus hidden to CT care.

Differences in CT positivity can possibly be explained by the perceived susceptibility of young people in combination with the different options of home sampling test kit provision. Perceived susceptibility refers to one's perception of the risk or the chances of contracting CT. In a German survey study among students between 12 and 20 years of age, those who were sexual active generally perceived their own risk of getting infected with HIV/STI as lower than that of their peers [8]. This is called optimistic bias; people generally perceive themselves to be less at risk than others $[8,9]$, particularly when the risk is behaviour related $[8,10]$. When using emails for the provision of home sampling test kits (chapter 3 ) friends have to make their own judgement 
about their CT risk. In a Dutch population-based screening strategy le.g., Chlamydia Screening Implementation program "CSI") among young people between 16 and 29 years of age the provision of home sampling test kits via internet did not readily reach the targeted high-risk young people and lead to low CT positivity $[6,11]$. In chapter 6 , tested young people judged the CT risk of a peer and provided them in person with a direct solution, i.e. a home sampling test kit. In a study among university students direct kit distribution was more effective in student testing engagement than distribution via Internet (indirect) [12].

In conclusion, young people are willing to recruit friends for CT testing via home sampling test kits. Our strategies show the potential value of peer-driven testing in terms of reaching friends who never tested before and undetected CT infections. These CT infections would normally be missed through the conventional partner notification process, where only sexual partners are notified. Finally, because chapter 3 was a feasibility study a comparison between CT positivity in chapter 3 and 6 is hard to make. In chapter 6 the value of direct peer-driven testing in recruiting potentially CT positive friends is good.

\section{Value of peer-driven testing in sexual networks}

The notification of sex partners has been a cornerstone for CT control for more than a decade and aims to control onward transmission among sex partners [13]. To be successful in decreasing transmission and the duration of infectiousness, prompt laboratory testing of sex partners is important [14]. Home sampling test kits are an attractive method for both young males and females to test for CT [15-17]. Compared to the testing of sex partners in a health care setting, the use of home sampling test kits lead to higher number of partners actually getting tested and treated $[14,18]$. In chapter 3 and 6 we studied the value of peer-driven testing in PN using home sampling test kits.

Of all reachable untested sex partners that had not been warned yet, $29 \%$ was recruited via our indirect strategy by $13 \%$ of the CT positive young people in chapter 3 . This finding is comparable with a study in which $14 \%$ of sexual transmitted infection (STI) positive clients used a personal code for online notification of a sex partners [19]. Although the low recruitment of sex partners in our study, all who returned a requested test kit were never tested before and $13 \%(n=1)$ was CT positive. In chapter 6 peer-driven testing was facilitated via the in person provision of home sampling test kits to peers. Of all peers returning a test kit, only $16 \%$ was a sex partner, of which $29 \%$ was never tested before (data not presented in this thesis). All turned out to be CT negative. Similar to friends, the actual number of sex partners who received a test in chapter 6 may have been higher, as we were unable to determine how many test kits were passed on to sex part- 
ners, but did not return for testing. Remarkable is the fact that when participants stated that they intended to pass on the additional test to a sex partner, the tested peer turned out to be a friend in $29 \%$ of the cases. We did not study the reason for doing so.

PN is hampered by several barriers such as stigma and confidentially issues $[20,21]$ and it has been estimated that only $40-60 \%$ of CT positive people notify their partners [22]. In addition, systematic reviews about $\mathrm{PN}$ suggest that no single method is suitable to reach all sex partners therefore recommending the implementation of different notification methods [23,24]. For instance, young people prefer face-to-face notification, especially in steady long-term relationships [22,25], while Internet (email) notification seems more acceptable for causal or anonymous sex partners, [25].

In conclusion, the value of peer-driven testing in sexual networks is moderate considering the recruitment rate (chapter 3 ), the number of returned tests (chapter 6 ) and CT positivity. However, a substantial part of tested peers was not previously tested and thus hidden to health care. We did not study the reasons for non-recruitment or non-provision of test kits in respectively chapter 3 and 6 . It might be that the intimate history a person shares with a sex partner can lead to anticipated negative reactions such as blame, aggression and stigma $[20,25]$. This could withhold young people from disclosing their testing behaviour and the provision of a test kits to a sex partner (chapter 4).

\section{Value of Web-RDS in peer-driven testing}

In chapter 2 Web-RDS was found promising as a method to recruit never tested young people in social and sexual networks surrounding a CT positive for testing. In chapter 3 the pilot implementation of the web-RDS testing strategy showed feasible for targeting young people in social networks and those who never tested before. However, recruitment chains were short and network sizes small. Similar findings were found in a web-based RDS survey among men who have sex with men (MSM) in Sweden to study sexual risk behaviour for HIV/STI [26]. They also found short recruitment chains and small network sizes and concluded that this could be due to technical challenges such as a server break down and recruitment via email instead of SMS. Both technical challenges were also found in our study (chapter 3). Another factor at play is stigma. To avoid stigmatizing reactions, stigma management strategies are applied, such as selective disclosure and encouragement of others to test in only small trusted peer networks (chapter 4). However, stigma cannot be the sole explanation as short recruitment chains were also found in less stigmatized infections such as respiratory infections among non-hidden populations of university students [27]. Attractive monetary incentives were found to be a success factor for 
large recruitment chains in a Web-RDS survey among a hidden population of MSM in Vietnam [28]. In our study only non-monetary incentives were available, i.e., free CT home sampling test kits.

Peer-driven CT testing via web-RDS has the potential to reach especially friends among highrisk young people. However, as recruitment chains are short and networks are small we do not expect more from this methodology. With the inclusion of an SMS function, decreasing technical problems and the use of monetary incentives recruitment may be optimized.

\section{The role of sexual health care professionals in peer-driven testing}

Informing young people about PN during their consultation is one of the core tasks of public sexual health professionals as stated in the national PN guidelines [29]. Although in our study (chapter 5) professionals stated to be comfortable discussing PN, in practice they focus more on the care and treatment of the individual index patient rather than on discussing PN, or on motivating and helping patients to engage in PN. Additionally, professionals experience barriers during the PN process. Some of these barriers could apply to peer-driven testing as well, namely sub-optimal guidelines, a lack of feedback regarding the motivational strategies that were used, and the lack of feedback regarding overall PN effectiveness. Since our study the PN guidelines have been updated and now include a more detailed description of how to implement PN in daily practice [29]. The importance of networks is mentioned, but no directions are given on how to apply the principle of network notification through peer-driven testing. Through visualization of networks (see figure 2 of chapter 3 ) and discussing the result of our peer-driven strategy in chapter 6 professionals were provided with the previously lacking feedback on the effectiveness of their strategies used and the overall notification process. Consequently, professionals in our study stated that they were more aware of the CT risk in networks and emphasised the importance of network recruitment during consultations, i.e. improved commitment (chapter 3).

Factors found in chapter 5 that facilitate PN and that could also apply to peer-driven testing are that professionals felt comfortable with discussing PN and were experienced in motivational interviewing (MI). $\mathrm{MI}$ is a client-centred approach that can be used to change behaviour by helping people to feel confident to perform a particular behaviour according to their needs and abilities [30]. When applied in partner notification training for sexual health care providers $\mathrm{MI}$ has been shown to improve skills and behaviour in dealing with patients' resistance towards PN [31]. When combining MI with peer-driven testing, clients may also be more motivated to recruit their social network beside their sexual network. 


\section{The role of stigma in peer-driven testing}

Anticipated stigma plays an important role among young people in the process of disclosing CT test behaviour and results to peers [21,32]. To avoid stigmatizing reactions, young people therefore use stigma management strategies, such as selective disclosure and selective encouragement of others to test (chapter 4). In our study among CT tested and never tested young people between 16-24 years, participants stated that they only disclosed their testing experience to a small and selective group that provides them with emotional support and empathy. From others they fear stigmatizing reaction. Similar findings have been found in other studies among young adults who tested for STI [21,32]. To decrease anticipated stigma the peer-driven testing strategy in chapter 3 had embedded the option to notify peers anonymous. Still, more than two third of all peers in the study were recruited with personal messages $140 \%$ among sex partners and $78 \%$ among friends).

Despite anticipated stigma sex partners and friends can be reached for testing, due to personal stigma management strategies. Therefore, peer-driven strategies that target friends and sex partners of young people are potentially effective. Yet, their effectiveness could potentially be limited by the small size of trusted networks reached. Nonetheless, others may reach a person outside an individual's trusted network, because he or she may be a trusted friend or sex partner in someone else's network.

\section{Recommendations for sexual health care practice}

With half of all CT infections among young people hidden, the Dutch standard sexual health care, as described in the introduction section of this thesis, is insufficient. Currently, no friends of high-risk young people are actively notified. We recommend including the notification of friends, beside the standard PN, because this leads to a substantial number of young people tested who never tested before and are CT positive. For the notification of sex partners peer-driven testing seems less suitable, because of low numbers of recruitment and CT positivity. However, a substantial percentage of sex partners were not previously tested and thus hidden to health care. Because differences in preferences exist between the notification of casual and steady partners, it is important to offer complementary testing strategies that fit the preferences of young people $[25,33]$. Currently a new Internet Partner Notification (IPN) method has been implemented nationally at STI clinics and general practices (GP). STI positives receive a personal code, which they can use to notify sex partners anonymous or non-anonymous via Internet. This strategy only focuses on sex partners and has mostly been used anonymously (88\%) [19]. Our strategy is therefore complementary as it provides in person home sampling test kits and focuses on both friends and sex partners. 
In person provision of home sampling test kits is promising. We therefore recommend providing high-risk young people with home sampling test kits for their peers. However, to overcome waste of resources the following could be considered. Obtain prior permission before sending a test for peers to high-risk young people. Send multiple reminders to pass on test kits to peers and to return test kits. Provide CT positive young people at their CT treatment consultation with test kits for their peers saving delivery costs.

As CT-testing in the Netherlands is done by GPs in addition to STI clinics, GPs play an important role in decreasing stigma among young people. Barriers for GPs to discuss PN include provider discomfort and unawareness or misunderstanding of their role in PN. We recommend adding $\mathrm{PN}$ and peer-driven testing in continuing medical education for GPs. Our strategy of providing home sampling test kits could also be an accessible manner for GPs to promote CT testing among young people and their peers.

\section{Recommendation for future research}

The scope of this thesis was to study the value of peer-driven testing in terms of recruitment of hidden (i.e., never tested before) CT positive peers. We did not study the cost-effectiveness of our peer-driven testing strategies. In chapter 6 no prior permission was obtained before sending an additional test kit to young people and more than two third of test kits were not passed on to friends or returned by friends for testing. With decreasing financial resources, budgets are limited and should be targeted at those who need the care the most. Future research is needed to study the cost-effectiveness of peer-driven testing compared to other testing strategies.

Reasons for non-recruitment and non-testing remain unknown. To improve recruitment and testing, potentially raising cost-effectiveness, more research is needed on the motives of young people to (not) pass on home sampling test kits to their peers. The same goes for the motives of peers to (not) use the test kit.

The use of peer-driven testing through home sampling test kits, facilitated by web-RDS, has not proven to be successful in CT-testing in this thesis, though it has been proven to be successful in HIV- and syphilis-testing. The use of web-RDS for CT-testing could be studied and developed further to explore if more waves, sex partners and men can be reached. As technical difficulties arose in our study, the full potential of web-RDS may not have been exploited. 


\section{References}

1. Fuqua $\mathrm{V}, \mathrm{Chen} \mathrm{YH}$, Packer $\mathrm{T}$, Dowling T, Ick TO, Nguyen B, Colfax GN, Raymond HF: Using Social Networks to Reach Black MSM for HIV Testing and Linkage to Care. AIDS Behav. 2012;16:256-265. DOI 10.1007/ s10461-011-9918-x

2. Rothenberg R: The tranformation of Partner Notification. CID 2002, 35(2):S138-S145.

3. Youm Y, Laumann EO. Social Network Effects on the Transmission of STI. Sex Trans Dis 2002, 29(11):689-697.

4. Loaring J, Hickman M, Oliver I, Campbell R, Trotter C, Macleod J, Pye K, Crichton J: Horner, P. Could a peer-driven intervention increase uptake of chlamydia screening? A proof of principle pilot study. J. Fam. Plann. Reprod. Health Care 2013, 39, 21-28.

5. Rothenberg R, Kimbrough L, Lewis-Hardy R, Heath B, Williams OC, Tambe $P$, Johnson D, Schrader M: Social network methods for endemic foci of syphilis: a pilot project. Sex Transm Dis. 2000;27(1):12-8.

6. Van Bergen JEAM, Fennema JSA, van den Broek IVF, Brouwers EHHG, de Feijter EM, Hoebe CJPA, Koekenbier $\mathrm{RH}, \mathrm{Op}$ de Coul ELM, van Ravesteijn SM, Götz HM. Rationale, design, and results of the first screening round of a comprehensive, register-based, Chlamydia screening implementation programme in the Netherlands.
BMC Infectious Diseases 2010 , 10:293 doi:10.1186/1471-2334-10-293.

7. National Institute for Public Health and the Environment. Sexually Transmitted Infections, Including HIV, in the Netherlands in 2014. Annual Report National Institute for Public Health and the Environment: Bilthoven, The Netherlands, 2015.

8. Samkange-Zeeb F, Pottgen S, Zeeb H. Higher Risk Perception of HIV than of Chlamydia and HPV among Secondary School Students in Two German Cities. 2013; PLOS ONE 8(4):E61636.

9. Hoor GA ten, Ruiter RAC, Bergen JEAM van, Hoebe CJPA, Dukers-Muijrers NHTM, Kok G. Predictors of Chlamydia Trachomatis Testing: Perceived Norms, Susceptibility, Changes in Partner Status, and Underestimation of Own Risk, BMC Public Health 2016.

10. Klein CTF, Helweg-Larsen M. Perceived control and the optimistic bias: A meta-analytic review. Psychol Health. 2002;17:437-446.

11. Ten Hoor, G.A.; Ruiter, R.A.C.; van Bergen, J.E.A.M.; Hoebe, C.J.P.A.; Houben, K.; Kok, G. Non-participation in chlamydia screening in the Netherlands: Determinants associated with young people's intention to participate in chlamydia screening. BMC Public Health 2013, 13, 1091,1-10.

12. Jenkins WD, Weis $R$, Campbell $P$, Barnes M, Barnes P, Gaydos C. Comparative effectiveness of two 
self-collected sample kit distribution systems for Chlamydia screening on a university campus. Sex Trans Infect 2012, 88:363-367.

13. European Centre for Disease Prevention and Control. http://ecdc.europa.eu/en/ publications/Publications/Partnernotification-for-HIV-STI-June-2013.pdf [accessed on 13-11-2015]

14. Østergaard L, Andersen B, Møller J.K, Olesen F, Worm AM. Managing partners of people diagnosed with chlamydia trachomatis: A comparison of two partner testing methods. Sex. Trans. Infect. 2003, 79, 358-362.

15. Gaydos CA, Dwyer K, Barnes M, Rizzo-Price PA, Wood BJ, Flemming T, Hogan MT: Internet-Based Screening for Chlamydia trachomatis to Reach Nonclinic Populations With Mailed Self-Administered Vaginal Swabs. OSex Trans Dis 2006, 33(7):451-457. doi: 10.1097/01.olq.0000200497.14326.fb.

16. Woodhall SC, Sile B, Talebi A, Nardone A, Baraitser P. Internet testing for Chlamydia trachomatis in England, 2006 to 2010. BMC Public Health201212:1095

17. Greenland KE, Op De Coul ELM, Van Bergen JEAM, Brouwers EEHG, Fennema HJSA, Gotz HM, Hoebe CJPA, Koekenbier RH, Pars LL, Van Ravesteijn SM, Van Den Broek IVF: Acceptability of the Internet-Based Chlamydia Screening Implementation in the Netherlands and Insights Into Nonresponse. Sex Trans Dis 2011, 38:6.
18. Trelle S, Shang A, Nartey L, Cassell JA, Low N: Improved effectiveness of partner notification for patients with sexually transmitted infections: systematic review. BMJ 2007, 334(7589):354.

19. Götz, H.M.; van Rooijen, M.S.; Vriens, P.; Op de Coul, E.; Hamers, M.; Heijman, T.; van den Heuvel, F.; Koekenbier, R.; van Leeuwen, A.P.; Voeten, H.A. Initial evaluation of use of an online partner notification tool for STI, called' suggest a test: A cross sectional pilot study. Sex Trans. Infect. 2014, 90, 195-200.

20. Pavlin, N.L.; Gunn, J.M.; Parker, R.; Fairley, C.K.; Hocking, J. Implementing chlamydia screening: what do women think? A systematic review of the literature. BMC Public Health 2006, 6, 221-231.

21. Balfe, M.; Brugha, R. Disclosure of STI testing activities by young adults: The influence of emotions and social networks. Soc. Health IIIn. 2010, 32, 1041-1058

22. Hopkins CA, Temple-Smith MJ, Fairley CK, Pavlin NL, Tomnay JE, Parker RM, Bowden FJ, Russell DB, Hocking JS, Chen MY. Telling partners about chlamydia: how acceptable are the new technologies? BMC Infectious Diseases 2010, 10:58

23. Ferreira $A$, Young $T$, Mathews $C$, Zunza M, Low N. Strategies for partner notification for sexually transmitted infections, including HIV. Cochrane Database Syst Rev. 2013,3;10. 
24. Hogben M, Collins D, Hoots B, O'Connor K. Partner Services in Sexually Transmitted Disease Prevention Programs: A Review. Sex Transm Dis. 2016 Feb;43 (2 Suppl 1):S53-62.

25. National Collaborating Centre for Infectious Diseases. Outcomes related to STI partner notification, 2013. http://centreinfection.s3.amazonaws. com/wp/sites/2/2015/03/31155415/ NCCID_PartnerNotify_Taylor_04.pdf [accessed on 13-11-2015]

26. Strömdahl S, Lu X, Bengtsson L, Liljeros F, Thorson A. Implementation of Web-Based Respondent Driven Sampling among Men Who Have Sex with Men in Sweden. PLoS One. 2015 Oct 1;10(10):e0138599. doi: 10.1371/ journal.pone.0138599. eCollection 2015.

27. Stein, M.L.; van Steenbergen, J.E.; Buskens, V.; van der Heijden, P.G.; Chanyasanha, C.; Tipayamongkholgul, M.; Thorson, A.E.; Bengtsson, L.; Lu, X.; Kretzschmar, M.E. Comparison of contact patterns relevant for transmission of respiratory pathogens in Thailand and The Netherlands using respondent-driven sampling. PLoS ONE 2014, 9, e113711, doi: 10.1371/ journal.pone.0113711

28. Bengtsson L, Lu X, Nguyen QC, Camitz M, Hoang NL, Nguyen A, Liljeros F, Thorson A: Implementation of Web-Based Respondent-Driven Sampling among Men Who Have Sex with Men in Vietnam. PLoS ONE. 2012;7(11): e49417. doi:10.1371/journal. pone. 0049417

29. National Institute for Public Health and the Environment. Draaiboek Partnermanagement bij soa/hiv Waarschuwen, testen en behandelen van seksuele partners mei 2015. http://www.rivm. $n l /$ dsresource?objectid=rivmp: $7445 \&$ type $=$ org \&disposition $=$ inline \&ns_nc $=1$ [accessed on 13-11-2015]

30. Rollnick, W.R.; Miller, S.R.; Butler, C.C. Motivational Interviewing in Health Care. Helping Patients Change Behavior. Available online: $h t t p: / / w e b . v u . l t / m f /$ r.viliuniene/files/2014/10/ MotivationalInterviewing-in-Health-Care.Helping-Patients-Change-Behavior.pdf laccessed on 30 January 2016).

31. Op de Coul E.L.; Spijker, R.; van Aar, F.; van Weert, Y.; de Bruin, M. With whom did you have sex? Evaluation of a partner notification training for STI professionals using motivational interviewing. Patient Educ. Couns. 2013, 93, 596-603.

32. Nack, A. Damaged goods: Women managing the stigma of STDs. Deviant Behav. 2000, 21,95-121.

33. Hogben M: Partner Notification for Sexually Transmitted Diseases. CID 2007, 44(supp(3):S160 S174. 


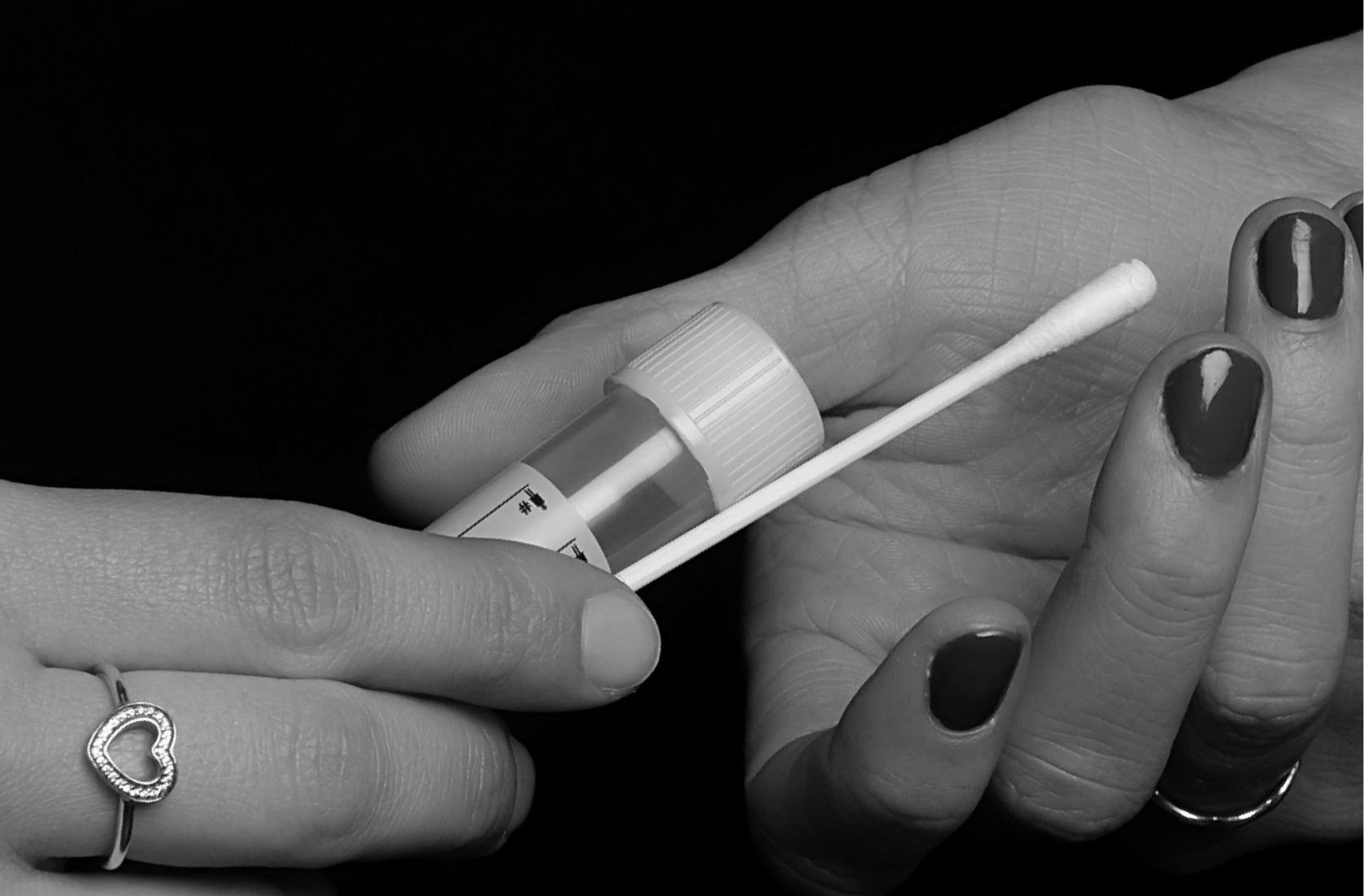




\section{Chapter 8}

Summary

Nederlandse samenvatting

Dankwoord

Curriculum Vitae

Publications

Courses and training

Valorisation of the thesis 


\section{Summary}

In this thesis studies are described that focused on the development of peer-driven Chlamydia trachomatis (CT) testing strategies, the pilot implementation and evaluation in practice of these strategies and its use among young people and sexual health care nurses.

In chapter 2 we described the development of a peer-driven CT testing strategy using the Intervention Mapping (IM) protocol. IM is a systematic approach to develop theory- and evidencebased interventions; applying IM should increase the likelihood of developing an effective intervention. During the needs assessment (IM step 1) estimates showed that although CT is the most frequently diagnosed bacterial sexual transmitted infection (STI) among young people approximately half of all infection still remains hidden to health care. Peer-driven testing was found promising in finding hidden infections, because of the scientific evidence of high STI prevalence in social and sexual networks surrounding STI positive people. Based on the health problem two behavioural outcomes were formulated: high-risk young people (1) get tested for CT, and (2) recruit peers via their social and sexual network to get tested. After the most important and changeable determinants were identified and the performance objectives selected, matrices of change objectives were created. IM proved a useful approach and eventually resulted in the development of a web-based Respondent Driven Sampling (web-based RDS) application using home sampling test kits.

In chapter 3 we pilot implemented and evaluated the web-based RDS strategy above among CT positive clients at the STI clinic South Limburg. They were able to recruit their friends and sex partners (hereafter called peers) via email to test for CT. These peers could recruit their peers, who in turn recruit their peers and so on (called waves). Of all participating CT positive clients $40 \%$ recruited a peer of which two recruited their peers. Of the in total 35 eligible peers $23 \%$ requested and returned a home sampling test kit. Almost $88 \%$ tested for the first time and $13 \%$ was CT positive. Most of the eligible peers were female friends (80\%). Recruitment of sex partners was low and recruitment waves stopped early. Among the participating nurses the strategy was highly acceptable. The use of peer-driven testing in combination with home sampling test kits seemed promising to recruit peers who had never tested before. However, future research should target optimising web-based RDS and increase the number of waves.

In chapter 4 we studied the role of stigma; an important barrier among young people regarding the disclosure of $\mathrm{CT}$ testing to peers and the encouragement of these peers to test for CT. Twentythree semi-structured interviews were analysed from CT tested and never tested heterosexual young people between 16-24 years. Both groups anticipated shame and stigmatizing reactions if they would disclose their testing experience to others outside their trusted network. Therefore, 
they only disclose to a trusted group of peers. This stigma management strategy prevents stigma and negative reactions and leads to social support and empathy. Similar findings were found regarding the encouragement of other to test. Due to the selective disclosure and encouragement only a small trusted network surrounding a person is reached. Future research should explore interventions that also reach individuals outside the trusted network of a person.

In chapter $\mathbf{5}$ we described the barriers and facilitators during the partner notification (PN) process perceived by sexual health care professionals. PN is essential in the management of CT and should be discussed by health care professionals during a consultation with young heterosexual individuals diagnosed with CT. Semi-structured interviews were conducted among 22 health care professionals from 5 of the 8 Dutch STI clinics. They were between the age of 20 and 50 years old and worked at least six months at the STI clinic. Professionals perceived time, one-on-one consultations, interviewing skills and a proactive helping style as facilitators for PN. They identified sub-optimal guidelines, inaccurate sexual history, a lack of feedback regarding the motivational strategies used and regarding the overall effectiveness of PN, as barriers. Although professionals felt comfortable discussing PN they were more committed to the care and treatment of the individual rather than on the discussion of PN, or on motivating and helping individuals to perform in PN. Future CT control strategies should overcome the identified barriers and maintain the perceived facilitators.

Chapter $\mathbf{6}$ describes the development, pilot implementation and evaluation of a second peerdriven testing strategy using homesampling test kits. In this strategy young heterosexuals between 16 and 24 years old who previously tested positive $(n=536)$ or negative $(n=536)$ in two STI clinics in Limburg received an short messaging services (SMS) text, 3 to 20 months after their initial test to retest. When replying to the SMS they received a free home sampling test kit and an additional test kit for a peer. Of all young people who requested a retest at least $23 \%$ provided a peer with a test kit. Of these peers $84 \%$ were friends and $31 \%$ tested for the first time. Of the tested friends $8 \%$ were positive of which $50 \%$ never tested before. By including a peer-driven testing component to the re-test of young people, undetected CT infections can be found among mainly friends.

Chapter $\mathbf{7}$ discusses the main findings of this thesis to evaluate the value of peer-driven testing for CT control taken into account social and sexual networks, web-RDS, the role of professionals and stigma.

Young people are willing to recruit social networks for CT testing via home sampling test kits. There is potential value in terms of reaching friends who never tested before and undetected CT infections. Recruitment of sexual networks is moderate in peer-driven CT testing. However, a 
substantial part of tested sex partners was not previously tested and thus hidden to health care. Because differences in preferences exist between the notification of casual and steady partners, it is important to offer complementary testing strategies that fit the preferences of young people. Future studies are needed to assess the reasons behind (not) passing on a test kit to a peer or (non-) testing among peers.

Peer-driven CT testing via web-RDS especially reaches social networks. However, recruitment waves are short (maximum of two) and networks are small (mean of three persons). We stated based on scientific literature that recruitment may increase after inclusion of a SMS function, decreasing technical problems and the use of monetary incentives.

Professionals experience barriers during the PN process and they have in general low commitment towards PN and towards motivating and helping patients to engage in PN. Our peer-driven testing strategies tackled some barriers and increased the professional's commitment towards $\mathrm{PN}$ and social network recruitment. For example, through the visualization of networks and the discussion of recruitment results professionals are provided with the previously lacking feedback on the effectiveness of their strategies used and that of the PN process. Consequently, professionals feel more aware of the CT risk in networks and emphasize the importance of network recruitment during consultations. Motivational Interviewing (MI) is an important facilitator as it has been shown to improve skills and behaviour in dealing with patients' resistance towards PN. When combining MI with peer-driven testing, clients may also be more motivated to recruit their social network beside their sexual network.

Despite anticipated stigma, peer-driven strategies that target friends and sex partners of young people are potentially effective. Yet, their effectiveness could potentially be limited by the small size of trusted networks reached due to stigma management strategies. Nonetheless, a person outside an individual's trusted network may be a trusted friend or sex partner in someone else's network.

Future studies are needed to investigate the cost-effectiveness of peer-driven CT testing strategies, the reasons for non-recruitment and non-testing in peer-driven strategies and the introduction of peer-driven testing in General Practitioners (GP) practice. 


\section{Nederlandse samenvatting}

In dit proefschrift beschrijven wij onderzoek naar teststrategieën voor Chlamydia trachomatis (CT), waarbij jongeren werden aangespoord hun vrienden en sekspartners (hierna te noemen peers) te rekruteren, ook wel peer-driven testing genoemd. Wij hebben ons gericht op de ontwikkeling, implementatie en praktijkevaluatie van deze strategieën en het gebruik onder jongeren en SOA-verpleegkundigen.

In hoofdstuk 2 hebben we gebruik gemaakt van Intervention Mapping (IM) voor de ontwikkeling van een peer-driven $\mathrm{CT}$ teststrategie. IM is een systematische benadering waarmee interventies kunnen worden ontwikkeld onderbouwd met theoretisch en wetenschappelijk bewijs; de toepassing hiervan verhoogt de kans op het ontwikkelen van een geslaagde interventie. Tijdens de needs assessment (IM stap 1) lieten schattingen zien dat, hoewel CT de meest gediagnosticeerde bacteriële seksueel overdraagbare aandoening (SOA) is, ongeveer de helft van de CT infecties niet wordt ontdekt. Peer-driven testing lijkt veelbelovend in het vinden van verborgen infecties, omdat eerder onderzoek heeft aangetoond dat de prevalentie van SOA's hoger is in sociale en seksuele netwerken van mensen met een SOA. Op basis van het gezondheidsprobleem zijn twee gedragsuitkomsten geformuleerd: hoog-risico jongeren (1) worden getest op CT en (2) rekruteren peers uit hun sociale en seksuele netwerk om zich ook te laten testen. Nadat de belangrijkste en veranderbare determinanten waren geïdentificeerd en de gedragsdoelen waren geselecteerd, werden matrices met veranderdoelen opgesteld. IM bleek een succesvolle benadering en resulteerde in de ontwikkeling van een online Respondent Driven Sampling (online RDS) strategie die gebruikt maakt van CT thuis afname testen.

Hoofdstuk 3 beschrijft de pilot implementatie en evaluatie van de hierboven beschreven online RDS strategie onder CT positieve cliënten op de SOA-poli van Zuid-Limburg. Cliënten konden via email hun peers rekruteren om zich te laten testen op CT. Deze peers konden ook weer hun peers rekruteren en zo verder look wel recruitment waves genoemd). Van alle deelnemende CT positieve cliënten rekruteerde $40 \%$ een peer van wie twee ook weer hun peers rekruteerden. Van de in totaal 35 geschikte peers heeft $23 \%$ een thuis afname test aangevraagd en geretourneerd. Voor bijna $88 \%$ van de peers die een thuis afname test teruggestuurde was dit de eerste keer dat zij getest werden en $13 \%$ was positief. Het merendeel van de gerekruteerde peers waren vriendinnen (80\%). Het aantal gerekruteerde sekspartners was laag en de recruitment waves kort. Onder de participerende verpleegkundigen was de strategie zeer bruikbaar. Het gebruik van peer-driven testing in combinatie met thuis afname testen lijkt een veelbelovende methode om peers te bereiken die nog nooit op CT zijn getest. Toekomstig onderzoek moet zich richten op het optimaliseren van online RDS en het verhogen van het aantal recruitment waves. 
In hoofdstuk 4 onderzoeken we de rol van stigma; een belangrijke barrière onder jongeren omtrent het bespreken van hun CT testgedrag met peers en om peers aan te sporen om ook te testen voor CT. Drieëntwintig semigestructureerde interviews met jongeren tussen 16-24 jaar die wel en niet getest zijn op CT zijn geanalyseerd. Jongeren uit beide groepen verwachtten schaamte en stigmatiserende reacties wanneer ze hun testgedrag delen met anderen buiten hun vertrouwde netwerk. Daarom bespreken ze dit alleen met een selectieve groep peers. Deze stigma management strategie voorkomt stigma en negatieve reacties en leidt tot sociale steun en empathie. Hetzelfde geldt voor het aansporen van peers om zich te laten testen. Door het selectief bespreken van testgedrag en selectief aanmoedigen van peers om te testen wordt alleen een kleine vertrouwde groep peers rondom een jongere bereikt. In de toekomst moet gezocht worden naar interventies die ook peers buiten het vertrouwde netwerk bereiken.

In hoofdstuk 5 beschrijven we de barrières en facilitatoren die SOA-verpleegkundigen ervaren tijdens het proces van partnerwaarschuwing (PW). PW is essentieel in het managen van CT en moet door zorgverleners tijdens de consulten met CT-positieve heteroseksuele jongeren besproken worden. Semigestructureerde interviews werden afgenomen met 22 zorgverleners van 5 van de 8 Nederlandse SOA-poli's. De zorgverleners waren 20 tot 50 jaar oud en werkten ten minste 6 maanden op de SOA-poli. Zorgverleners ervoeren tijd, een-op-een consulten, interviewvaardigheden en proactieve ondersteuning bij PW als facilitatoren. Zij noemden suboptimale richtlijnen, inaccurate seksuele voorgeschiedenis een gebrek aan terugkoppeling ten aanzien van de gebruikte motivatie strategieën en de algehele effectiviteit van PN als barrières. Hoewel zorgverleners zich comfortabel voelden bij het bespreken van PN, waren zij toch meer gericht op de zorg en behandeling van de individuele cliënt dan op het bespreken van PN of het motiveren en helpen van jongeren bij het uitvoeren hiervan. Toekomstig CT beleid moet rekening houden met de genoemde barrières en de ervaren facilitatoren behouden.

Hoofdstuk 6 beschrijft de ontwikkeling, pilot implementatie en evaluatie van een tweede peerdriven teststrategie die gebruik maakt van thuis afname testen. Hierin ontvingen heteroseksuele jongeren tussen 16-24 jaar een sms-bericht, 3 tot 20 maanden na een positieve $(n=536)$ of negatieve ( $n=536$ ) CT-test bij twee Limburgse SOA-poli's, met de oproep om zich te laten hertesten. Wanneer zij op dit bericht reageerden ontvingen zij twee gratis CT thuis afnamen testen, een voor zichzelf en een voor een vriend of sekspartner. Van alle jongeren die een test hebben aangevraagd gaf ten minste $23 \%$ een CT test aan een peer. Van deze peers was $84 \%$ een vriend en 31\% testte voor het eerst op CT. Van de geteste vrienden was $8 \%$ CT positief van wie de helft nooit eerder was getest. Door gebruik te maken van een peer-driven teststrategie bij het hertesten van jongeren kunnen verborgen CT infecties worden opgespoord in sociale netwerken. 
In hoofdstuk 7 bespreken we de belangrijkste bevindingen van dit proefschrift waarin de toegevoegde waarde van peer-driven testing voor het managen van CT wordt geëvalueerd. Hierbij wordt gekeken naar sociale en seksuele netwerken, online RDS en de rol van de zorgverlener en stigma.

Jongeren zijn bereid hun sociale netwerk te rekruteren met CT thuis afname testen. Er is potentiele meerwaarde voor het bereiken van vrienden die nooit eerder zijn getest en het opsporen van verborgen CT infecties. Het rekruteren middels peer-driven testing binnen seksuele netwerken is matig. Desondanks was een substantieel deel van de geteste sekspartners nog nooit eerder getest en dus verborgen voor de seksuele gezondheidszorg. Vanwege de verschillen tussen het waarschuwen van losse en vaste sekscontacten is het belangrijk om aanvullende test strategieën aan te bieden die aansluiten bij de voorkeuren van jongeren. Meer onderzoek is nodig om beweegredenen voor het (niet) doorgeven van een thuis afname test aan een peer of het (niet) testen onder peers vast te stellen.

Peer-driven CT testing via online RDS bereikt vooral vrienden (sociale netwerken). De recruitment waves zijn echter kort (maximaal twee) en de bereikte netwerken zijn klein lgemiddeld drie personen). Wij concluderen op basis van de beschikbare wetenschappelijke literatuur dat de werving mogelijk verbetert wanneer een sms-functie om peers te rekruteren wordt toegevoegd, technische problemen worden verholpen en een financiële vergoeding wordt aangeboden.

Zorgverleners ervaren barrières tijdens het proces van partnerwaarschuwing en voelen zich weinig verantwoordelijk voor PN en het motiveren en helpen van jongeren bij het uitvoeren hiervan. Onze peer-driven teststrategieën halen een aantal barrières weg en vergroten het verantwoordelijkheidsgevoel van zorgverleners ten opzicht van PW en sociale netwerk recruitment. Bijvoorbeeld door de visualisatie van gerekruteerde netwerken en het bespreken van de rekruteringresultaten met zorgverleners krijgen zij de eerder missende feedback over de effectiviteit van de gebruikte strategieën en het PN proces. Als gevolg hiervan zijn zorgverleners meer bewust van de het CT risico binnen netwerken en benadrukken zij de noodzaak van het rekruteren van netwerken tijdens de consulten. Motivational Interviewing (MI) is een belangrijke facilitator die de vaardigheden en het gedrag van zorgverleners in het omgaan met de weerstand van de cliënt ten aanzien van PN verbetert. Wanneer MI wordt gecombineerd met peerdriven testing zijn cliënten mogelijk meer gemotiveerd om hun sociale netwerken te rekruteren in aanvulling op hun seksuele netwerk.

Ondanks het geanticipeerd stigma lijken peer-driven teststrategieën die zich richten op vrienden en sekspartners potentieel effectief. Hun effectiviteit zou echter beperkt kunnen worden door de kleine selectieve netwerken die bereikt worden als gevolg van stigma management strategieën. lemand buiten dit vertrouwde netwerk is mogelijk wel een vertrouwde vriend of sekspartner in 
het netwerk van een andere jongere.

Aanvullende studies zijn nodig om onderzoek te doen naar de kosteneffectiviteit van peer-driven CT teststrategieën, de beweegredenen voor niet rekruteren en niet testen in peer-driven strategieën en de introductie van peer-driven testen in de huisartsenpraktijk. 


\section{Dankwoord}

Nog wat onwennig begin ik aan dit dankwoord. Wat ik op sommige momenten niet meer voor mogelijk achtte, is dan toch echt gelukt. Een uitdagend, leerzaam en af en toe zwaar traject dat ik in 2011 gestart ben bij de GGD Zuid Limburg is afgerond en vormt nu een boekje. Aan alle collega's dank voor jullie hulp bij het uitvoeren van mijn onderzoeken. Lieve kennissen, vrienden en familie ook dank aan jullie voor het aanhoren van mijn verhalen over jongeren, seks en chlamydia. Een aantal mensen wil ik graag persoonlijk bedanken.

Als eerste wil ik mijn promoteren bedanken. Prof. dr. Hoebe, beste Christian, dank dat je vertrouwen in mij hebt gehad en mij wegwijs hebt gemaakt in de wereld van het onderzoek. Je gedrevenheid en passie voor SOA bestrijding werkten aanstekelijk. Je grappen en woordspelingen zullen mij nog lang bijblijven. Beste Prof. dr. Kok, beste Gerjo, onze overleggen waren erg prettig en je input vanuit de toegepaste psychologie zeer waardevol. Ik ben vereerd dat je mijn tweede promoter was.

Beste dr. Dukers-Muijrers, beste Nicole. Als copromotor was jij mijn dagelijks begeleider. Dank voor je inbreng en expertise tijdens de vele manuscripten, interventies en presentaties. Mede dankzij jou is dit boekje tot stand gekomen en daar ben ik je enorm dankbaar voor.

Beste verpleegkundigen, doktersassistenten en artsen van de soa poli's Noord en Zuid Limburg zonder jullie had ik mijn onderzoeken niet kunnen uitvoeren. Een waardevolle blik vanuit de praktijk is onmisbaar bij het ontwikkelen van goede interventies. Lieve Maria en Inge, natuurlijk een zeer grote dank voor jullie betrokkenheid, input en enthousiasme. Chris, Eslie en Eveline onze gezellige gesprekken zullen mij nog lang bijblijven.

Oud studenten Pim en Stan dank dat jullie je stage met zoveel gedrevenheid hebben uitgevoerd. Veel succes met jullie carrières. Nicole, Helen, Ine, Marita en Nathalie als secretariaat hebben jullie veel ondersteuning geboden, deze was zeer welkom. Dank daarvoor! Chakib and the Infact team thank you for all the hard work and hospitality during our lovely visit in Leeds.

Ook aan alle coauteurs dank voor jullie bijdrage tijdens het schrijven van de artikelen in dit proefschrift. Arjan en Rik ik heb onze gesprekken als zeer prettig en verrijkend ervaren.

Leden van de beoordelingscommissie, bedankt dat u wilde plaatsnemen.

Mede-onderzoekers Jeanne en Steffi onze wandelingen en gesprekken waren erg fijn. Succes met jullie promoties. Dr. van Liere, lieve Genevieve, jij bent mijn tweede paranimf, hopelijk 
geniet je er net zo van als ik. Ik heb genoten van onze reisjes samen, zowel op persoonlijk- als werkvlak. Onze grappen waren legendarisch en zal ik niet snel vergeten. Laura wij waren goed in discussies voeren, maar ik denk met mooie en leuke herinneringen terug aan ons tripje naar London en Leeds. Ook een grote dank aan de collega's bij Medische Microbiologie en in het bijzonder Petra voor het meedenken en het uitvoeren van de onderzoeken.

Lieve vrienden jullie hebben voor de broodnodige ontspanning gezorgd. Marla, ik hoop dat er nog veel coffee breaks bij annex CF gaan volgen. De koffie en natuurlijk je gezelschap waren zeer welkom in het weekend. Veel succes met het afronden van je promotie. Lieve Zoe, een glimlach of knuffel kan zo fijn zijn als het allemaal wat tegenzit. Tom, lang geleden zijn wij samen aan onze carrières begonnen bij de Universiteit van Maastricht. Aan dit hoofdstuk komt nu een einde. Dank voor alle steun, gesprekken en vooral de mooie vriendschap. Veel succes bij Vandaag Zorgvernieuwing met het uitdragen van je waardevolle kennis. Ik heb in ieder geval al vaak naar je promotieboekje gerefereerd tijdens mijn werk. Elwin, de halve liters Erdinger en onze motorritjes deden vaak zo goed en relativeerde enorm. Succes met je promotie. Dominique, onze geplande avondjes die toch altijd heel anders verliepen waren heel fijn. Hopelijk volgen er nog veel meer.

Lieve zus, misschien besef je het niet altijd maar jij bent toch echt mijn grote voorbeeld. De steun die ik van jou heb gekregen de afgelopen jaren hebben mij enorm geholpen om door te zetten. Je bent een lieverd en onmisbaar in mijn leven. Natuurlijk kan Rick niet ontbreken. Als grappige en aardige toekomstige schoonbroer met een achtergrond in infectieziekte bestrijding wist ik zeker dat jij mijn eerste paranimf moest worden. Pap en mam betere ouders kan niemand zich wensen. Niks hoefde en alles mocht. Dank dat jullie zo'n geweldige ouders zijn en mij altijd hebben ondersteund. Ik ben trots op jullie. Lieve oma, het wordt tijd om je geen zorgen meer te maken, het boekje is af.

Lieve Ninke, ik introduceerde je al tijdens onze eerste date met het onderwerp van mijn proefschrift en dat heeft je gelukkig niet afgeschrikt. Streng en liefdevol was je tijdens de laatste loodjes van dit boekje. Ondanks mijn herhaaldelijke betogen over promoveren wist jij me elke keer weer te motiveren. Het is nu tijd om lekker te genieten van ons huis, de verre reizen die gaan komen en alle andere leuke dingen. Heel veel succes met de opleiding tot kinderarts en een mega dikke kus. 


\section{Curriculum Vitae}

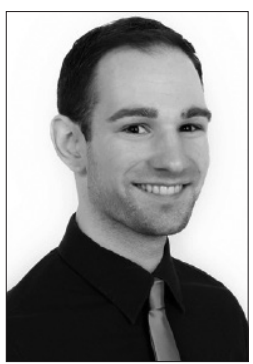

Kevin Theunissen is geboren op 10 juli 1987 en opgegroeid in Heerlen. In 2005 behaalde hij zijn VWO diploma aan het Sintermeertencollege te Heerlen. In datzelfde jaar startte Kevin met zijn studie Gezondheidswetenschappen aan de Universiteit van Maastricht waar hij koos voor de minor Arbeid en Gezondheid en de major Beleid en Management. In 2008 ontving hij hiervoor zijn Bachelor diploma waarna hij begon aan de Master Beleid, Economie en Organisatie van de Zorg. Zijn afstudeerstage heeft hij bij de Universiteit Maastricht uitgevoerd waar hij onderzoek deed naar de inzetbaarheid van verschillende vragenlijsten om depressie te meten. In 2009 behaalde Kevin zijn Master en begon hij zijn loopbaan bij de afdeling Health Technology Assessment (HTA). Bij HTA deed Kevin onderzoek naar het conditioneel vergoeden van dure -en weesgeneesmiddelen. Voor dit onderzoek was hij een jaar lang gedetacheerd bij het College voor Zorgverzekeringen (CVZ) te Amsterdam. In deze samenwerking bezocht Kevin meerdere Europese landen om onderzoek te doen naar de verschillende financieringssystemen voor dure- en weesgeneesmiddelen. Dit internationaal onderzoek resulteerde uiteindelijk in een nationaal rapport voor het CVZ.

Omdat de praktijk hem aantrok maakte Kevin in 2011 de overstap naar de GGD Zuid Limburg waar hij voor de afdeling seksuele gezondheid, infectieziekten en milieu ging werken. Eerst als onderzoeker/data manager en daarna als promovendus. Gedurende 5 jaar heeft Kevin onderzoek gedaan naar een betere strategie om jongeren te bereiken met Chlamydia testen. Hiervoor werkte Kevin samen met de universiteit Maastricht, MUMC+, Open Universiteit Nederland en een Engels ICT bedrijf genaamd Infact. Nog tijdens het afronden van zijn promotie begon Kevin in 2015 aan een nieuw avontuur bij stichting MEE. Nog dichter bij de praktijk en als project manager verantwoordelijk voor een 25 tal projecten die gericht zijn op licht verstandelijk beperkten inwoners binnen 15 gemeenten in Midden en Noord Limburg. 


\section{Publications}

2015

Kevin A. T. M. Theunissen, Nicole H. T. M. Dukers-Muijrers, Petra T. Wolffs, Gerjo Kok, Christian J. P. A. Hoebe. Acceptance of home-based chlamydia genital and anorectal testing using short message service, (SMS) in previously tested young people and their social and sexual networks. PLoS ONE 2015, 10(7): e0133575.

Kevin Theunissen, Christian Hoebe, Gerjo Kok, Rik Crutzen, Chakib Kara-Zaïtri, Nanne de Vries, Jan van Bergen, Robert Hamilton, Marianne van der Sande and Nicole Dukers-Muijrers. A webbased respondent driven sampling pilot targeting young people at risk for Chlamydia trachomatis in social and sexual networks with testing: a use evaluation.

Int. J. Environ. Res. Public Health 2015, 12, 9889-9906

Kevin A.T.M. Theunissen, Arjan ER Bos, Christian J.P.A. Hoebe, Gerjo Kok, Stan Vluggen, Rik Crutzen, Nicole H.T.M. Dukers-Muijrers. Chlamydia Trachomatis Testing Among Young People: The Role of Anticipated and Experienced Stigma.

BMC Public Health 2015 15:651. DOI: 10.1186/s12889-015-2020-y

2014

Kevin A.T.M. Theunissen, Pim Schipper, Christian J.P.A. Hoebe, Rik Crutzen, Nicole H.T.M. Dukers-Muijrers. A qualitative study: Public health care nurses' perceptions of barriers to and facilitators of Partner Notification for Chlamydia trachomatis.

BMC Health Services Research 2014, 14:647. D0I:10.1186/s12913-014-0647-5

2013

Kevin A.T.M. Theunissen, Christian J.P.A. Hoebe, Rik Crutzen, Anne-Marie Niekamp, Chakib Kara-Zaïtri, Nanne K. de Vries, Jan E.A.M. van Bergen, Marianne A.B. van der Sande, Nicole H.T.M. Dukers-Muijrers. Using intervention mapping for the development of a targeted secure web-based outreach strategy named SafeFriend, for Chlamydia trachomatis testing in young people at risk.

BMC Public Health 2013, 13:996. DOI: 10.1186/1471-2458-13-996. 
Gerhards S.A.H., Huibers M.J.H., Theunissen K.A.T.M., de Graaf L.E., Widdershoven G.A.M., Evers S.M.A.A. The responsiveness of quality of life utilities to change in depression: a comparison of instruments (SF-6D, EQ-5D and DFD).

Value Health. 2011 Jul-Aug;14(5):732-9.

2010

Kevin Theunissen, Gepke Delwel, Ties Hoomans. Implementing Coverage with Evidence Development Schemes for Innovative Health Technologies: Practical Experiences in Several Western Jurisdictions and the Lessons for The Netherlands.

Report The Dutch Healthcare Insurance Board, 2010.

Sylvia AH Gerhards, MSc, Kevin A.T.M. Theunissen, MSc, Silvia M.A.A. Evers, PhD, L. Esther de Graaf, PhD, Guy A.M. Widders-hoven, Prof PhD, Marcus J.H. Huibers, Prof PhD. Change in the course of depression severity (BDI-II) and quality of life (SF-6D): evidence for a temporal relation? Phd thesis Sylvia Gerhards. 


\section{Courses and training}

2013

Network analyses,

Congress International Network for Social Network Analysis Hamburg

2012

Intervention Mapping,

SOAids Nederland

Project management,

Team@work

2011

Data analyses summer course,

Essex University Social Science Data Analyses and Collection

Mind Mapping,

World of Minds

2010

Trial-based economic evaluations,

Health Sciences Research Master, Maastricht University

Cost-effectiveness modelling methods,

Health Sciences Research Master, Maastricht University

Bayesian methods for economic evaluations,

International Society for Pharmacoeconomics \& outcomes research

Academic English writing,

Maastricht University 


\section{Valorisation of the thesis}

\section{Relevance for society and economy}

Besides its scientific relevance this thesis also has implications for society and economy as it interventions are complementary to standard sexual health care practice.

In the Netherlands testing for Chlamydia trachomatis (CT) in sexual transmitted infection (STI) clinics is free of charge for various risk groups. These groups are young people below 25 years of age, sex workers, men who have sex with men (MSM), swingers, people with symptoms and people with more than 3 sex partners in the past six months. People mainly present themselves at the STI clinics for testing. Some exceptions are outreach activities for MSM and sex workers. Trained sexual health care nurses are responsible for the consultation with STI clinic visitors. At the first consultation nurses conduct the sexual anamnesis, perform testing when necessary and educate visitors. In case of STI positivity people are invited for a treatment consultation. During this consultation nurses explain the treatment provided and should also inform and support the notification of partners. In this thesis we found that although informing young people about PN is one of the core tasks of public sexual health such as STI clinics, nurses focus more on the care and treatment of the individual index patient rather than on discussing PN, or on motivating and helping patients to engage in PN. Our findings resulted in a national debate about PN and were part of a revision of national PN guidelines. Now the revised guidelines explain more in detail how to implement PN in daily practice. For example, using a standardized and structured list of questions to discuss PN with clients and suggestions how do handle with patients resistance towards PN.

In current CT control there is an emphasis towards the notification of people where CT positives had sex with in the past six months. However another finding of relevance for society found in this thesis is that young people are also willing to recruit social networks for CT testing. This has potential value in the number of CT infections found and the number of people who never tested before. These friends would possibly be missed when only applying the notification of sexual networks (PN). While anger towards a partner and fear for aggression could play a role in the intimate history sex partner's share, these factors are absent in social networks. Currently, the STI clinic South Limburg has implemented social and sexual recruitment using home sampling kits alongside PN in standard sexual health care. However, to overcome waste of resources they no longer immediately send out an extra peer test, but only after prior consent of the index. Next to this they also added a fifth and sixth SMS reminder to increase test kit return rates.

Peer-driven strategies using home sampling test kits are complementary to standard sexual health care, because different preferences exist among young people for the notification of sex 
partners and friends. Peer-driven testing seems more appropriate for friends compared to sex partners. Next to this, home sampling test kits are only appropriate for heterosexual young people without symptoms. As recommended in the Dutch guidelines people with symptoms should visit the STI clinic for an accurate assessment of tests and treatment needed. Men who have sex with men (MSM) are also recommended to visit the STI clinic. They need to be tested for syphilis and HIV using a blood sample; a method that is currently not available in home sampling test kits although our research group has developed a promising bloodspot tool to overcome this gap.

\section{Target groups}

Findings in this thesis are of importance for the control of sexual transmitted infection (STI) in general and for the control of CT among heterosexual young people who are sexual active in particular. When applying peer-driven testing using home sampling test kits individuals can be reached who are CT positive and never tested before; hidden to sexual health care. This decreases the transmission of infections and complications from occurring.

Our interventions were all carried out at the STI clinics Limburg, but could also be of importance to general practitioners (GP). A large proportion of CT testing in the Netherlands is done by GPS next to STI clinics. Our strategy of providing people with home sampling test kits could also be an accessible manner for GPs to promote CT testing among young people and their peers. Test kits can be used to overcome barriers among GPs such as discomfort and time. And as the majority of CT diagnoses are seen by GPs they are a valuable resource for young people who could motivate their social en sexual network to test for CT using home sampling test kits. 


